\title{
Chronologisches Verzeichnis
}

Die Werkgenese von Horváths Komödien Das unbekannte Leben und Mit dem Kopf durch die Wand (beide 1935) reicht im Wesentlichen bis zu der dunklen "Komödie“ Eine Unbekannte aus der Seine (1933) zurück. Der Titel Letzterer taucht in der Form Die Unbekannte der Seine in der Vorarbeit als Titel des Werkprojekts, in den weiteren Konzeptionen $\left(\mathrm{K}^{1}-\mathrm{K}^{3}\right)$ als Titel eines zu drehenden Filmes auf, über den im Stück diskutiert bzw. verhandelt wird. In $\mathrm{K}^{1}$ lautet der Titel des Werkprojekts L'inconnue de la Seine. Mit $\mathrm{K}^{2} / \mathrm{E}^{15}-\mathrm{E}^{17}$ ändert Horváth diesen zu Das unbekannte Leben. Erst im Verlauf von $\mathrm{K}^{3}$ kommt der definitive Titel Mit dem Kopf durch die Wand zustande (erstmals in $\mathrm{K}^{3} / \mathrm{E}^{6}$ bzw. $\left.\mathrm{E}^{9}\right)$. Horváth plante möglicherweise bereits 1933 ein Drehbuch auf der Grundlage seines Stückes Eine Unbekannte aus der Seine zu schreiben (vgl. den Brief an Rudolph S. Joseph vom 30. Oktober, Original im Deutschen Exilarchiv Frankfurt am Main, EB 96/111 - B.01.0082). Nach seinen negativen Erfahrungen im nationalsozialistischen Filmbetrieb der Jahre 1934/35 kam er jedoch auf die Idee, den Stoff der Unbekannten in einer Filmkomödie ironisch zu verarbeiten, die eine Parodie auf den (reichsdeutschen) Filmbetrieb darstellt. Das Ergebnis dieser Arbeiten sind die Komödien Das unbekannte Leben und Mit dem Kopf durch die Wand. Noch Anfang bis Mitte 1936 erwog der Autor neuerlich eine Wiederverwertung des Stoffes im Rahmen eines Drehbuchs bzw. Filmes (vgl. die beiden Listen „Fünf Filme“ $\mathrm{K}^{3} / \mathrm{E}^{14}$ und $\mathrm{E}^{15}$ ).

\section{Vorarbeit}

\section{Vorarbeit: Die Unbekannte der Seine}

$\mathrm{H}^{1}=$ ÖLA 3/W 59 - BS 51 [1], Bl. 4

1 Blatt unliniertes Papier $(282 \times 218 \mathrm{~mm})$, schwarzblaue Tinte

$\mathrm{E}^{1}=$ Strukturplan in 5 Bildern mit Konfigurationsplänen, Notizen und einer Replik (links oben)

$\mathrm{E}^{2}=$ fragm. Strukturplan in 2 Bildern (rechts oben)

$\mathrm{E}^{3}=$ Strukturplan in 1 Bild (mittig)

$\mathrm{E}^{4}=$ Strukturplan in 8 Bildern (links unten)

$E^{5}=$ Strukturplan in 8 Bildern (rechts unten)

Das vorliegende Blatt dürfte das erste Blatt sein, das zum Konvolut des Werkprojekts Mit dem Kopf durch die Wand zu rechnen ist. Es handelt sich dabei um ein Entwurfsblatt mit Strukturplänen zu der Vorarbeit Die Unbekannte der Seine. Wahrscheinlich sind mit den notierten Abschnitten Bilder gemeint, eine Einteilung des Stückes in fünf Akte nimmt Horváth erst im Verlauf von $\mathrm{K}^{1}$ vor. $\mathrm{E}^{1}$ umfasst die fünf Bilder: "Friedhof", "Sylvester", "Bei der Baronin“, "Nach dem Gefängnis" und noch einmal "Bei der Baronin“. Das erste Bild "Friedhof" verweist zurück auf die dunkle "Komödie“ Eine Unbekannte aus der Seine (1933; vgl. WA 6/K²/TS1/ÖLA 27/W 15, Bl. 13f.), zu der das Werkprojekt Mit dem Kopf durch die Wand in enger thematischer Verbindung steht. Die Figur der Baronin findet sich nur in den ganz frühen Entwürfen, sie wird später durch die Marquise ( $a b \mathrm{~K}^{1} / \mathrm{E}^{1}$ ) und dann durch den Marquis (ab $\mathrm{K}^{1} / \mathrm{E}^{23}$ )

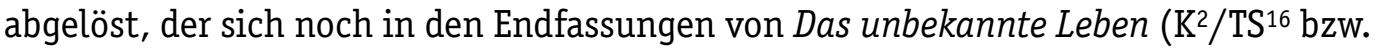
$\mathrm{TS}^{17}$ ) und Mit dem Kopf durch die Wand $\left(\mathrm{K}^{3} / \mathrm{TS}^{21}\right)$ findet. Allerdings taucht die Mar- 
quise in einigen Entwürfen von $\mathrm{K}^{1}$ und $\mathrm{K}^{2}$ parallel zum Marquis wieder auf (vgl. $\mathrm{K}^{1} / \mathrm{E}^{36}, \mathrm{~K}^{2} / \mathrm{E}^{1}$ und $\left.\mathrm{E}^{10}\right)$. Zum vierten Bild notiert Horváth die Replik eines Kommissars, der von einem Brief spricht. Dieser sei für die hier ebenfalls notierten Figuren Anna und Klara bestimmt. Diese finden sich auch in den folgenden Entwürfen. In $\mathrm{E}^{2}$ vermerkt Horváth neuerlich das Bild "Friedhof" und ein "S", das wohl für "Sylvester" steht, er nimmt also die Bilderfolge von $\mathrm{E}^{1}$ wieder auf, bricht aber mit dem fragmentarisch notierten zweiten Bild ab. In $E^{3}$ hält er lediglich das Bild "Waisenhaus" fest und dazu eine "Leiterin", bricht dann aber sofort wieder ab.

$\mathrm{E}^{4}$ ist demgegenüber wesentlich ausgereifter. Hier notiert Horváth acht Bilder: "Friedhof", "Sylvester", „Baronin“, "Gefängnis", „Baronin“, "Bahnhof", „Baronin“ und "Krankenhaus". In einer Korrektur legt er die beiden Bilder "Baronin" und "Gefängnis" zu dem Bild "Gärtner" zusammen, wodurch ein siebenteiliger Strukturplan zustande kommt. Statt "Bahnhof" hatte Horváth zunächst "Stadt“ notiert, statt "Krankenhaus" ein zweites Bild "Friedhof". Der "Bahnhof" findet im späteren Bild "Hotel Terminus" seine Umsetzung und bleibt bis in die Endfassungen von Das unbekannte Leben und Mit dem Kopf durch die Wand erhalten (vgl. $\mathrm{K}^{2} / \mathrm{TS}^{16} / \mathrm{BS}$ 71, Bl. 26, $\mathrm{TS}^{17}$ und $\mathrm{K}^{3} / \mathrm{TS}^{21} / \mathrm{BS} 52, \mathrm{Bl}$. 3). Zum nominell achten, realiter siebten Bild notiert Horváth erstmals die Figur der Unbekannten. Sie soll „auf Krücken“ gehen und mit dem Gärtner gemeinsam auftreten, der sich „nur ein kleinwenig“ verliebt. Der Gärtner dürfte ein Vorläufer der späteren Figur Bientôt (erstmals in $\mathrm{K}^{1} / \mathrm{E}^{35}$ ) sein. Genaueren Aufschluss über den Inhalt des in $\mathrm{E}^{4}$ skizzierten Strukturplans bietet jener von $\mathrm{E}^{7}$, in dem Horváth im Wesentlichen die Struktur von $\mathrm{E}^{4}$ wiederaufnimmt, aber mit zahlreichen inhaltlichen Notizen versieht.

In $\mathrm{E}^{5}$ schließlich notiert der Autor zunächst eine Struktur in neun Bildern, streicht aber die Bildnummer 9 wieder, sodass ein achtteiliger Strukturplan übrigbleibt: "Friedhof", "Sylvester", "Bei der Baronin", "Nach dem Gefängnis", „Bei der Baronin", "In der Stadt", "Bei der Baronin" und "Friedhof". Im Gegensatz zu E4 ist dieser Strukturplan zyklisch angelegt, mit einem Beginn und einem Ende am "Friedhof". Die Baronin nimmt zu diesem Zeitpunkt der Werkgenese noch einen großen Stellenwert ein, wie ihre dreimalige Nennung zeigt. Zum zweiten Bild "Sylvester" wird erstmals die "Tombola“ erwähnt, die sich weiters in $\mathrm{E}^{7}$ findet, dann aber aus dem Werkprojekt ausscheidet. Eine Silvesterfeier kommt in den Endfassungen von Das unbekannte Leben und Mit dem Kopf durch die Wand nicht mehr vor, wohl aber in der 1936 abgeschlossenen Komödie Figaro läßt sich scheiden, und zwar in der ersten Endfassung, jener in dreizehn Bildern (WA 8/ $\mathrm{K}^{2} / \mathrm{TS}^{1} / \mathrm{A}^{7}$ ). In der Werkgenese von Mit dem Kopf durch die Wand wird die Silvesterfeier durch einen "Filmball" abgelöst (erstmals in $\mathrm{K}^{1} / \mathrm{E}^{39}$ ). Laut $\mathrm{E}^{5}$ sollen "sie“, damit sind wohl Anna und Klara (vgl. $\left.E^{1}\right)$ gemeint, bei der Tombola des Silvesterballs die "Maske der Unbekannten“ gewinnen. Im fünften Bild hängt die Maske bei der Baronin. Zum sechsten Bild "In der Stadt" notiert Horváth "das Geld wird ihr gestohlen“, womit ein zentrales Motiv des Werkprojekts erstmals genannt ist. Im siebten Bild soll die Baronin der Maske ins Gesicht schlagen. 


\section{$\mathrm{H}^{2}=$ ÖLA 3/W 59 - BS 51 [1], Bl. 5}

1 Blatt unliniertes Papier $(282 \times 218 \mathrm{~mm})$, schwarzblaue Tinte

$\mathrm{E}^{6}=$ Konfigurationspläne zum 1. Bild „Friedhof" mit Werktitel „Die Unbekannte der Seine“ und Dialogskizze

In $\mathrm{E}^{6}$ notiert Horváth unter dem Titel „Die Unbekannte der Seine“, der damit zum ersten Mal vorkommt (vgl. den Kommentar zu E7), Konfigurationspläne zum ersten Bild „Friedhof" der Strukturpläne E1 ${ }^{1} E^{2}, E^{4}$ und E5. Dabei erwähnt er die seit $E^{1}$ bereits mehrfach genannte "Baronin", weiters zwei neue Figuren, eine "Gesellschafterin" und einen "Chauffeur". Diese befinden sich in der ersten Szene "vor dem Grabe". In Klammern notiert Horváth die bereits seit $\mathrm{E}^{1}$ vorhandenen Figuren "Anna“ und "Klara", die in der zweiten Szene auf den Friedhof kommen und einen "Totengräber" ansprechen, der hier erstmals erwähnt wird. Zu dieser zweiten Szene vermerkt Horváth eine Dialogskizze. Die beiden Frauen suchen darin das Grab einer gewissen "Ludmilla Steinmeyer", das sie mit Hilfe des Totengräbers auch finden. Sie behaupten, die Tote sei die Mutter einer entfernten Verwandten, die ihnen geschrieben habe, sie sollten am Grab "das Unkraut ein bisserl ausrupfen“. Es sei ja bald Weihnachten, und deshalb würden sie das "aus Pietät" machen. Möglicherweise liegt mit der Figur der Ludmilla Steinmeyer ein erster deutlicher Bezug zu Frank Wedekinds Drama Die Büchse der Pandora (1902) vor, in dem eine Ludmilla Steinherz auftritt (vgl. auch die Kommentare $\mathrm{zu} \mathrm{K}^{2} / \mathrm{E}^{12}$ und $\mathrm{K}^{3} / \mathrm{TS}^{21}$ ).

\section{$\mathrm{H}^{3}=$ ÖLA 3/W 59 - BS 51 [1], Bl. 6}

1 Blatt unliniertes Papier $(282 \times 218 \mathrm{~mm})$, schwarzblaue Tinte

$\mathrm{E}^{7}=$ Strukturplan in 7 Bildern mit Werktitel „Die Unbekannte der Seine“ mit Notizen, einer Replik und Konfigurationsplänen

$\mathrm{E}^{7}$ ist wie $\mathrm{E}^{6}$ mit dem Werktitel „Die Unbekannte der Seine“ überschrieben. Dieser Titel, der noch unter deutlichem Einfluss der dunklen Komödie Eine Unbekannte aus der Seine (1933; vgl. WA 6) steht, ist kennzeichnend für die frühen Entwürfe des Werkprojekts Mit dem Kopf durch die Wand. Er wird zunächst durch den Titel L'inconnue de la Seine (vgl. $\mathrm{K}^{1} / \mathrm{E}^{9}$ ), dann durch Das unbekannte Leben abgelöst (vgl. $\mathrm{K}^{2} / \mathrm{E}^{15}-\mathrm{E}^{17}$ ) und erst sehr spät durch den definitiven Titel Mit dem Kopf durch die Wand ersetzt (erstmals in $\mathrm{K}^{3} / \mathrm{E}^{6} \mathrm{bzw} . \mathrm{E}^{9}$ ). Allerdings bleibt der Titel Die Unbekannte der Seine bis zu den Endfassungen von Das unbekannte Leben und Mit dem Kopf durch die Wand als Titel des in dem Stück verhandelten Filmes erhalten (vgl. $\mathrm{K}^{2} / \mathrm{TS}^{16} / \mathrm{BS} 71$, Bl. 10, $\mathrm{TS}^{17}$ und $\mathrm{K}^{3} / \mathrm{TS}^{21} / \mathrm{BS} 52, \mathrm{Bl} .9$ ).

Im vorliegenden $\mathrm{E}^{7}$ skizziert Horváth einen Strukturplan in sieben Bildern: „Friedhof", "Sylvester", "Baronin“, "Gärtnerei“, "Bahnhof", "Baronin“ und „Krankenhaus". Der Autor kehrt damit im Wesentlichen wieder zu der Bilderfolge von $\mathrm{E}^{4}$ zurück. Er versieht den Strukturplan mit einer Reihe von Notizen. So sollen Anna und Klara (vgl. E ${ }^{1}$ ) im ersten Bild eine "Tasche“ finden. Im zweiten Bild gewinnt Anna auf der Tombola eine Maske der "inconnue” (vgl. E5). Einem Herrn fällt die "Ähnlichkeit” wohl zwischen Anna und der "inconnue" auf, die, so wird es angedeutet, wohl ihre Mutter war und "Komplexe“ hatte (vgl. den Titel Falsche Komplexe, den Horváth für die Zwischenfassung $\mathrm{K}^{3} / \mathrm{TS}^{4}$ wählt; vgl. die Kommentare $\mathrm{zu} \mathrm{K}^{3} / \mathrm{TS}^{1}{ }^{1} \mathrm{TS}^{4}$, TS ${ }^{5}$ und TS ${ }^{21}$ ). Die Baronin erfährt im dritten Bild von der Auffindung der Tasche und beschließt, das Mädchen zu sich zu nehmen. Ihre Gesellschafterin ist aber dagegen. Im vierten 
Bild arbeitet Anna bereits in der "Gärtnerei“. Die Gesellschafterin „intrigiert" gegen sie und alle lachen sie "wegen ihrer Idee, die Unbekannte wäre ihre Mutter", aus. Nur der Gärtner ist für Anna, ein Motiv, das bis in die Endfassungen von Das unbekannte Leben und Mit dem Kopf durch die Wand erhalten bleibt (vgl. K²/TS16/BS 71, Bl. 79, $\mathrm{TS}^{17}$ und $\mathrm{K}^{3} / \mathrm{TS}^{21} / \mathrm{BS}$ 52, Bl. 64). Im fünften Bild soll Anna im "Nachtzug" das Geld verlieren. Sie verdächtigt die wiederaufgetauchte Klara. Die Baronin und ihre Gesellschafterin rücken im sechsten Bild, das bei „Nacht“ spielt, Tischchen und die Baronin "zitiert den Geist der Unbekannten“, "aber der kommt nicht”, wie es in einer weiteren Notiz heißt, worauf die beiden zu Bett gehen. Ein Arbeiter bringt das verlorene Geld zurück. Da trifft auch die Nachricht ein, dass Anna einen "Selbstmordversuch“ unternommen habe. Das letzte Bild zeigt sie im Krankenhaus. Der Gärtner besucht sie dort und "bringt ihr die Maske mit zum Geschenk". Im Wesentlichen ist damit die so genannte und vermeintliche "wahre Geschichte" der "Unbekannten aus der Seine" beschrieben, wie sie der Marquis in den Endfassungen von Das unbekannte Leben und Mit dem Kopf durch die Wand zum Besten gibt (vgl. K²/TS ${ }^{16} / \mathrm{BS}$ 71, Bl. 79f., $\mathrm{TS}^{17}$ und $\mathrm{K}^{3} / \mathrm{TS}^{21} / \mathrm{BS} 52, \mathrm{Bl}$. 64f.). Die in der Vorarbeit und insbesondere in $\mathrm{E}^{7}$ skizzierte Handlung wird also im Lauf der Werkgenese zur Binnenhandlung.

\section{Konzeptionen}

\section{Konzeption 1: L'inconnue de la Seine - Komödie in fünf Akten}

\section{$\mathrm{H}^{1}=$ ÖLA 3/W 43 - BS 43 b, Bl. 2}

1 Blatt unliniertes Papier $(225 \times 144 \mathrm{~mm})$, geschnitten, schwarze Tinte, Bleistift

$\mathrm{E}^{1}=$ gestrichener fragm. Werktitel (rechts ganz oben)

$\mathrm{E}^{2}=$ Werktitel (rechts oben)

$\mathrm{E}^{3}=$ Werktitel (rechts mittig)

Druck in: WA 6, S. $420 f$.

Das vorliegende Blatt unterscheidet sich materiell nicht von den vorhergehenden. Es ist von derselben Qualität, wurde aber in der Mitte zerschnitten. $\mathrm{H}^{1}$ ist auch Teil der Werkgenese der Posse Hin und her (1934), die Horváth im Laufe des Jahres 1934 noch einmal überarbeitete (vgl. die Adaptierungsarbeiten $\mathrm{K}^{2}$ in WA 6), da eine bereits für Herbst 1933 angesetzte Uraufführung am Wiener Deutschen Volkstheater schließlich auf Druck der Wiener Presse nicht zustande kam (vgl. WA 6, S. 181-183). Sie erfolgte schließlich am 13. Dezember 1934 am Schauspielhaus Zürich. Das vorliegende Blatt wurde deshalb wohl im Laufe des Jahres 1934 beschrieben. Neben den drei Entwürfen zu Hin und her befinden sich auf dem Blatt drei Titelentwürfe zu dem Werkprojekt Die Unbekannte der Seine bzw. L'inconnue de la Seine. Das Blatt markiert den Übergang der Vorarbeit zu $\mathrm{K}^{1}$, denn Horváth notiert in $\mathrm{E}^{1}$ noch den Ansatz zum Werktitel der Vorarbeit, Die Unbekannte der Seine, indem er "Die U” schreibt; er streicht diesen Entwurf jedoch wieder und trägt darunter $\mathrm{E}^{2}$ und $\mathrm{E}^{3}$ ein, die beide den Titel "L'inconnue de la Seine“ beinhalten. Im ersten Fall ist er erweitert um den Zusatz "(Glaube Liebe Hoffnung)" und die Gattungsbezeichnung "Schauspiel in drei Teilen", im zweiten Fall findet sich nur der erwähnte Titel mit dem Zusatz "Schauspiel von Horváth".

Warum Horváth in $\mathrm{E}^{2}$ unter den Titel "L'inconnue de la Seine“ den Titel "Glaube 
Liebe Hoffnung" notiert, lässt sich nicht mit Sicherheit sagen. Das Volksstück Glaube Liebe Hoffnung wurde 1933 fertiggestellt und hat einen gemeinsamen Kern mit Kasimir und Karoline (1932; vgl. WA 4 sowie WA 5/VA ${ }^{1}$ ). Zum Zeitpunkt des Entstehens des vorliegenden Blattes war Glaube Liebe Hoffnung noch nicht aufgeführt (UA: 13.11.1936 in Wien, Regie: Ernst Jubal, unter dem Titel Liebe, Pflicht und Hoffnung, vgl. den Kommentar zu K${ }^{3} / \mathrm{TS}^{22}$ ). Eine geplante Uraufführung in Berlin 1933 wurde auf Druck der Nationalsozialisten schließlich fallen gelassen (vgl. KW 6, S. 156). Möglicherweise erwog Horváth deshalb den Titel seines früheren Werkes für sein späteres Werkprojekt L'inconnue de la Seine zu verwenden. In diese Richtung weisen auch die Titelentwürfe $\mathrm{K}^{2} / \mathrm{E}^{15}$, unter denen sich auch der (allerdings gestrichene) Titel "Komödie der Pflicht“ findet. Die Pflicht ist ein wichtiges Motiv der Endfassungen von Das unbekannte Leben ( $\mathrm{K}^{2} / \mathrm{TS}^{16}$ und $\mathrm{TS}^{17}$ ) und Mit dem Kopf durch die Wand $\left(\mathrm{K}^{3} / \mathrm{TS}^{21}\right)$. In beiden Fassungen wird sie vor allem auf den Sekretär des Generaldirektors der Pandora-Filmgesellschaft, Dr. Peter Huelsen, angewandt. Von ihm sagt seine Freundin, die Unbekannte, Folgendes: „[B]ei dem steht die Pflicht an erster Stelle und dann kommt noch ewig nichts!“ und "Peter ist ein absoluter Pflichtmensch" ( $\mathrm{K}^{2} / \mathrm{TS}^{16} / \mathrm{BS} 71, \mathrm{Bl} .40, \mathrm{TS}^{17}$ und $\mathrm{K}^{3} / \mathrm{TS}^{21} / \mathrm{BS} 52$, Bl. 23f.). Möglicherweise wollte Horváth aber mit dem Eintrag Glaube Liebe Hoffnung auch nur auf thematische Ähnlichkeiten der beiden Werkprojekte hinweisen.

\section{$\mathrm{H}^{2}=$ ÖLA 3/W 59 - BS 51 [1], Bl. 3}

1 Blatt unliniertes Papier $(282 \times 218 \mathrm{~mm})$, schwarzblaue Tinte

$\mathrm{E}^{4}=$ Strukturplan in 6 Bildern (links oben)

$\mathrm{E}^{5}=$ Strukturplan in 3 Bildern (mittig oben)

$\mathrm{E}^{6}=$ gestrichener Strukturplan in 1 Bild (mittig oben)

$\mathrm{E}^{7}=$ Strukturplan in 2 Bildern (mittig)

$\mathrm{E}^{8}=$ gestrichener fragm. Strukturplan in 4 Bildern (links unten)

$\mathrm{E}^{9}=$ fragm. Strukturplan in 5 Bildern (mittig unten)

$\mathrm{E}^{10}=$ fragm. Strukturplan in 4 Bildern (links unten)

$\mathrm{E}^{11}=$ Strukturplan in 3 Bildern (rechts unten)

Auf dem vorliegenden Blatt notiert Horváth eine Reihe von Strukturplänen, die zwar hinter VA/E $\mathrm{E}^{7}$ zurückzufallen scheinen, aufgrund der Ersetzung der "Baronin“ durch die "Marquise" aber dennoch zeitlich später einzuordnen sind. Diese Ersetzung spiegelt auf personaler Ebene die Ersetzung des Titels "Die Unbekannte der Seine“ (VA) durch "L'inconnue de la Seine“ $\left(\mathrm{K}^{1}\right)$, die eine noch deutlichere Verortung der Handlung in Frankreich bzw. in einem französischsprachigen Kontext zum Ausdruck bringt. Die Marquise wird ab E ${ }^{23}$ durch den Marquis ersetzt, der als Marquis von Bresançon bis in die Endfassungen von Das unbekannte Leben (K ${ }^{2} / \mathrm{TS}^{16}$ bzw. TS ${ }^{17}$ ) und Mit dem Kopf durch die Wand ( $\left.\mathrm{K}^{3} / \mathrm{TS}^{21}\right)$ erhalten bleibt. Wie in den Strukturplänen der Vorarbeit beginnt die Bilderfolge in $\mathrm{E}^{4}-\mathrm{E}^{9}$ und $\mathrm{E}^{11}$ mit "Friedhof". In $\mathrm{E}^{10}$ ist das erste Bild ausgelassen. Auch das zweite Bild ist konstant, es lautet in allen Entwürfen von BS 51 [1], Bl. 3 „Marquise“ bzw. „Bei der Marquise“. Mit Ausnahme von E6 , der nur ein Bild umfasst, trägt das dritte Bild in allen Entwürfen den Titel "Gärtnerei“ (in E7 nur "Gärt", das wieder gestrichen wurde; vgl. auch den Kommentar zu E ${ }^{10}$ ). In $E^{4}$ folgen auf dieses die Bilder "Bahnhof", "Marquise“ und "Krankenhaus", womit mit Ausnahme des dort zweiten Bildes "Sylvester" alle Bilder von $\mathrm{VA} / \mathrm{E}^{7}$ wiederaufgenommen werden. Die Entwürfe $\mathrm{E}^{5}-\mathrm{E}^{11}$ stellen Variationen von $\mathrm{E}^{4}$ dar, wobei keiner der folgenden Strukturpläne über vier Bilder hinauskommt. Eine Neuerung von $\mathrm{E}^{9}$ und $\mathrm{E}^{10}$ be- 
trifft das vierte Bild, das dort mit "Kammer" betitelt ist, ein Bildtitel, der möglicherweise in jenem von $\mathrm{E}^{21}$, „Im Zimmer des Poeten“, verändert wiederkehrt.

\section{$\mathrm{H}^{3}=$ ÖLA 3/W 59 - BS 51 [1], Bl. 2v}

1 Blatt kariertes Papier $(285 \times 225 \mathrm{~mm})$, Wasserzeichen „M.-K.-Papier“, gefalteter Bogen, schwarze Tinte

$\mathrm{E}^{12}=$ gestrichener fragm. Strukturplan in 2 Bildern (links oben)

$E^{13}=$ Strukturplan in 9 Bildern und 3 Akten mit Notizen (oben und mittig)

$\mathrm{E}^{14}=$ gestrichener fragm. Werktitel (unten mittig)

Druck in: WA 6, S. $426 \mathrm{f}$.

Das vorliegende Blatt unterscheidet sich materiell deutlich von den vorhergehenden. Es handelt sich dabei um kariertes Papier der Größe $285 \times 225 \mathrm{~mm}$ mit dem Wasserzeichen "M.-K.-Papier", während zuvor nur unliniertes Papier der Größe $288 \times 225$ mm bzw. $225 \times 144 \mathrm{~mm}$ (geteilter Bogen) ohne Wasserzeichen verwendet wurde. Karierte Blätter mit dem Wasserzeichen „M.-K. Papier“, einem Produkt der Max-Krause-Papierfirma, liegen in den Konvoluten zu Geschichten aus dem Wiener Wald (WA 3/K $\mathrm{K}^{1}$ ) und Kasimir und Karoline (vgl. WA 4/ $\mathrm{K}^{5 a}$ und $\mathrm{K}^{5 \mathrm{c}}$ ) vor, unlinierte Blätter mit dem Wasserzeichen "Aeolus M.-K.-Papier" in jenem des Romanprojekts Himmelwärts (vgl. WA 13/WP17).

Das vorliegende Blatt ist auch Teil der Werkgenese von Horváths Posse Hin und her (1934), zu der der Autor in dem auf dem Blatt untenstehenden Entwurf die beiden alternativen Werktitel "Hin und Her" und "Auf und Ab" notiert. Aufgrund materieller, aber auch inhaltlicher Indizien ist dieser Entwurf zu Hin und her wohl nicht vor 1934 entstanden und Teil der Adaptierung des Stückes in $\mathrm{K}^{2}$. Dies lässt Rückschlüsse auch auf die Genese der Vorarbeit, Die Unbekannte der Seine, und von $\mathrm{K}^{1}$, L'inconnue de la Seine, zu. Horváth dürfte mit den frühesten Entwürfen zu dem Werkprojekt, das schließlich in die Komödie Mit dem Kopf durch die Wand (1935) mündete, nicht vor 1934 begonnen haben. Wahrscheinlich handelt es sich bei dem Werkprojekt Die Unbekannte der Seine bzw. L'inconnue de la Seine um eine Zweitverwertung des Stoffes, der bereits der dunklen Komödie Eine Unbekannte aus der Seine (1933) zugrunde lag. Diese hätte im Jänner 1934 im Schönbrunner Schlosstheater durch 0tto Preminger und mit Schülern des Reinhardt-Seminars uraufgeführt werden sollen (vgl. WA 6, S. 13). Dazu kam es aber nicht. Auch eine weitere, im August 1934 angekündigte Aufführung in den Wiener Kammerspielen kam nicht zustande (vgl. dazu auch die Anmerkungen zur Uraufführung von Glaube Liebe Hoffnung im Kommentar $\left.\mathrm{zu} \mathrm{K}^{1} / \mathrm{E}^{1}-\mathrm{E}^{3}\right)$. Horváth versuchte deshalb wahrscheinlich mit dem Werkprojekt Die Unbekannte der Seine (VA) bzw. L'inconnue de la Seine (K1) den Stoff der Unbekannten aus der Seine noch einmal in einer vermeintlich markttauglicheren Form zu bearbeiten (vgl. $\mathrm{K}^{3} / \mathrm{TS}^{22}$ ). Sowohl die Vorarbeit dieses Werkprojekts als auch $\mathrm{K}^{1}$ wie auch die späteren Parodien auf das Filmgeschäft von $\mathrm{K}^{2}$ und $\mathrm{K}^{3}$, in der die Geschichte der Unbekannten nur noch die Binnenhandlung darstellt, fußen deutlich auf der von Horváths Freundin Hertha Pauli bereits am 4. November 1931 im Berliner Tageblatt veröffentlichten Erzählung L'inconnue de la Seine (vgl. in diesem Band KOM/TS ${ }^{1}$; vgl. auch WA 6, S. 3f. und 10 sowie das Vorwort dieses Bandes, S. $333 \mathrm{f}$.).

Die Zugehörigkeit des vorliegenden Blattes $\mathrm{zu} \mathrm{K}^{1}$ erschließt sich vor allem durch die Tatsache, dass die in der Vorarbeit noch so genannte „Baronin“ (vgl. zuletzt 
$\mathrm{VA} / \mathrm{E}^{7}$ ) in $\mathrm{E}^{13}$ durch die "Marquise“ ersetzt ist. In $\mathrm{E}^{12}$ notiert Horváth nur den ersten Bildtitel "Café" und die Nummer des zweiten, streicht den Entwurf aber wieder. Das erste Bild "Friedhof", das seit VA/E $\mathrm{E}^{1}$ belegt und unverändert ist, wird in den auf dem unmittelbar folgenden Blatt notierten Entwürfen $\mathrm{E}^{20}$ und $\mathrm{E}^{21}$ durch das Bild „Im Filmbüro" ersetzt, das zweite Bild lautet dort „Im Cafe“”. Während das „Filmbüro“ bis zur Endfassung von Mit dem Kopf durch die Wand erhalten bleibt, findet sich ein Bild "Café" in weiterer Folge nicht mehr. Dies unterstreicht die Nähe der Entwürfe auf Bl. $2 \mathrm{v}$ und Bl. 2, die nicht zuletzt durch die Verortung auf demselben Bogen Papier materiell gestützt ist.

In $\mathrm{E}^{13}$ skizziert Horváth einen Strukturplan in neun Bildern, den er mit einer Einteilung in drei Akten überlagert. Die Bilderfolge lautet: "Friedhof", "Unter der La-

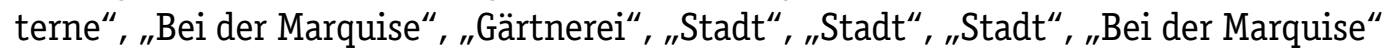
und "Epilog". Die Bildtitel "Unter der Laterne“ und „Epilog" stellen Neuerungen dar, ein Bild "Stadt" war erstmals in VA/E ${ }^{4}$ vorgesehen, wurde dort aber wieder gestrichen. Die drei Akte von $\mathrm{E}^{13}$ umfassen jeweils drei Bilder, sind also gleich gewichtet. Das sechste Bild hätte zunächst "Bei der Marquise“ lauten sollen, wird dann aber durch "Stadt" ersetzt. Zum fünften Bild, das ebenfalls bereits mit "Stadt" betitelt ist, notiert Horváth: „Kameraden Klaras wollen der Unbekannten das Geld abnehmen“ und "Martin, der einzig noch anständige bringt den einen um". Damit ist nicht nur die Figur der "Klara“ wieder erwähnt (vgl. VA/E ${ }^{1}, E^{6}$ und $E^{7}$ ), sondern auch die Idee eines Diebstahls neuerlich formuliert (vgl. VA/E ${ }^{5}$ ). Wie in VA/E $\mathrm{E}^{4}$ ist die Unbekannte in $\mathrm{E}^{13}$ tatsächlich als Figur in dem Werkprojekt vorgesehen, während sie in einigen vorhergehenden Entwürfen der Vorarbeit nur in Form der Maske bzw. als Geist präsent war (vgl. VA/E ${ }^{5}$ und $E^{7}$ ). Die Kameraden Klaras kommen in der Folge nicht mehr vor. Auch eine Figur namens Martin findet sich im weiteren Verlauf des Werkprojekts nicht mehr. In $\mathrm{E}^{14}$ setzt Horváth wohl noch einmal zum Werktitel "Die Unbekannte der Seine" an, der charakteristisch für die Vorarbeit war, notiert aber nur "Di“ und streicht diesen Eintrag sofort wieder. Es könnte sich aber auch um einen Eintrag zu Hin und her handeln, da der Entwurf doch näher bei dem Entwurf zur Posse steht. Demnach hätte Horváth möglicherweise neuerlich den Titel "Die brave Fee von Felsenstadt" notieren wollen (vgl. WA 6/Hin und her $/ \mathrm{K}^{2} / \mathrm{E}^{10}$ ).

\section{$\mathrm{H}^{4}=$ ÖLA 3/W $59-$ BS 51 [1], Bl. 2}

1 Blatt kariertes Papier (285 × 225 mm), Wasserzeichen „M.-K.-Papier“, gefalteter Bogen, schwarze Tinte

$\mathrm{E}^{15}=$ gestrichener Strukturplan in 1 Akt mit Werktitel "L'inconnue de la Seine“ (links oben)

$\mathrm{E}^{16}=$ fragm. Strukturplan in 7 Bildern mit Werktitel "L'inconnue de la Seine" (links mittig)

$\mathrm{E}^{17}=$ Strukturplan in 7 Bildern (links unten)

$\mathrm{E}^{18}=$ Strukturplan in 7 Bildern (mittig unten)

$\mathrm{E}^{19}=$ Strukturplan in 7 Bildern (rechts ganz unten)

$\mathrm{E}^{20}$ = gestrichene Figurenliste zum 1. Bild „Im Büro des Filmes" (rechts oben)

$\mathrm{E}^{21}$ = gestrichener Strukturplan in 4 Bildern mit Werktitel "L'inconnue de la Seine. / Schauspiel“ (rechts mittig)

$\mathrm{E}^{22}=$ gestrichener fragm. Strukturplan in 3 Bildern mit Werktitel "L'inconnue de la Seine" (rechts unten)

Die Entwürfe $\mathrm{E}^{12}-\mathrm{E}^{22}$ befinden sich auf der Recto- und Versoseite desselben Bogens karierten Papiers, das eine Besonderheit im Konvolut von L'inconnue de la Seine darstellt, da dieses Material sonst nicht vorkommt (vgl. zur Papierqualität und zur Da- 
tierung den Kommentar zu E $\left.{ }^{12}-E^{14}\right)$. Wahrscheinlich hat Horváth zunächst die Entwürfe auf der linken Seite und am unteren Rand von Bl. 2 eingetragen $\left(\mathrm{E}^{15}-\mathrm{E}^{19}\right)$, erst dann dürfte er die rechte Seite beschrieben haben $\left(\mathrm{E}^{16}-\mathrm{E}^{22}\right)$. In $\mathrm{E}^{15}-\mathrm{E}^{19}$ notiert Horváth eine Reihe von Strukturplänen, die teils unter dem für $\mathrm{K}^{1}$ charakteristischen Werktitel "L'inconnue de la Seine“ stehen (vgl. $\mathrm{E}^{15}$ und $\mathrm{E}^{16}$ ). In $\mathrm{E}^{15}$ vermerkt er dazu "Schauspiel in drei Akten“, eine Strukturgröße, die sich auch in $\mathrm{E}^{13}$ fand, in unmittelbarer Folge aber wieder zugunsten einer Einteilung in Bildern fallen gelassen wird. In $\mathrm{E}^{16}$ skizziert Horváth einen fragmentarischen Strukturplan in sieben Bildern, der mit "Friedhof", "Sylvester", „Bei der Marquise“, "Gärtnerei“, "Stadt" und „Bei der Marquise“ deutlich an $\mathrm{E}^{13}$, aber auch an $\mathrm{E}^{1}$ anschließt. Ein Großteil der genannten Bilder findet sich auch schon in der Vorarbeit (vgl. etwa VA/ $\mathrm{E}^{5}$ und $\mathrm{E}^{7}$ ). Das siebte Bild ist nur nummeriert, wird jedoch nicht mehr ausgeführt. In $\mathrm{E}^{17}-\mathrm{E}^{19}$ variiert Horváth die Bilderfolge von $\mathrm{E}^{16}$, weshalb von einem unmittelbaren genetischen Naheverhältnis dieser Entwürfe auszugehen ist. Zum zweiten Bild notiert Horváth in $\mathrm{E}^{17}$ zunächst "Sylvester", dann - wie in $\mathrm{E}^{13}$ - "Unter der Laterne“, streicht beide Einträge jedoch wieder und notiert erneut das seit der Vorarbeit verbürgte "Sylvester". Das siebte Bild, das in $\mathrm{E}^{16}$ noch gefehlt hatte, lautet hier "Epilog“. Die ersten sechs Bilder von $\mathrm{E}^{17}$ entsprechen exakt $\mathrm{E}^{16}$. In $\mathrm{E}^{18}$, einem weiteren Strukturplan in sieben Bildern, variiert Horváth das letzte Bild von "Epilog" über "Strasse“ zu "Seine-Ufer" und setzt damit neuerlich einen thematischen und lokalen Fokus (vgl. den Kommentar zu $\left.\mathrm{E}^{4}-\mathrm{E}^{11}\right)$. In $\mathrm{E}^{19}$ schreibt der Autor die Bilderfolge von $\mathrm{E}^{18}$ gewissermaßen rein.

Erst nach der Ausarbeitung von $\mathrm{E}^{15}-\mathrm{E}^{19}$ dürfte Horváth auf der rechten Seite des Blattes $E^{20}-E^{22}$ eingetragen haben. Hier zeigt sich eine entscheidende thematische Wende, indem in der Figurenliste $\mathrm{E}^{20}$ erstmals vom "Büro des Filmes" die Rede ist, der Autor die Handlung also ins Filmmilieu versetzt, was zuvor nicht gegeben war. Als Figuren notiert er: "Direktor der Verleiher", "Produktionsleiter“, "Dramaturg”, ,Regisseur", "Darstellerin“ und "Dichter". In E ${ }^{21}$ skizziert er unter dem Werktitel "L'inconnue de la Seine / Schauspiel“, wohl zu diesem Personal, einen Strukturplan in vier Bildern mit der Bilderfolge "Im Filmbüro", "Im Café", "Im Zimmer des Poeten" und "Am Seine-Ufer“. Die zunächst notierte fünfte Bildnummer wurde wieder gestrichen. Die Bilderfolge weist erstmals den Bildtitel "Im Filmbüro" auf, der die Verlagerung ins Filmmilieu, die mit $\mathrm{E}^{20}$ angedacht wurde, auch auf struktureller Ebene manifest werden lässt und als erstes Bild bzw. erster Akt die weiteren Strukturpläne bis zur ersten Endfassung von Das unbekannte Leben $\left(\mathrm{K}^{2} / \mathrm{TS}^{16}\right)$ kennzeichnen wird. Erst mit der zweiten Endfassung von Das unbekannte Leben $\left(\mathrm{K}^{2} / \mathrm{TS}^{17}\right)$ und in der Endfassung von Mit dem Kopf durch die Wand ( $\mathrm{K}^{3} / \mathrm{TS}^{21}$ ) beginnt das Stück mit dem ersten Akt „Hotel Terminus“. Allerdings wurden $\mathrm{E}^{20}-\mathrm{E}^{22}$ nachträglich gestrichen, was vermuten lässt, dass die darin enthaltenen Figuren und Bildtitel für Horváth keine weitere Gültigkeit hatten. Das zweite Bild "Im Café” von $\mathrm{E}^{21}$ verweist zurück auf $\mathrm{E}^{12}$, das dritte "Im Zimmer des Poeten" vermutlich auf die "Kammer" von $\mathrm{E}^{6}$ und $\mathrm{E}^{7}$, das "Seine-Ufer" auf $\mathrm{E}^{18}$ und $\mathrm{E}^{19}$. In $\mathrm{E}^{22}$ schließlich notiert Horváth die ersten beiden Bilder von $\mathrm{E}^{21}$, "Im Filmbüro" und "Im Café" noch einmal, bricht jedoch den Strukturplan nach der Bildnummer des dritten Bildes ab. 


\section{$\mathrm{H}^{5}=$ ÖLA 3/W 59 - BS 51 [1], Bl. 15}

1 Blatt unliniertes Papier $(305 \times 228 \mathrm{~mm})$, schwarzblaue Tinte

$\mathrm{E}^{23}=$ Strukturplan in 4 Akten (links oben)

$\mathrm{E}^{24}=$ Strukturplan in 4 Akten (mittig oben)

$\mathrm{E}^{25}=$ Strukturplan in 4 Akten (rechts oben)

$\mathrm{E}^{26}=$ Strukturplan in 3 Bildern (links mittig)

$\mathrm{E}^{27}=$ Strukturplan in 3 Bildern (rechts mittig)

$\mathrm{E}^{28}=$ Strukturplan in 3 Bildern (unten)

Auf dem vorliegenden Blatt notiert Horváth eine Reihe von Strukturplänen, wobei er zwischen einer römischen und einer arabischen Bezifferung schwankt, was gemäß seinen Gepflogenheiten einer strukturellen Gliederung in Akten bzw. Bildern entspricht. Dementsprechend sind die Strukturpläne hier benannt, bei römischen Ziffern in Akten, bei arabischen in Bildern. In $\mathrm{E}^{23}-\mathrm{E}^{28}$ findet gewissermaßen eine Amalgamierung der Strukturpläne $\mathrm{E}^{20}-\mathrm{E}^{22}$ mit jenen von $\mathrm{E}^{16}-\mathrm{E}^{19}$ statt, indem die in der Vorarbeit entwickelte Handlung um eine "Baronin" bzw. "Marquise“ mit der Idee von $\mathrm{E}^{20}-\mathrm{E}^{22}$ verbunden wird, die Handlung im Filmmilieu spielen zu lassen. Dies äußert sich deutlich in der Struktur, die im Wesentlichen in allen Strukturplänen von BS 51 [1], Bl. 15 einheitlich ist, und folgende Teile umfasst: "Filmbüro", "Hotel”, "Beim Marquis" und "Hotel“ (E23-E $\mathrm{E}^{25}$, in $\mathrm{E}^{26}-\mathrm{E}^{28}$ fehlt jeweils der vierte Abschnitt). Das "Filmbüro" ist seit $\mathrm{E}^{20}$ bzw. $\mathrm{E}^{21}$ belegt, das in $\mathrm{E}^{21}$ und $\mathrm{E}^{22}$ genannte "Café" (vgl. auch $\mathrm{E}^{12}$ ) wird mit $\mathrm{E}^{23}$ und den folgenden Entwürfen in ein "Hotel“ transformiert. Erstmals wird in $\mathrm{E}^{23}$ die "Marquise“ (zuletzt in $\mathrm{E}^{19}$ ), die als „Baronin“ seit den frühesten Strukturplänen im Werkprojekt vertreten ist (vgl. VA/E ${ }^{1}$ und $\left.E^{4}-E^{7}\right)$, durch den "Marquis" ersetzt. Er bleibt bis in die Endfassungen von Das unbekannte Leben ( $\mathrm{K}^{2} / \mathrm{TS}^{16}$ und $\mathrm{TS}^{17}$ ) und Mit dem Kopf durch die Wand $\left(\mathrm{K}^{3} / \mathrm{TS}^{21}\right)$ im Werkprojekt als eine zentrale Figur erhalten. In $\mathrm{E}^{27}$ wird mit "Sekretär“ erstmals die Figur eines Sekretärs angedacht. Als solcher wird später die Figur des (Peter) Huelsen eingeführt (erstmals in $\mathrm{E}^{49}$ ).

\section{$\mathrm{H}^{6}=$ ÖLA 3/W $59-\mathrm{BS} 51$ [1], Bl. 11}

1 Blatt unliniertes Papier $(305 \times 228 \mathrm{~mm})$, schwarzblaue Tinte $\mathrm{E}^{29}=$ Strukturplan in 4 Akten mit Notizen und Konfigurationsplänen

In $\mathrm{E}^{29}$ nimmt Horváth noch einmal die Akt- bzw. Bilderfolge von E23-E25 auf: „Filmbüro", "Hotel“, "Marquis" und "Hotel“, die er mit Notizen versieht. So soll der Marquis im zweiten Akt im "Hotel“ erscheinen (vgl. $\mathrm{E}^{28}$ ). Im dritten Akt treffen beim Marquis der erstmals genannte spätere Regisseur Mayberg, die Marquise und eine Dame zusammen. Die Marquise, die seit $\mathrm{E}^{4} \mathrm{im}$ Werkprojekt vertreten ist und die in der Vorarbeit erwähnte Baronin ersetzt, in $\mathrm{E}^{23} \mathrm{E}^{28}$ jedoch nicht genannt wurde, wird hier von Horváth also noch neben dem Marquis beibehalten (vgl. auch $\mathrm{E}^{35}, \mathrm{~K}^{1} / \mathrm{E}^{1}$ und $\mathrm{E}^{10}$ ). Eine zweite Szene sieht (den Regisseur) Mayberg und den Marquis vor. In einer dritten Szene sind der Marquis und "der alte Gärtner“ (vgl. den Kommentar zu VA/E7) genannt, in einer vierten der Marquis und ein nicht näher spezifizierter "Neffe". Es handelt sich wohl um die spätere Figur des Nevieux, dessen Name aus dem französischen Wort für Neffe (le neveu) gebildet wird. Dessen „Tante“ wird mit $\mathrm{E}^{35}$ eingeführt, der Name Nevieux fällt erstmals in $\mathrm{E}^{40}$ (gestrichen) bzw. TS 3 . 


\section{$\mathrm{H}^{7}=$ ÖLA 3/W 59 - BS 51 [1], Bl. 14}

1 Blatt unliniertes Papier $(305 \times 228 \mathrm{~mm})$, schwarzblaue Tinte

$\mathrm{E}^{30}=$ fragm. Strukturplan in 3 Akten mit Werktitel "L'inconnue de la Seine / Komödie in fünf Akten" (links oben)

$\mathrm{E}^{31}=$ Strukturplan in 3 Akten (rechts oben)

$\mathrm{E}^{32}=$ fragm. Strukturplan in 4 Akten (rechts mittig)

$\mathrm{E}^{33}$ = fragm. Strukturplan in 4 Akten mit Notiz (mittig)

$\mathrm{E}^{34}=$ Strukturplan in 3 Akten (links unten)

$\mathrm{E}^{35}=$ Strukturplan in 5 Akten mit Konfigurationsplänen (rechts unten)

In den Strukturplänen $\mathrm{E}^{30}-\mathrm{E}^{35}$ ringt Horváth sichtlich um eine Struktur in fünf Akten, wie sie der Titel von $\mathrm{E}^{30}$ erwähnt. Tatsächlich erreicht er eine solche erst im letzten der auf Bl. 14 versammelten Strukturpläne, und zwar mit E35, der folgende Aktfolge aufweist: "Filmbüro", "Hotel", "Marquis", "Hotel“ und "Filmbüro". Die zuvor notierten Strukturpläne $\mathrm{E}^{30}-\mathrm{E}^{34}$ sind allesamt nur dreiaktig (bzw. fragmentarisch in vier Akten) und weisen dieselben ersten drei Akte auf wie $\mathrm{E}^{35}$, wobei Horváth zwischen "Beim Marquis" und dem bloßen "Marquis" variiert. Erstmals wird in $\mathrm{E}^{33}$ "Prof. Bossard" genannt, der spiritistische Scharlatan und Berufsschauspieler der Endfassungen von Das unbekannte Leben $\left(\mathrm{K}^{2} / \mathrm{TS}^{16}\right.$ und $\left.\mathrm{TS}^{17}\right)$ und Mit dem Kopf durch die Wand $\left(\mathrm{K}^{3} / \mathrm{TS}^{21}\right)$. Der Marquis kommt im zweiten Akt ins "Hotel“ und bittet Professor Bossard zu sich. Zum dritten Akt von $\mathrm{E}^{35}$ notiert Horváth eine Reihe von Konfigurationsplänen mit teilweise neuen Figuren. So tauchen hier erstmals eine "Tochter", die "Tante" und "der alte Bientôt" (vgl. den "Gärtner" in VA/ $\mathrm{E}^{7}$ und $\mathrm{K}^{1} / \mathrm{E}^{29}$ ) auf. Ebenfalls erwähnt werden die Figuren "Mayberg" (vgl. E29), "Damen", "der Marquis", "die Marquise“, der "Neffe" (vgl. ebd.) und die "Unbekannte“ (vgl. VA/E $\mathrm{E}^{4}, \mathrm{E}^{7}$ und $\mathrm{K}^{1} / \mathrm{E}^{13}$ ), die hier wie schon in $\mathrm{VA} / \mathrm{E}^{4}$ und $\mathrm{K}^{1} / \mathrm{E}^{13}$ als im Stück auftretende Figur vorgesehen ist.

\section{$\mathrm{H}^{8}=$ ÖLA 3/W 59 - BS 51 [1], Bl. 13}

1 Blatt unliniertes Papier $(305 \times 228 \mathrm{~mm})$, schwarzblaue Tinte

$\mathrm{E}^{36}=$ Strukturplan in 6 Akten mit Werktitel "L'inconnue de la Seine. / Komödie in fünf Akten“ mit

Notizen und Konfigurationsplänen (links oben bis unten)

$\mathrm{E}^{37}=$ Strukturplan in 4 Akten mit einer Notiz (rechts mittig)

$E^{38}=$ Strukturplan in 4 Akten mit einer Replik und einer Notiz (rechts unten)

$E^{36}$ sieht erstmals eine Struktur in sechs Akten vor, auch wenn Horváth im Titel noch „in fünf Akten“ notiert. Offensichtlich hat er während der Niederschrift sein Konzept geändert und folgende Akte festgehalten: „Filmbüro" , "Hotel“, "Beim Marquis", „Hotel“, "Beim Marquis" und "Filmbüro“. Der Strukturplan erinnert vor allem an E ${ }^{35}$, demgegenüber er nur um einen weiteren Akt „Beim Marquis“ erweitert ist; alle anderen Akte entsprechen dem früheren Entwurf. Auffallend ist vor allem die zyklische Struktur mit den beiden Akten "Im Filmbüro" am Beginn und am Schluss, wie sie auch in $\mathrm{E}^{35}$ gegeben ist.

In den beiden Strukturplänen $E^{37}$ und $E^{38}$ scheint der Autor zu einer Struktur in vier Akten zurückzukehren. Beide weisen die Aktfolge "Filmbüro", "Hotel", "Beim Marquis" und "Hotel“ auf, was den ersten vier Akten von $\mathrm{E}^{36}$ bzw. E23-E25, E29 und $\mathrm{E}^{35}$ entspricht. Bemerkenswert sind indes die Notizen, die er zu den beiden Strukturplänen hinzufügt. Wie in $\mathrm{E}^{28}$ und $\mathrm{E}^{29}$ soll der Marquis in $\mathrm{E}^{37}$ ins "Hotel“ kommen, in diesem Fall gemeinsam mit Mayberg (vgl. $E^{29}$ ). Zu E ${ }^{38}$ notiert Horváth eine Replik Bossards (vgl. $\mathrm{E}^{33}$ ), wonach dieser sagt, er habe aus dem Marquis Informationen über die 
Unbekannte "herauzukitzeln" versucht, doch der habe "nichts richtiges" gesagt. Aber ein Marquis wäre auf jeden Fall „in unserer Handlung etwas Richtiges“, meint er abschließend, womit er wahrscheinlich auf das zu schreibende Drehbuch über die Unbekannte anspielt. Zuletzt ist eine Notiz zum Sekretär vermerkt, der seit E $^{27}$ im Werkprojekt vertreten ist. Er soll erscheinen und "heftige Vorwürfe“ machen. Möglicherweise ist damit Huelsens Auftritt im Hotel angedeutet, in dem er den Schauspielern um Bossard vorwirft, den Direktor Semper getäuscht zu haben (vgl. $\mathrm{K}^{2} /$ $\mathrm{TS}^{16} / \mathrm{BS}$ 71, Bl. 41f. und 51 sowie $\mathrm{TS}^{17}$ und $\mathrm{K}^{3} / \mathrm{TS}^{21} / \mathrm{BS}$ 52, Bl. 25f. und 33-36).

\section{$\mathrm{H}^{9}=$ ÖLA 3/W 59 - BS 51 [1], Bl. 16}

1 Blatt unliniertes Papier $(305 \times 228 \mathrm{~mm})$, schwarzblaue Tinte $\mathrm{TS}^{1}$ = fragm. Fassung des II. Aktes „Hotel“ (Grundschicht)

TS1 ist wahrscheinlich im Kontext der Strukturpläne $\mathrm{E}^{36}-\mathrm{E}^{38}$ entstanden, da darin der erstmals in $\mathrm{E}^{27}$ genannte Sekretär, der in $\mathrm{E}^{36}$ und $\mathrm{E}^{38}$ wiederauftaucht, tatsächlichen Anteil an der Handlung nimmt. Horváth skizziert in $\mathrm{TS}^{1}$ einen Dialog zwischen Mayberg (erstmals in $\mathrm{E}^{29}$ ), dem Sekretär und Bossard (erstmals in $\mathrm{E}^{33}$ ), in dem es darum geht, ob der Marquis erfahren darf, dass Mayberg, Huelsen und Bossard dem "wahren Sachverhalt" über die Unbekannte "auf der Spur sind“. Bossard meint, der Marquis sei ihm "willkommen".

\section{$\mathrm{H}^{10}=$ ÖLA 3/W 59 - BS 51 [1], Bl. 9}

1 Blatt hochkariertes Papier $(287 \times 227 \mathrm{~mm})$, schwarzblaue Tinte

$\mathrm{E}^{39}=$ Strukturplan in 4 Akten (links)

$\mathrm{TS}^{2}$ = fragm. Fassung des I. Aktes "Garage“ (rechts; Grundschicht)

Erstmals verwendet Horváth mit dem vorliegenden Blatt hochkariertes Papier des Formats $287 \times 227 \mathrm{~mm}$ (vgl. auch $\mathrm{H}^{12}$ und $\mathrm{H}^{14}$ ). Die Reihung des vorliegenden Blattes orientiert sich an der Struktur von E39, der mit dem ersten Akt "Hotel Terminus" eine zweifache Neuerung darstellt. Erstens wurde das "Hotel“, das seit E23 im Werkprojekt vorhanden ist und das in $\mathrm{E}^{21}$ und $\mathrm{E}^{22}$ genannte "Café" ersetzt (vgl. auch $\mathrm{E}^{12}$ ), noch nie an erster Stelle genannt, wo seit $\mathrm{E}^{21}$ konstant das "Filmbüro" steht. Zweitens wird das Hotel hier erstmals um den Zusatz „Terminus“ erweitert, was eine Nähe zu dem in $\mathrm{VA} / \mathrm{E}^{7}$ und $\mathrm{K}^{1} / \mathrm{E}^{1}$ genannten "Bahnhof" vermittelt, der aber motivisch wohl in einen anderen Kontext gehört, sollte doch laut VA/E7 die Figur Anna mit dem "Nachtzug" fahren, in dem sie das ihr von der Baronin anvertraute Geld verliert. Nicht zuletzt ist es die Einführung des zweiten Aktes "Filmball“, der eine späte Reihung von $\mathrm{E}^{39}$ gerechtfertigt erscheinen lässt. Dieser "Filmball“ bleibt als wesentliches Element des Stückes bis in die Endfassungen von Das unbekannte Leben und Mit dem Kopf durch die Wand erhalten (vgl. $\mathrm{K}^{2} / \mathrm{TS}^{16} / \mathrm{BS} 71, \mathrm{Bl} .14-68$, $\mathrm{TS}^{17}$ sowie $\mathrm{K}^{3} / \mathrm{TS}^{21} / \mathrm{BS} 52, \mathrm{Bl}$. 28-52) und findet sich etwa auch in $\mathrm{E}^{48}$.

Auch die Fassung TS ${ }^{2}$ stützt die vorgenommene Reihung des Blattes. In ihr ist ein Dialog zwischen der Unbekannten und Albert in einer bisher zwar nicht, aber in der Folge öfters genannten "Garage“ (bzw. "Reparaturwerkstätte“ bzw. "Tankstelle“) ausgearbeitet (vgl. TS ${ }^{3}, \mathrm{E}^{45}, \mathrm{E}^{52}, \mathrm{E}^{58}, \mathrm{E}^{60}$ und $\mathrm{E}^{69}$ ). Die Figur Albert geht auf Eine Unbekannte aus der Seine (1933) zurück und findet sich auch in $\mathrm{K}^{2} / \mathrm{E}^{5}$ (dort allerdings gestrichen) und $\mathrm{E}^{6}$. Der Inhalt der Fassung $\mathrm{TS}^{2}$ ist denkbar einfach: Albert hat die Unbekannte in seine Garage gelockt und hält sie dort fest. Er behauptet, sie habe 
ihm seine "Geldtasche" gestohlen, die er zurückfordert. Die Unbekannte hat sie tatsächlich gestohlen und gibt sie ihm zurück, worauf die Ausarbeitung abbricht.

\section{$\mathrm{H}^{11}=$ ÖLA 3/W 59 - BS 51 [1], Bl. 8V}

1 Blatt unliniertes Papier $(282 \times 224 \mathrm{~mm})$, schwarzblaue Tinte

$\mathrm{E}^{40}=$ gestrichene Notizen zum I. Akt (links ganz oben)

$\mathrm{E}^{41}=$ gestrichene Konfigurationspläne zum I. Akt (links oben)

$\mathrm{E}^{42}=$ gestrichener Akttitel (links mittig)

$\mathrm{TS}^{3}$ = fragm. Fassung des I. Aktes "Garage“ (links unten; Grundschicht)

$\mathrm{E}^{43}=$ Figurenliste (rechts ganz oben)

$\mathrm{E}^{44}=$ Konfigurationsplan zum I. Akt (rechts oben)

$\mathrm{E}^{45}=$ Strukturplan in 2 Akten mit Notizen und Konfigurationsplänen (rechts mittig)

$\mathrm{E}^{46}=$ Akttitel zum I. Akt „Bei Nevieux” (rechts unten)

Die Entwürfe und die Textstufe des vorliegenden Blattes zeigen, dass in dieser Phase der Werkgenese die zuvor ausgearbeiteten Strukturpläne offensichtlich für Horváth kaum mehr Gültigkeit haben. Er entwickelt auf $\mathrm{Bl} .8 \mathrm{v}$, das offensichtlich vor der Rectoseite des Blattes beschrieben wurde (vgl. $\mathrm{H}^{15}=\mathrm{E}^{66}-\mathrm{E}^{73}$ ), äußerst disparate Entwürfe zum ersten und zweiten Akt. Zunächst notiert er in $\mathrm{E}^{40}$ zum ersten Akt den Akttitel "Garage" (vgl. TS2, TS3, E52, $\mathrm{E}^{58}$ und $\mathrm{E}^{60}$ ), streicht diesen aber wieder und ersetzt ihn durch "Cafè" (vgl. E ${ }^{12}$, $\mathrm{E}^{21}$ und $\mathrm{E}^{22}$ ), zu welchem er vermerkt, dass der hier erstmals Nevieux genannte "Neffe" (vgl. den Kommentar zu E ${ }^{29}$ ) Klavier spielen soll. Horváth streicht jedoch schließlich $\mathrm{E}^{40}$. Das Gleiche gilt für $\mathrm{E}^{41}$, in dem er Konfigurationspläne zum ersten Akt mit gänzlich anderen Figuren skizziert; hier werden der "Marquis", ein "Notar“ (vgl. die Kommentare zu K3/TS4 und TS ${ }^{21}$ ), ein "Chauffeur" und eine gewisse "Irene“ genannt, die, wie der zuvor einmal (in TS²) erwähnte Albert, auf die dunkle Komödie Eine Unbekannte aus der Seine (1933) zurückverweist. $\mathrm{E}^{42}$, in dem er zum ersten Akt den Titel "Glashaus" notiert, streicht Horváth ebenfalls.

Schließlich skizziert er zum ersten Akt "Garage“ einen Dialog TS3 zwischen der Unbekannten und dem Chauffeur, der erstmals in $\mathrm{E}^{41}$ genannt, dort aber wieder gestrichen wurde. Die Unbekannte hält den Chauffeur zunächst für den Marquis, der Chauffeur klärt sie jedoch über seinen wahren Stand auf, worauf es zu einer "Liebesszene" zwischen dem Chauffeur und der Unbekannten kommt, eine Idee, die Horváth in der Folge nicht weiterverwendet. Zuletzt taucht zum ersten Mal der Diener "Jean" auf, der bis in die Endfassungen von Das unbekannte Leben (K $/ \mathrm{TS}^{16}$ und $\mathrm{TS}^{17}$ ) und Mit dem Kopf durch die Wand $\left(\mathrm{K}^{3} / \mathrm{TS}^{21}\right.$ ) erhalten bleibt, und erklärt dem Chauffeur, dass er "Nevieux" (vgl. E ${ }^{40}$ ) "nachhause“ bringen solle. Das Auftreten Nevieux' erzeugt bei der Unbekannten, die in dieser Szene auch anwesend ist, einen Zustand der Panik, weil sie diesem offensichtlich nicht begegnen will.

Auf der rechten Seite des Blattes notiert Horváth vier weitere Entwürfe. Zunächst vermerkt er in der Figurenliste $\mathrm{E}^{43}$ die Figuren "Marquis", "Nevieux", "Tante" und "Bientôt", die allesamt bis in die Endfassungen von Das unbekannte Leben ( $\mathrm{K}^{2} / \mathrm{TS}^{16}$ und $\mathrm{TS}^{17}$ ) und Mit dem Kopf durch die Wand $\left(\mathrm{K}^{3} / \mathrm{TS}^{21}\right.$ ) erhalten bleiben. In $\mathrm{E}^{44}$ notiert der Autor zum ersten Akt die Konfiguration "Marquis - Notar", womit er die gestrichene Konfiguration von $E^{41}$ doch wiederaufnimmt. Der Strukturplan $E^{45}$, den er darunter einträgt, umfasst zwei Akte, wobei der erste in einer "Reparaturwerkstätte" spielen soll (vgl. die "Garage“ in TS2, TS ${ }^{3}, \mathrm{E}^{52}, \mathrm{E}^{58}$ und $\mathrm{E}^{60}$ ). Die Unbekannte soll dorthin kommen, nachdem sie aus der "Korrektionsanstalt" "entsprungen" ist (zur "Kor- 
rektionsanstalt" vgl. das Kloster in Hertha Paulis Erzählung L'inconnue de la Seine, KOM/TS ${ }^{1}$; vgl. auch $\mathrm{K}^{2} / \mathrm{TS}^{16} / \mathrm{BS} 71, \mathrm{Bl}$. 79, $\mathrm{TS}^{17}$ und $\mathrm{K}^{3} / \mathrm{TS}^{21} / \mathrm{BS} 52, \mathrm{Bl}$. 64). Erstmals wird hier auch der "Tankwart" erwähnt. Weiters notiert Horváth dazu die Figuren: "Aufseher", "Gendarm“ und "Marquis". Darunter vermerkt der Autor zum zweiten Akt nur den bereits bekannten Titel "Beim Marquis". Vermutlich sollte die Unbekannte zum Marquis gelangen (vgl. die späteren Endfassungen von Das unbekannte Leben und Mit dem Kopf durch die Wand, wo ein ähnliches Handlungselement vorkommt, $\mathrm{K}^{2} / \mathrm{TS}^{16} / \mathrm{BS} 71, \mathrm{Bl}$. 68, TS ${ }^{17}$ und $\left.\mathrm{K}^{3} / \mathrm{TS}^{21} / \mathrm{BS} 52, \mathrm{Bl} .52\right)$. Zuletzt notiert Horváth in $\mathrm{E}^{46}$ zum ersten Akt den Titel „Bei Nevieux“, womit neuerlich ein völlig anders gearteter Dramenbeginn angedeutet ist.

$\mathrm{H}^{12}=$ ÖLA 3/W 59 - BS 51 [1], Bl. 10

1 Blatt hochkariertes Papier $(287 \times 225 \mathrm{~mm})$, schwarzblaue Tinte $\mathrm{E}^{47}=$ gestrichener Akttitel zum II. Akt (links oben)

$\mathrm{E}^{48}=$ Strukturplan in 5 Akten (links mittig und rechts oben)

$\mathrm{E}^{49}=$ Strukturplan in 3 Szenen mit Konfigurationsplänen (rechts mittig)

$\mathrm{E}^{50}=$ gestrichener fragm. Strukturplan in 1 Szene (rechts mittig unten)

$\mathrm{E}^{51}=$ fragm. Strukturplan in 1 Szene (links mittig unten)

Die Papierqualität des vorliegenden Blattes ist dieselbe wie im Fall von $\mathrm{H}^{10}$ und $\mathrm{H}^{14}$ (vgl. die Kommentare dort). Von einem genetischen Naheverhältnis dieser Blätter ist deshalb unbedingt auszugehen. Wahrscheinlich ist $\mathrm{H}^{12}$ jedoch erst nach $\mathrm{H}^{10}$ beschrieben worden, denn der in $\mathrm{E}^{49}$ genannte Huelsen findet sich zuvor noch nicht, während der im selben Entwurf erwähnten "Diener" "Jean" bereits in TS ${ }^{3}$ vorgekommen war. Vom Diener heißt es, dass er mit dem "Geld“ komme, vermutlich zu Huelsen, der eine Weiterentwicklung des Sekretärs von $\mathrm{E}^{36}$ und $\mathrm{E}^{38}$ darstellt, und zur Unbekannten, die in der dritten Szene des Strukturplans $\mathrm{E}^{49}$ genannt wird.

In $E^{47}$ notiert Horváth nur den Titel des zweiten Aktes, "Hotel Terminus" (vgl. $\mathrm{E}^{39}$ ), streicht diesen Eintrag aber sofort wieder, um den Strukturplan in fünf Akten E48 zu skizzieren. Darin findet sich die Aktfolge "Hotel Terminus“, „Filmball“, „Beim Marquis", "Beim Marquis" und "Hotel Terminus". Damit stellt dieser Strukturplan eine Weiterentwicklung gegenüber $\mathrm{E}^{39}$ dar, in dem nur vier Akte genannt sind, aber auch gegenüber den Entwürfen von $\mathrm{H}^{11}\left(\mathrm{E}^{40}-\mathrm{E}^{46}\right)$, die in eine völlig andere Richtung gehen, aufgrund des erwähnten Personals (vor allem Nevieux und Jean) aber doch in genetischer Nähe zu den Entwürfen von $\mathrm{H}^{10}$ und $\mathrm{H}^{12}$ zu platzieren sind. In $\mathrm{E}^{50}$ und E $^{51}$ notiert Horváth noch einmal zwei Anläufe zu einem Strukturplan in Szenen, wie ihn auch $E^{49}$ enthält, kommt aber jeweils über die erste Szenennummer nicht hinaus. 


\section{$\mathrm{H}^{13}=$ ÖLA 3/W $59-\mathrm{BS} 51$ [1], Bl. 7}

1 Blatt unliniertes Papier $(285 \times 225 \mathrm{~mm})$, schwarzblaue Tinte

$\mathrm{E}^{52}=$ gestrichener Konfigurationsplan zum I. Akt "Garage" (links ganz oben)

$\mathrm{E}^{53}=$ gestrichener Akttitel zum I. Akt "Beim Photographen" (rechts ganz oben)

$\mathrm{E}^{54}$ = gestrichener Akttitel zum I. Akt „Beim Marquis“ (links oben)

$\mathrm{E}^{55}=$ gestrichener Akttitel zum I. Akt (links mittig oben)

$\mathrm{E}^{56}$ = gestrichener Konfigurationsplan zum I. Akt "Beim Marquis" (mittig oben)

$\mathrm{E}^{57}=$ gestrichener Konfigurationsplan (rechts oben)

$\mathrm{E}^{58}$ = gestrichener Akttitel zum I. Akt "Garage“ mit Notiz (links mittig)

$\mathrm{E}^{59}=$ gestrichener Konfigurationsplan zum I. Akt „Beim Marquis” (mittig)

$\mathrm{E}^{60}=$ Konfigurationsplan zum I. Akt „Garage“ (links unten)

Wie schon in $\mathrm{E}^{40}-\mathrm{E}^{46}$ ringt Horváth auf BS 51 [1], Bl. 7 neuerlich um den ersten Akt, der mit $E^{48}$ festzustehen schien. Von den neun Entwürfen des vorliegenden Blattes bleibt nur einer gültig, alle anderen werden gestrichen. Dabei handelt es sich um $\mathrm{E}^{60}$, einen Konfigurationsplan zum ersten Akt "Garage", der die Figuren "Chauffeur", "Unbekannte“, „2 Kumpane“ und „Jean“ vorsieht. Bis auf die zwei Kumpane kommen alle diese Figuren bereits in TS ${ }^{3}$ vor, in deren unmittelbarer Nähe $\mathrm{E}^{60}$ entstanden sein dürfte. Die zuvor notierten Entwürfe $\mathrm{E}^{52}-\mathrm{E}^{59}$ nennen als Titel des ersten Aktes "Garage" ( $E^{52}$ und $\left.E^{58}\right)$, "Beim Photographen" $\left(E^{53}\right)$ und "Beim Marquis" ( $E^{54}$, $E^{56}$ und $\left.\mathrm{E}^{59}\right)$. Zuletzt scheint sich Horváth aber doch für "Garage" $\left(\mathrm{E}^{60}\right)$ zu entscheiden. Die Konfigurationspläne von $\mathrm{E}^{56}, \mathrm{E}^{57}$ und $\mathrm{E}^{59}$ erinnern an jene von $\mathrm{E}^{41}$ und $\mathrm{E}^{44}$ mit Figuren wie dem „Marquis", dem „Notar" und der „Unbekannten“. Die "Direktrice der Korrektionsanstalt" von $\mathrm{E}^{59}$ (vgl. auch $\mathrm{E}^{67}$ ) verweist zurück auf $\mathrm{E}^{45}$, in dem es von der Unbekannten geheißen hatte, sie sei aus der "Korrektionsanstalt" "entsprungen" (vgl. auch den Kommentar dort).

\section{$\mathrm{H}^{14}=$ ÖLA 3/W $59-\mathrm{BS} 51$ [1], Bl. 12}

1 Blatt hochkariertes Papier $(287 \times 225 \mathrm{~mm})$, schwarzblaue Tinte

$\mathrm{E}^{61}=$ fragm. Strukturplan in 5 Akten (rechts ganz oben)

$\mathrm{E}^{62}=$ gestrichener Konfigurationsplan zum I. Akt „Beim Marquis“ (links oben)

$\mathrm{E}^{63}=\mathrm{tw}$. gestrichener Konfigurationsplan und Notiz zum I. Akt "Beim Marquis“ (links mittig)

$\mathrm{E}^{64}$ = gestrichene Figurenliste zum II. Akt "Die Abendeinladung" (rechts mittig)

$E^{65}=$ gestrichener Akttitel zum I. Akt "Das Heim zum guten Hirten“ (rechts mittig unten)

$\mathrm{TS}^{4}=$ fragm. Fassung des II. Aktes (rechts unten; Korrekturschicht)

$\mathrm{H}^{14}$ entspricht materiell $\mathrm{H}^{10}$ und $\mathrm{H}^{12}$ (vgl. die Kommentare dort). Ein genetischer $\mathrm{Zu}$ sammenhang dieser Blätter ist deshalb anzunehmen. Die Ähnlichkeit der Konfigurationspläne $\mathrm{E}^{62}$ und $\mathrm{E}^{63}$ mit jenen von $\mathrm{E}^{56}, \mathrm{E}^{57}$ und $\mathrm{E}^{59}$ legt jedoch auch einen genetischen Zusammenhang des vorliegenden Blattes zu BS 51 [1], Bl. $7\left(\mathrm{H}^{13}\right)$ nahe. Die beiden Blätter werden deshalb nacheinander gereiht. Vor allem der Akttitel des ersten Aktes, "Beim Marquis", findet sich auf beiden Blättern mehrfach und stützt die Vermutung einer Verwandtschaft. Zunächst hat Horváth wohl rechts oben auf Bl. 12 den fragmentarischen Strukturplan $E^{61}$ eingetragen, der nur die fünf Aktnummern enthält und diese Strukturgröße untermauert, die seit $\mathrm{E}^{30}$ zumindest formell und seit $\mathrm{E}^{35}$ realiter gegeben ist. Der gestrichene Konfigurationsplan $\mathrm{E}^{62}$ nennt neben dem Marquis als Figuren den Diener, den Notar und Nevieux, was für eine Entstehung nach $\mathrm{E}^{40}, \mathrm{E}^{41}$ und $\mathrm{TS}^{3}$ spricht, in denen diese Figuren erstmals genannt werden. In $\mathrm{E}^{63}$ heißt es von Nevieux, dass er "kommt und [Geld] verlangt", womit bereits die ver- 
wickelte pekuniäre Beziehung zwischen dem Marquis, der Tante und ihrem Neffen "Nevieux" angedeutet ist, die bis in die Endfassungen von Das unbekannte Leben $\left(\mathrm{K}^{2} / \mathrm{TS}^{16}\right.$ bzw. $\left.\mathrm{TS}^{17}\right)$ und Mit dem Kopf durch die Wand $\left(\mathrm{K}^{3} / \mathrm{TS}^{21}\right)$ erhalten bleibt. In $\mathrm{E}^{65}$ notiert Horváth zum ersten Akt den Akttitel "Das Heim zum guten Hirten“, womit die Handlung doch, wie in Hertha Paulis Erzählung L'inconnue de la Seine von 1931 (vgl. KOM/TS ${ }^{1}$ ), mit der Unbekannten in der Korrektionsanstalt (vgl. $\mathrm{E}^{45}$ und $\mathrm{E}^{59}$ ) einsetzen sollte, was der Autor aber gleich wieder verwirft. Die Korrektionsanstalt bleibt indes bis in die Endfassungen von Das unbekannte Leben (K2/TS ${ }^{16}$ bzw. TS ${ }^{17}$ ) und Mit dem Kopf durch die Wand ( $\mathrm{K}^{3} / \mathrm{TS}^{21}$ ) erhalten (vgl. den Kommentar zu $\mathrm{E}^{45}$ ).

$\mathrm{E}^{64}$ sowie $\mathrm{TS}^{4}$ dokumentieren Horváths Bemühen um den zweiten Akt. Zunächst erwägt er in $\mathrm{E}^{64}$ dafür eine "Abendeinladung" mit einer "entfernte[n] Verwandte[n]", der "Unbekannte[n]" und ihrem "Bräutigam", streicht diesen Entwurf jedoch wieder und trägt darunter TS ${ }^{4}$ ein, die eine Fassung des zweiten Aktes mit den Figuren Semper, Huelsen und Bossard enthält und als zentrales Handlungselement bereits die Filmvorführung mit dem "Gespenst" der Unbekannten umfasst. Da dies inhaltlich einen beträchtlichen Sprung darstellt, ist anzunehmen, dass Horváth TS ${ }^{4}$ möglicherweise mit einem größeren zeitlichen Abstand eingetragen hat, eventuell auch erst nach den Entwürfen von BS 51 [1], Bl. $8\left(\mathrm{H}^{15}\right)$, insbesondere nach $\mathrm{E}^{71}$. Dort bzw. in TS ${ }^{4}$ wird die Figur des späteren Direktors der Filmgesellschaft Pandora, Semper, zum ersten Mal genannt. Er zeigt sich bereits in $\mathrm{TS}^{4}$ skeptisch gegenüber den vermeintlichen Filmaufnahmen des "Gespenst[es]" der Unbekannten, ist aber vom Pianisten und dessen Musik begeistert, was sich in ähnlicher Form noch in den Endfassungen von Das unbekannte Leben und Mit dem Kopf durch die Wand findet (vgl. $\mathrm{K}^{2} / \mathrm{TS}^{16} / \mathrm{BS} 71, \mathrm{Bl}$. 33, $\mathrm{TS}^{17}$ und $\mathrm{K}^{3} / \mathrm{TS}^{21} / \mathrm{BS} 52, \mathrm{Bl} .16$ ).

\section{$\mathrm{H}^{15}=$ ÖLA 3/W 59 - BS 51 [1], Bl. 8}

1 Blatt unliniertes Papier $(282 \times 224 \mathrm{~mm})$, schwarzblaue Tinte

$\mathrm{E}^{66}=$ gestrichene Konfigurationspläne zum I. Akt "Beim Marquis“ (links oben)

$\mathrm{E}^{67}=$ gestrichene Konfigurationspläne (rechts oben)

$\mathrm{E}^{68}$ = gestrichene Konfigurationspläne zum I. Akt (links mittig oben)

$\mathrm{E}^{69}=$ Konfigurationsplan zum 1. Bild "Tankstelle“ (links mittig)

$E^{70}=$ gestrichener fragm. Konfigurationsplan zum 1. Bild „Bei Bossard” (links mittig unten)

$\mathrm{E}^{71}=$ gestrichener Bildtitel zum 1. Bild "Bei Bossard” (links unten)

$\mathrm{E}^{72}=$ Konfigurationspläne zum 1. Bild "Büro des Generaldirektors“ (rechts unten)

$\mathrm{E}^{73}=$ Konfigurationsplan und Notiz zum IV. Akt „Beim Marquis“ (links ganz unten)

Auch auf Bl. 8 lassen sich Horváths Überlegungen zum ersten Akt bzw. ersten Bild seines Werkprojekts nachverfolgen. Zunächst, in $\mathrm{E}^{66}$, bleibt er bei der Idee, den ersten Akt "[b]eim Marquis" spielen zu lassen, was bereits durch etliche vorangehende Struktur- und Konfigurationspläne angelegt ist (vgl. die allerdings teils gestrichenen $\mathrm{E}^{54}, \mathrm{E}^{56}, \mathrm{E}^{59}, \mathrm{E}^{62}$ und $\mathrm{E}^{63}$ ), streicht diesen Entwurf aber in der Folge teilweise. Auch die ebenfalls getilgten Konfigurationspläne von $\mathrm{E}^{67}$ und $\mathrm{E}^{68}$ zeugen noch von dieser konzeptionellen Vorstellung. Mit $E^{69}$ nimmt Horváth jedoch einen neuen Anlauf in der Anlage des ersten Aktes, indem er zumindest dessen erstes Bild an einer "Tankstelle" spielen lassen will (vgl. $\mathrm{E}^{45}$ sowie die "Garage“ in TS${ }^{2}, \mathrm{E}^{40}, \mathrm{TS}^{3}, \mathrm{E}^{52}, \mathrm{E}^{58}$ und $\mathrm{E}^{60}$ ). Hierzu notiert der Autor eine Reihe von Konfigurationen, die einen "Tankwart", einen "Spezi", "der ihn verführen will“, die "Unbekannte", einen "Gendarm[en]" sowie schließlich auch den "Marquis" und „Nevieux" umfassen sollen. Damit werden ein 
schrittweiser Einstieg in die Handlung und eine stufenweise Exposition zentraler Charaktere angedeutet.

Mit $\mathrm{E}^{69}$ verschwindet die Idee, eine "Garage“ (vgl. oben), "Reparaturwerkstätte“ (vgl. $\mathrm{E}^{45}$ ) oder "Tankstelle" $\left(\mathrm{E}^{69}\right)$ an den Beginn des Stückes zu stellen, wieder aus dem Werkprojekt. Bereits $\mathrm{E}^{70}$ und $\mathrm{E}^{71}$ scheinen diese konzeptionelle Idee zu konterkarieren, indem sie beide das erste Bild "Bei Bossard“ vorsehen (vgl. E ${ }^{55}$ ). Horváth streicht jedoch diese Entwürfe sogleich wieder und trägt stattdessen $\mathrm{E}^{72}$ ein. Dieser hält für das erste Bild oder den ersten Akt den Schauplatz "Büro des Generaldirektors" fest, was bereits durch frühere Entwürfe mit dem Titel "Im Büro des Filmes" bzw. „Filmbüro" (vgl. E $E^{20}-E^{38}$ ) angelegt war. Die zu E ${ }^{72}$ notierten Figuren Semper und Huelsen finden sich bereits in $\mathrm{E}^{49} \mathrm{bzw}$. TS${ }^{4}$. Möglicherweise ist diese Textstufe auch erst nach den Entwürfen von BS 51 [1], Bl. $8\left(\mathrm{H}^{15}\right)$ entstanden (vgl. den Kommentar dort). Weiters hält Horváth zu $E^{72}$ die Unbekannte und Bossard fest, auch diese gehören zum Setting von TS4. Der ebenfalls in $\mathrm{E}^{72}$ erwähnte (Regisseur) Mayberg geht auf $\mathrm{E}^{29}$ zurück. In $\mathrm{E}^{73}$ schließlich trägt Horváth einen Konfigurationsplan und eine Notiz zum vierten Akt ein, der den Titel „Beim Marquis“ tragen soll. Hierzu vermerkt der Autor die Konfiguration "Marquis - Notar" (vgl. E41 und E44) und notiert zum Marquis, dass dieser sein "Testament“ ändert. Ein etwas kryptischer Eintrag lässt annehmen, dass er sein Geld nun "statt de[n] Heime[n]" und "Nevieux" einem gewissen "Frl. Catherine $\{$ Guld\}" vermachen will.

Mit den Entwürfen von BS 51 [1], Bl. 8 endet eine Konzeptionsphase in der Erstellung des Stückes Das unbekannte Leben bzw. Mit dem Kopf durch die Wand, hier noch unter dem Titel L'inconnue de la Seine. Die Entwürfe der folgenden Konzeption sind stärker auf die spiritistische Séance und die Filmhandlung ausgerichtet, die in den Entwürfen der VA und von $\mathrm{K}^{1}$ nur eine untergeordnete Rolle spielen.

\section{Konzeption 2: Das unbekannte Leben - Komödie}

\section{$\mathrm{H}^{1}=$ ÖLA 3/W 60 - BS 51 [2], Bl. 2}

1 Blatt kariertes Papier $(330 \times 209 \mathrm{~mm})$, schwarzblaue Tinte

$\mathrm{E}^{1}=$ Strukturplan in 6 Akten mit Werktitel "L'inconnue de la Seine / Komödie in fünf Akten“ mit Repliken und Dialogskizzen

Das vorliegende und die folgenden Blätter markieren einen wesentlichen Fortschritt und eine Neuorientierung in der Arbeit an der Komödie L'inconnue de la Seine, weshalb hier ein konzeptioneller Schnitt gesetzt wird, obwohl sich auf einem Teil der Entwürfe von $\mathrm{K}^{2}$ noch der Werktitel von $\mathrm{K}^{1}$ "L'inconnue de la Seine " befindet (vgl. $\mathrm{E}^{1}$, $\mathrm{E}^{2}, \mathrm{E}^{9}, \mathrm{E}^{10}$ und $\mathrm{E}^{15}$, hier "L'inconnue dans la Seine $\left.{ }^{\prime \prime}\right)$. Horváth entwickelt den neuen Werktitel „Das unbekannte Leben“ erst im Laufe von $\mathrm{K}^{2}$ (vgl. $\left.\mathrm{E}^{15}-\mathrm{E}^{17}\right)$. Materiell sind $\mathrm{H}^{1}-\mathrm{H}^{4}$ identisch, das heißt, sie weisen dieselbe Papierqualität auf: überlanges, schmales, kariertes Papier der Größe $330 \times 209$ mm. Dies kann als Indiz für den genetischen Zusammenhang der entsprechenden Blätter gewertet werden. Dieser lässt sich auch inhaltlich belegen. Auf Bl. 2 entwirft Horváth einen Strukturplan in sechs Akten, den er mit dem für $\mathrm{K}^{1}$ charakteristischen Werktitel "L'inconnue de la Seine / Komödie in fünf Akten“ versieht. Darin entwickelt er einen Handlungsverlauf, der von den unmittelbar vorhergehenden Strukturplänen einigermaßen abweicht und sich eher wieder an den mittleren Entwürfen von $\mathrm{K}^{1}$ orientiert (vgl. etwa $\mathrm{K}^{1} / \mathrm{E}^{30}-\mathrm{E}^{38}$ ). 
Die Aktfolge lautet jetzt „Im Filmbüro“, "Bei den Spiritisten“, „Im Filmbüro“, „Beim Marquis", "Bei den Spiritisten“ und "Vorführraum“. Den letzten Akt hat Horváth nachträglich eingefügt, sodass die im Gattungstitel genannte Strukturgröße "in fünf Akten“ dem Entwurf nicht mehr entspricht. Der Akttitel "Bei den Spiritisten“ ist neu und findet sich nur noch in den folgenden Entwürfen $E^{2}-E^{4}$. Danach kehrt Horváth für die entsprechenden Akte zu der Betitelung "Hotel“ zurück (vgl. E5). Der erste Akt „Im Filmbüro“ bleibt bis TS ${ }^{16}$, der ersten Endfassung, jener in fünf Akten, erhalten. Während Horváth in $\mathrm{E}^{1}$ noch einen dritten Akt "Im Filmbüro" plant, fällt dieser in der Folge weg. Der dritte Akt spielt ab E2 "Beim Marquis“. Die ursprüngliche Aktfolge von $\mathrm{E}^{1}$ lautete "Im Filmbüro", "Bei den Spiritisten“, "Im Filmbüro“, "Bei der Marquise" und "Im Filmbüro", eine symmetrische Struktur mit drei Akten "Im Filmbüro", was einzigartig in der Konzeption von Das unbekannte Leben bzw. Mit dem Kopf durch die Wand ist. Die geänderte Aktfolge wie oben angeführt enthält nur noch zwei Akte "Im Filmbüro" am Beginn des Stückes und im dritten Akt. Der zuletzt eingefügte sechste Akt "Vorführraum" ist neu und wird in den folgenden Strukturplänen $\mathrm{E}^{2}-\mathrm{E}^{4}$ wiederaufgenommen, was die Reihung dieser Entwürfe nach $\mathrm{E}^{1}$ stützt.

Motivisch finden sich einige bekannte, aber auch neue Elemente in $\mathrm{E}^{1}$. Der Direktor behauptet im ersten Akt, den Film "nach einer wahren Begebenheit" machen zu wollen, und vermerkt dazu, dass er bereits "auf der Spur der wahren Geschichte“ sei (vgl. $\mathrm{K}^{1} / \mathrm{TS}^{1}$ ). Im zweiten Akt soll der "Marquis" zu den Spiritisten kommen. Im dritten Akt bekräftigt zunächst der Marquis, "schuld“ am Tod er Unbekannten zu sein, dann versichert jedoch "der alte Bientôt", sie „in das Wasser gestossen“ zu haben, denn er habe etwas mit ihr gehabt. Zu diesem Akt notiert Horváth auch eine "Gesellschafterin" (vgl. VA/E $E^{6}$ und $E^{7}$ ). Diese verschwindet jedoch mit $E^{1}$ wieder aus dem Werkprojekt. Im letzten Akt, dem Vorführraum, äußert der Direktor, dass er den Film nicht machen werde, er wolle jedoch denjenigen, der sich das alles ausgedacht habe, als „ersten kaufmännischen Direktor" engagieren. Alfred, wohl sein Sekretär, meint dazu, dass das wohl nicht gehen werde, denn es sei "Angèle“. Dieser Name taucht im weiteren Verlauf der Werkgenese nicht mehr auf. Damit ist aber wohl die spätere Unbekannte gemeint, in weiterer Folge auch Susanne genannt (vgl. $\mathrm{K}^{3} / \mathrm{TS}^{14}$ und $\mathrm{TS}^{16}$ ). Der in $\mathrm{E}^{1}$ angedeutete Schluss findet sich in ähnlicher Form in TS${ }^{16} / \mathrm{BS}$ 71, Bl. 104 und TS17/BS 52, Bl. 91, wo der Direktor denjenigen, der sich den ganzen "Spuk" ausgedacht hat, als "Reklamechef" engagieren will.

\section{$\mathrm{H}^{2}=$ ÖLA 3/W 60 - BS 51 [2], Bl. 1}

1 Blatt kariertes Papier $(330 \times 209 \mathrm{~mm})$, schwarzblaue Tinte

$\mathrm{E}^{2}$ = fragm. Strukturplan in 4 Akten mit Werktitel "L'inconnue de la Seine / Komödie in fünf Akten

(sechs Bildern) von Ödön von Horváth“ mit Notizen, Repliken und Dialogskizzen (links)

$\mathrm{E}^{3}=$ Strukturplan in 5 Akten (mittig oben)

$\mathrm{E}^{4}=$ Strukturplan in 5 Akten (rechts oben)

Auf dem vorliegenden Blatt, das materiell dem vorhergehenden und den nachfolgenden entspricht (vgl. den Kommentar zu E ${ }^{1}$ ), notiert Horváth zunächst einen Strukturplan $\mathrm{E}^{2}$ in fünf Akten, den er mit zahlreichen Notizen, Repliken und Dialogskizzen versieht. Alternativ zu den "fünf Akten" des Gattungstitels vermerkt der Autor darin "sechs Bilde[r]", was dem vorliegenden Entwurf jedoch nicht entspricht. Die Aktfolge lautet in $\mathrm{E}^{2}$ : "Filmbüro", "Bei den Spiritisten“, "Beim Marquis", "Bei den Spiritisten“ und „Vorführraum" (vgl. E ${ }^{1}$ ). Den letzten Akt streicht Horváth jedoch, 
ohne ihn durch einen anderen zu ersetzen, weshalb man von einem fragmentarischen Entwurf ausgehen muss. Dem entspricht auch die Korrektur im Titel von "fünf" Akten zu "vier" und dann wieder zu "fünf". Zum zweiten Akt notiert der Autor, dass die Spiritisten die Unbekannte "bereits photographiert" haben, "allerdings nur mit einer kleinen Amateurkamera" (vgl. TS ${ }^{16} / \mathrm{BS}$ 71, Bl. 35 und TS ${ }^{17} / \mathrm{BS}$ 52, Bl. 18f.). Zum dritten Akt „Beim Marquis“ vermerkt er die folgende Replik des Marquis: "Wir Männer häufen in unserer Jugend alle grosse Sünden auf uns - Sünden gegen arme Mädchen. Was wissen Sie von dem Schicksal Threr Geliebten -?“ Der ebenfalls hier genannte Mayberg geht auf frühere Entwürfe zurück (vgl. etwa $\mathrm{K}^{1} / \mathrm{E}^{29}$ und $\mathrm{E}^{35}$ ). Ein

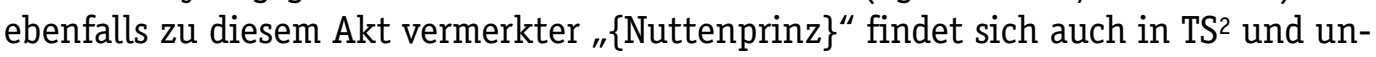
terstreicht die genetische Nähe dieser Ausarbeitungen. Zuletzt behauptet der alte Bientôt wie schon in $\mathrm{E}^{1}$, dass er die Unbekannte "ins Wasser geschmissen“ habe. Zum Neffen, der ebenfalls seit $\mathrm{K}^{1} / \mathrm{E}^{29}$ im Werkprojekt vertreten ist, notiert der Autor, dass dieser "die ganze Erpressung" "aus Angst" "gesteht", was bis zu den Endfassungen von Das unbekannte Leben und Mit dem Kopf durch die Wand erhalten bleibt (vgl. $\mathrm{TS}^{16} / \mathrm{BS}$ 71, Bl. 75 und 86 sowie TS ${ }^{17}$ bzw. $\mathrm{K}^{3} / \mathrm{TS}^{21} / \mathrm{BS}$ 52, Bl. 60 und 70f.). Auch die Tante wird hier erwähnt. Von ihr heißt es, dass sie "erscheinen" muss, was sich so ebenfalls in den drei Endfassungen findet (vgl. TS ${ }^{16} / \mathrm{BS} 71, \mathrm{Bl} .87 \mathrm{f}$. und TS ${ }^{17}$ bzw. $\mathrm{K}^{3} / \mathrm{TS}^{21}$ /BS 52, Bl. 72f.). Zum vierten Akt „Bei den Spiritisten“ vermerkt Horváth, dass der Marquis "die Schwindler entlarven“ will. Zum zunächst fünften Akt "Vorführraum" notiert der Autor jedoch, dass der "Dichter" die Schwindler "entlarvt". Der Direktor reagiert auf die Entlarvung schockiert: „Moment, Moment! Innere Kalkulation! Wenn das an die Öffentlichkeit kommt, bin ich blamiert!“ (vgl. TS16/BS 71, Bl. 103, TS17/BS 52, Bl. 90 und $\mathrm{K}^{3} / \mathrm{TS}^{21} / \mathrm{BS} 53$ [4], Bl. 7).

Die beiden Strukturpläne $\mathrm{E}^{3}$ und $\mathrm{E}^{4}$ nehmen entgegen der Streichung in $\mathrm{E}^{2}$ die Aktfolge "Filmbüro", "Spiritisten“, "Marquis", "Spiritisten" und "Vorführraum" wieder auf und scheinen diese zu bestätigen. Es ist jedoch möglich, dass Horváth die Überarbeitungen von $\mathrm{E}^{2}$ erst nach der Niederschrift von $\mathrm{E}^{3}$ und $\mathrm{E}^{4}$ eingetragen hat, wodurch deren Aktfolge obsolet wäre. Möglicherweise handelt es sich bei den in $\mathrm{E}^{3}$ und $\mathrm{E}^{4}$ genannten Abschnitten auch um Bilder, was die arabische Nummerierung und der Untertitel von $\mathrm{E}^{2}$ nahelegen würden.

\section{$\mathrm{H}^{3}=$ ÖLA 3/W 62 - BS 51 [4], Bl. 1-4}

4 Blatt kariertes Papier $(330 \times 209 \mathrm{~mm})$, schwarzblaue Tinte, roter Buntstift, Paginierung 3, 7-9 TS $^{1}=$ fragm. Fassung einer Szene (Korrekturschicht: schwarzblaue Tinte)

Mit TS ${ }^{1}$ liegt eine fragmentarische Fassung eines Dialogs zwischen dem Direktor, Bossard, dem Sekretär, Mayberg und einer Figur namens Schnatterpfeil vor. Es fehlen Beginn und Ende der Textstufe, die wohl weitere Blätter umfasst hat, sowie drei Blatt zwischen Bl. 1, das die Pagina 3 trägt, und Bl. 2, das mit der Pagina 7 fortsetzt. Das letzte überlieferte Blatt der Fassung, Bl. 4, trägt die Pagina 9. Damit war die Ausarbeitung aber noch nicht zu Ende, wie der in der Mitte abbrechende Satz auf Bl. 4 unten nahelegt.

Den Beginn der Fassung TS ${ }^{1}$ bildet ein Dialog zwischen dem Direktor und Bossard (vgl. $\mathrm{K}^{1} / \mathrm{E}^{36}, \mathrm{E}^{38}, \mathrm{TS}^{1}$ und $\mathrm{E}^{72}$ ) über parapsychologische Phänomene. Der Direktor berichtet von einem ersten Liebeserlebnis, durch das er sich in einem spezifischen "Licht" gefühlt habe, worauf Professor Bossard ihn nach "Geistesstörungen in der Familie“ (Bl. 1) befragt. Die Passage endet mit dem Wunsch des Direktors, sich von Bos- 
sard behandeln zu lassen (vgl. TS $16 / \mathrm{BS} 71, \mathrm{Bl}$. 94f., TS${ }^{17} / \mathrm{BS} 52, \mathrm{Bl}$. 81f. und K3/TS21/BS 53 [4], Bl. 3f.). Nach dem Textverlust setzt Bl. 2 mit einem Dialog zwischen dem Sekretär (vgl. $\mathrm{K}^{1} / \mathrm{E}^{27}, \mathrm{E}^{36}, \mathrm{E}^{38}$ und TS${ }^{1}$ ), einer Vorform des Doktor Huelsen (vgl. $\mathrm{K}^{1} / \mathrm{E}^{49}$ und $\mathrm{E}^{72}$ ), und dem Direktor über ein "Exposé”, das der Sekretär als "unfilmisch" bezeichnet. Allerdings ist er mit dem Herrn (bzw. der "Dame", wie es in der Korrektur heißt) befreundet, die es verfasst hat (vgl. TS ${ }^{16} / \mathrm{BS} 71, \mathrm{Bl} .11-13,51$ und 98, TS ${ }^{17} / \mathrm{BS} 52$, Bl. 9, 24, 36 und 85 sowie $\mathrm{K}^{3} / \mathrm{TS}^{21} / \mathrm{BS} 52$, Bl. 9, 24, 36, BS 53 [4], Bl. 8 und 16). Der Direktor beschließt jedoch, das Exposé zu erwerben und lässt nach dem "Dichter" schicken. Dieser sitzt bereits seit Tagen im "Vorzimmer" und wird als "Jammergestalt" in einem "Regenmantel" bezeichnet (Bl. 2). Der Name des Dichters ist "Schnatterpfeil“ (ebd.), was Mayberg mit den Worten "Kein alltäglicher Name“ (ebd.) quittiert. Er habe "ein paar wunderschöne Gedichte" (ebd.) geschrieben. Der Auftritt des Dichters Schnatterpfeil auf Bl. 3 und 4 wird dann zur platten Burleske. Der Dichter behauptet, dass sein Künstlername eigentlich "von der Aue“ (Bl. 3) sei. Der Direktor erklärt ihm, dass er "zeitlich als erster die Idee eingereicht" habe und dass er sein "Exposé" kaufen wolle (vgl. den Streit um die Ersteinreichung zwischen der Unbekannten bzw. Huelsen und Mayberg in TS ${ }^{16} / \mathrm{BS} 71$, Bl. 11f., $\mathrm{TS}^{17}$ und $\mathrm{K}^{3} / \mathrm{TS}^{21} / \mathrm{BS} 52$, Bl. 9 und 24). Als er ihn nach dem Preis fragt, gibt dieser zu erkennen, dass er kein Geld brauche, da sein Bruder ein Wirtshaus habe. Es gehe ihm nur um den Film, darum, dass sein Film gemacht werde. Der Direktor kontert jedoch, dass sein "Film“, gemeint ist das Drehbuch, nichts sei, "d.h. er ist gescheit, klug, dichterisch, aber völlig unfilmisch“ (vgl. TS16/BS 71, Bl. 13 und 40 sowie TS $^{17}$ und $\mathrm{K}^{3} / \mathrm{TS}^{21} / \mathrm{BS}$ 52, Bl. 9 und 24). Deshalb wolle er dem Dichter zwar seine "Idee“ zahlen bzw. den "Titel“, der "ein historischer Titel ist gewissermassen" (Bl. 3), aber sich sonst zu nichts verpflichten. Parallelen dieser Handlungselemente zu Horváths wahrscheinlich stattgefundenen eigenen Versuchen, den Stoff der Unbekannten als Filmsujet zu verarbeiten, sind anzunehmen (vgl. die Listen "Fünf Filme“ $\mathrm{K}^{3} / \mathrm{E}^{14}$ und $\mathrm{E}^{15}$, die allerdings später entstanden sind). Der Dichter bekennt, dass ihn diese "Maske“ (Bl. 4) "seit Jahren“ beschäftige: "[I]ch hab unzähliges versucht, bis ich die rechte Lösung gefunden habe!" (ebd.). Zuletzt droht der Dichter damit, einen Prozess gegen den Direktor anzuzetteln, wenn er nicht sein Exposé verfilmt, sondern nur seine Idee bzw. seinen Titel übernimmt. Schnatterpfeil bezeichnet die Filmleute schließlich als "Raubritter der Leinwand“ (ebd.), was der Direktor sogleich von seinem Sekretär als möglichen Filmtitel notieren lässt. Nach Schnatterpfeils Abgang gibt Mayberg zu bedenken, dass es "nicht leicht ist" "[ü]ber eine Maske etwas zu schreiben, das Leben zu rekonstruieren, über die man nichts weiss“, hofft aber, dass "unseren Autoren“ (ebd.) etwas einfällt. Der Direktor - zuletzt in einer nachträglich eingefügten Notiz auch mit dem Namen Semper bezeichnet - meint, er habe "unsere besten drei Autoren“ damit beauftragt, etwas zu schreiben, weshalb man doch hoffen könne, dass etwas Brauchbares dabei sei. Damit bricht TS ${ }^{1}$ ab. Dieses Handlungselement bleibt bis zu den Endfassungen von Das unbekannte Leben erhalten (vgl. TS ${ }^{16} / \mathrm{BS}$ 71, Bl. 16 und 106 sowie $\mathrm{TS}^{17} / \mathrm{BS}$ 52, Bl. 48 und 93). In der Endfassung von Mit dem Kopf durch die Wand $\left(\mathrm{K}^{3} / \mathrm{TS}^{21}\right)$ treten die drei Drehbuchautoren Hell, Barbou/Simone und Mayberg nicht mehr auf. Dort soll zuletzt Huelsen das Drehbuch zum Film über die Unbekannte schreiben (vgl. K³ ${ }^{3} S^{21} /$ BS 53 [4], Bl. 16).

Horváth wollte zumindest einen Teil von $\mathrm{TS}^{1}$ verschieben, wie eine Eintragung mit schwarzblauer Tinte auf Bl. 1 ersehen lässt. Dort vermerkt der Autor, dass ein Teil der Fassung in das zweite Bild des zunächst dritten, dann fünften Aktes übertragen wer- 
den soll. Später überschreibt er diesen Eintrag durch großflächige Markierungen mit rotem Buntstift auf Bl. 1 und Streichungen auf den Bl. 2-4, die darauf hindeuten, dass die markierten bzw. nicht gestrichenen Abschnitte im fünften Akt wiederverwendet hätten sollen. Teile des Dialogs zwischen Bossard und dem Direktor von Bl. 1 wandern tatsächlich in die Endfassungen von Das unbekannte Leben und Mit dem Kopf durch die Wand (vgl. oben).

\section{$\mathrm{H}^{4}=$ ÖLA 3/W 60 - BS 51 [2], Bl. 3, 4}

2 Blatt kariertes Papier $(330 \times 209 \mathrm{~mm})$, schwarzblaue Tinte und roter Buntstift, Paginierung 2, 3 $\mathrm{TS}^{2}=$ fragm. Fassung einer Szene (Korrekturschicht: schwarzblaue Tinte und roter Buntstift)

Die vorliegenden Blätter bilden mit $\mathrm{H}^{1}-\mathrm{H}^{3}$ eine materiell, aber auch inhaltlich gestützte genetische Reihe (vgl. den Kommentar zu E ${ }^{1}$ ). Ähnlich wie in TS ${ }^{1}$ geht es in TS² um die Frage der Verfilmung des Stoffes der "Unbekannten“. Zunächst ereifert sich der Direktor jedoch über alle möglichen Filmstars, u.a. über die Carry, die mit TS 2 als eingeführt gelten muss (vgl. auch $\mathrm{E}^{10}, \mathrm{E}^{12}, \mathrm{TS}^{16}$ und TS ${ }^{17}$ ). Der vom Direktor als "Nuttenprinz" (Bl. 3) bezeichnete Moreno verweist auf $\mathrm{E}^{2}$ und belegt die Nähe von TS $^{2}$ zu diesem Strukturplan. Auch der Drehbuchautor Hell, der bis TS ${ }^{16}$ und TS ${ }^{17}$ erhalten bleibt, ist mit TS² bereits eingeführt. Er soll ein Verhältnis mit der Carry haben. Die Fassung TS² wurde von Horváth großflächig überarbeitet. So notiert er auf Bl. 3 am Rand eine Variante zum zuvor ausgeführten Dialogtext, sodass ein Großteil des ursprünglichen Textes in der Transkription als Variante ausgewiesen ist. Außerdem wurde Bl. 4 in der Überarbeitung zur Gänze gestrichen und erscheint deshalb in der Transkription als Streichung im kritischen Apparat.

In der Grundschicht ist davon die Rede, dass es bereits in der Zeitung gestanden sei, dass die "\{Panropa $\}$ Film-Verleih A.G." (Bl. 3) einen Film über die "Unbekannte" plane. Der Hinweis auf die Filmgesellschaft lässt vermuten, dass die Textstufe im Umfeld von TS1 ${ }^{1}$, wo die „Panerga-Film“ (TS11/BS 51 [4], Bl. 3), und von E ${ }^{12}$, wo die „Panna-Film" erwähnt wird, entstanden ist. Ein weiterer Teil des Dialogs in der Grundschicht beschäftigt sich mit der Frage, ob nicht der Sekretär ein Drehbuch verfassen könnte, denn er ist "gebildet, schreib[t] ein klassisches deutsch und ha[t] viel freie Zeit", wie der Direktor meint. Doch der Sekretär entgegnet dem, dass er keine Zeit habe, denn er schreibe auch für die literarische Zeitschrift "Neue Tage“ (vgl. TS16/ BS ${ }^{71}$, Bl. 7). Außerdem habe er schon einmal ein Drehbuch unter falschem Namen eingereicht, das abgelehnt worden sei. In der Korrekturschicht endet die Fassung damit, dass der Direktor dem Sekretär vorwirft, dass er immer "neue Autoren“ entdecken will.

\section{$\mathrm{H}^{5}=$ ÖLA 3/W 61 - BS 51 [3], Bl. 3, ÖLA 3/W 59 - BS 51 [1], Bl. 17}

2 Blatt unliniertes Papier $(305 \times 228 \mathrm{~mm})$, schwarzblaue Tinte $\mathrm{E}^{5}=$ fragm. Strukturplan in 2 Akten mit Figurenliste zum II. Akt "Hotel“ (Bl. 3, oben)

$\mathrm{E}^{6}=$ Strukturplan in 4 Szenen mit Notizen und Dialogskizzen (Bl. 3, mittig und unten, sowie Bl. 17, oben)

$\mathrm{E}^{7}=$ Strukturplan in 1 Szene (Bl. 17, links mittig)

$\mathrm{E}^{8}=$ fragm. Strukturplan in 3 Akten (Bl. 17, links unten)

$\mathrm{E}^{9}=$ Strukturplan in 5 Akten mit Werktitel "L'inconnue de la Seine“ mit einem Konfigurationsplan (Bl. 17, rechts unten)

Die Zusammengehörigkeit der Blätter BS 51 [3], Bl. 3 und BS 51 [1], Bl. 17 ist bisher nicht erkannt worden, sie kann aber als relativ sicher gelten. Die ungewöhnliche 
Nummerierung der Abschnitte des darauf u. a. befindlichen Strukturplans E ${ }^{6}$, der die beiden Blätter übergreift, mit A und B bzw. C und D ist sonst im genetischen Konvolut zu Mit dem Kopf durch die Wand nicht anzutreffen. Zunächst notiert Horváth auf Bl. 3 oben den Werktitel "Die Reise ins Paradies", der auf das 1935 entstandene fragmentarische Prosa-Werkprojekt Die Reise ins Paradies verweist (vgl. WA 13/WP ${ }^{18}$ ). Darunter trägt Horváth eine Figurenliste $\mathrm{E}^{5}$ zum zweiten Akt "Hotel“ ein (vgl. $\mathrm{K}^{1} / \mathrm{E}^{36}-\mathrm{E}^{38}$ und $\left.\mathrm{K}^{2} / \mathrm{E}^{8}-\mathrm{E}^{10}\right)$. Diese umfasst Bossard, seinen Assistenten, den Pianisten, Adolf (vgl. E ${ }^{10} / \mathrm{Bl} .2$ sowie den späteren Kellner Adolf im Filmball-Akt von TS ${ }^{3}$, TS ${ }^{16}$, TS $^{17}$ und $\mathrm{K}^{3} / \mathrm{TS}^{21}$ ), die Unbekannte und Albert (vgl. $\mathrm{K}^{1} / \mathrm{TS}^{2}$ und $\mathrm{K}^{2} / \mathrm{E}^{6} / \mathrm{Bl}$. 17), der jedoch gestrichen wird.

Darunter notiert Horváth den Strukturplan $E^{6}$ in vier Abschnitten. Dabei hatte er zunächst mit einer Art Konfigurationsplan begonnen, diesen führt er jedoch durch die Nummerierung mit A-D in einen Strukturplan über. Wahrscheinlich handelt es sich bei den Abschnitten um Szenen, und es sollte damit die Szenenfolge im zweiten Akt "Hotel“ (zuletzt in $\mathrm{K}^{1} / \mathrm{E}^{38}$ ) oder "Bei den Spiritisten“ (vgl. $\mathrm{E}^{1}-\mathrm{E}^{4}$ ) ausgearbeitet werden. In Szene A sollen offensichtlich erstmals das Medium und die Unbekannte auftauchen. In der mit B betitelten "Pause mit Medium“ gehen der Direktor und Bossard ins Nebenzimmer ab, wo eine "kleine Tafel“ gerichtet ist. Währenddessen amüsieren sich der Assistent und Adolf darüber, dass der Direktor auf den Schwindel mit dem Medium und der Unbekannten hereinfällt. Das in Szene B genannte Fräulein Braun taucht als Fräulein Klein in $\mathrm{E}^{10}$ wieder auf. In der auf $\mathrm{Bl} .17$ befindlichen, mit "C" betitelten Szene soll die Unbekannte neuerlich auftreten, bei einer „Fehlzitierung" wird jedoch zunächst "Napoleon" heraufbeschworen (vgl. TS"16/BS 71, Bl. 26 und 40, TS ${ }^{17}$ sowie K³ ${ }^{3} S^{21} /$ BS 52, Bl. 3 und 24). Dann tauchen "andere Geister" auf, darunter "Albert", eine unmittelbare Referenz auf Horváths Komödie Eine Unbekannte aus der Seine (1933), in der Albert neben der Unbekannten die Hauptfigur darstellt (vgl. auch $\mathrm{K}^{1} / \mathrm{TS}^{2}$ ). In dem mit "D” betitelten Akt "Pause“ sieht sich der "Direktor" den Film an, was die Probeaufnahmen der Unbekannten vorwegnimmt, die sich Semper in den Endfassungen von Das unbekannte Leben und Mit dem Kopf durch die Wand ansieht und von denen er begeistert ist (vgl. TS ${ }^{16} / \mathrm{BS} 71, \mathrm{Bl} .94, \mathrm{TS}^{17} / \mathrm{BS} 52$, Bl. 80 und $\mathrm{K}^{3} / \mathrm{TS}^{21} / \mathrm{BS} 53$ [4], Bl. 2f.). Zum erstmals in $\mathrm{K}^{1} / \mathrm{E}^{27}$ genannten "Sekretär" (vgl. auch $\mathrm{K}^{1} / \mathrm{E}^{36}, \mathrm{E}^{38}$, $\mathrm{E}^{49}$ und $\mathrm{K}^{2} / \mathrm{TS}^{2}$ ) notiert Horváth folgende Replik: „Könnt Ihr das verantworten? Lasst die Gespenster der Vergangenheit ruhen!!“ Diese Replik präfiguriert eine Stelle in den beiden Endfassungen von Das unbekannte Leben, in der der Marquis darauf hinweist, dass man die Toten ruhen lassen soll (vgl. TS ${ }^{16} / \mathrm{BS}$ 71, Bl. 106 und $\mathrm{TS}^{17} / \mathrm{BS}$ 52, Bl. 93).

$E^{7}$ könnte als Wiederaufnahme des Beginns des Strukturplans $E^{6}$ gedeutet werden, da Horváth hier ebenfalls alphabetisch gliedert und neuerlich den "Assistent[en]“ für Szene A notiert. In $E^{8}$ skizziert er einen fragmentarischen Strukturplan in drei Akten mit der Aktfolge "Filmbüro", "Hotel“ und einem dritten, nicht betitelten Akt; der Entwurf verweist zurück auf die Strukturpläne $\mathrm{K}^{1} / \mathrm{E}^{23}-\mathrm{E}^{38}$, in denen dieselbe Aktfolge angelegt ist. Zuletzt notiert Horváth einen Strukturplan in fünf Akten $\mathrm{E}^{9}$, der, was die ersten drei Akte betrifft, $\mathrm{K}^{1} / \mathrm{E}^{35}$ entspricht: "Filmbüro", "Hotel" und „Beim Marquis". Der vierte Akt von $\mathrm{K}^{1} / \mathrm{E}^{35}$, "Hotel“, wandert in $\mathrm{E}^{9}$ an die fünfte Stelle und ersetzt dort das (zweite) "Filmbüro“ von $\mathrm{K}^{1} / \mathrm{E}^{35}$. Der vierte Akt von $\mathrm{E}^{9}$ lautet "Beim Marquis". $\mathrm{E}^{9}$ weist damit bereits große Ähnlichkeiten mit der Aktfolge der ersten Endfassung von Das unbekannte Leben, jener in fünf Akten $\left(\mathrm{TS}^{16}\right)$, auf. Einzig der dritte Akt ist dort anders betitelt, nämlich mit "Auf dem Filmball“ (erstmals in 
$\left.\mathrm{K}^{1} / \mathrm{E}^{39}\right)$. Die zum dritten Akt notierten Figuren Marquis, Mayberg und „Bossart” (sic!) sind seit $\mathrm{K}^{1} / \mathrm{E}^{23}, \mathrm{E}^{29}$ und $\mathrm{E}^{33}$ belegt.

\section{$\mathrm{H}^{6}=$ ÖLA 3/W $61-\mathrm{BS} 51$ [3], Bl. 1, 2}

2 Blatt unliniertes Papier $(305 \times 228 \mathrm{~mm})$, schwarzblaue Tinte, Paginierung 1 und 2

$\mathrm{E}^{10}=$ Strukturplan in 5 Akten mit Werktitel "L'inconnue de la Seine“ mit Notizen, Repliken und Dialogskizzen

Die vorliegenden Blätter entsprechen materiell $\mathrm{H}^{5}$. Von einem genetischen Naheverhältnis zu den darauf befindlichen Entwürfen $\mathrm{E}^{5}-\mathrm{E}^{9}$ ist deshalb auszugehen. Die beiden Blätter von $\mathrm{H}^{6}$ sind überdies durch eine darauf eingetragene Paginierung als zusammengehörig ausgewiesen. In $\mathrm{E}^{10}$ arbeitet Horváth einen groß angelegten Strukturplan in erst sechs, dann fünf Akten aus, den er neuerlich unter den in $\mathrm{K}^{1}$ entwickelten Werktitel "L'inconnue de la Seine“ stellt (vgl. auch $\mathrm{K}^{2} / \mathrm{E}^{1}$, $\mathrm{E}^{2}$ und $\mathrm{E}^{9}$ ). Bei dem Strukturplan handelt es sich, ebenso wie bei $\mathrm{E}^{11}$, um einen zentralen Entwurf im Zuge der Konzeption des Stückes. Mit E ${ }^{10}$ denkt Horváth die Handlung der Komödie in allen Details durch. Die Aktfolge lautet zuletzt "Filmbüro", "Hotel", "Beim Marquis", „Beim Marquis" und „Filmbüro“. Den dritten Akt legt Horváth aus den zwei vorangehenden Akten "Beim Marquis" und "Hotel“ zusammen. Der erste Akt, "Filmbüro“, ist nicht genauer spezifiziert. Zum zweiten Akt, "Hotel“, notiert der Autor, dass der Sekretär und die Unbekannte "wütend auseinander" gehen, setzt diesen Eintrag jedoch unter Fragezeichen, jedenfalls soll es zu "kein[em] Bruch“ kommen. Als Schlusswort zu diesem Akt hält Horváth fest, dass der Sekretär noch beim "Marquis Besançon" eingeladen ist.

Der folgende Akt „Beim Marquis" ist ein Vorläufer des Aktes „Auf dem Filmball“. Offensichtlich soll hier noch eine Art Ball beim Marquis stattfinden. Darauf deutet die Tatsache hin, dass hier nicht nur der Sekretär mit dem Marquis über den Film und die literarische Zeitschrift (vgl. TS²) diskutiert, sondern auch jene, dass sich hier Schauspieler und Drehbuchautoren bzw. Regisseure wie Kary, Mayberg und ein "Nuttenprinz" (vgl. E und TS²) aufhalten, die Horváth in einem Konfigurationsplan neben der Marquise erwähnt. Diese war zuletzt im Strukturplan $\mathrm{K}^{1} / \mathrm{E}^{36}$ sowie in der Grundschicht von $\mathrm{K}^{2} / \mathrm{E}^{1}$ (IV. Akt) erwähnt worden. Horváth plant in $\mathrm{E}^{10}$, diese Figur wieder in das Werkprojekt aufzunehmen und eine Ehekrise zwischen ihr und dem Marquis zu entwickeln. Die Marquise verlässt zunächst das Haus, kehrt dann aber wieder zurück. Zum dritten Akt notiert Horváth noch: "Sie dichten alle, kommen nicht weiter." Damit ist vermutlich das Handlungselement angedeutet, dass die Drehbuchautoren, die der Direktor engagiert hat, mit dem Stoff der Unbekannten nicht zurande kommen. Im vierten Akt soll die Unbekannte beim Marquis sein und ihm zwei „Besuch[e]“ abstatten. Dabei äußert der Marquis bereits den Satz: "Sie sehen ihr ähnlich“, womit eine äußerliche Ähnlichkeit zwischen der Unbekannten und der unbekannten Schauspielerin gemeint ist, was in späteren Fassungen vom Gärtner Bientôt geäußert wird (vgl. TS ${ }^{16} / \mathrm{BS} 71, \mathrm{Bl} .73$ und TS ${ }^{17}$ bzw. K ${ }^{3} / \mathrm{TS}^{21} / \mathrm{BS}$ 52, Bl. 57). Die Unbekannte verspricht beim zweiten Besuch, dass die Geschichte, die ihr der Marquis erzählt hat, ihr "Geheimnis" bleiben soll. Der Marquis bewirkt zuletzt die Versöhnung zwischen dem Sekretär und der Unbekannten.

Der fünfte Akt wird von Horváth ebenfalls sehr ausführlich erarbeitet. Er spielt im „Filmbüro“. Dort soll der Marquis auftauchen, der anbietet, einen Film zu finanzieren, und zwar den Film „Die Unbekannte der Seine“. Die Hauptrolle müsse aber ein 
gewisses "Frl. Klein“ spielen, mit der mit einiger Sicherheit die Unbekannte gemeint ist (vgl. das Fräulein Braun in $E^{6}$ ). Frl. Klein gesteht auch, dass die ganze Geschichte mit dem Geist der Unbekannten ein Schwindel war, und bezeichnet sich und ihre Schauspielkollegen als "Schwindler". Sie beschwört den Direktor, die Unbekannte nicht zu drehen und "die Toten“ "ruhen" zu lassen, und bietet dem Direktor stattdessen "ein wundervolles Lustspiel“, das das Medium geschrieben habe: „Das Lercherl von Hernals." Alternativ dazu notiert Horváth den Vorschlag der Unbekannten, "die Geschichte von uns Jungen" zu inszenieren (vgl. $\mathrm{E}^{11}$ und $\mathrm{TS}^{13}$ sowie die anders gearteten Schlussszenen in TS16/BS 71, Bl. 105f., TS17/BS 52, Bl. 92f. und $\mathrm{K}^{3} / \mathrm{TS}^{21} / \mathrm{BS} 53$ [4], Bl. 13-16). Unmittelbar darauf ist ein Auftritt des Dichters Schnatterpfeil (vgl. TS ${ }^{1}$ ) vorgesehen, der nachfragt, ob der Direktor sein Drehbuch gelesen habe. Der Marquis beteuert aber, dass das ein Gedicht von ihm sei, aus seiner "Jugend", aber er habe es von "Möricke" (gemeint ist: Eduard Mörike) abgeschrieben. Damit nimmt Horváth die Idee eines Plagiats auf, die das Werkprojekt bis zu den drei Endfassungen begleiten wird (vgl. TS ${ }^{16} / \mathrm{BS}$ 71, Bl. 12, 17 und 51, TS ${ }^{17} / \mathrm{BS}$ 52, Bl. 36 und 62 sowie $\mathrm{K}^{3} / \mathrm{TS}^{21} / \mathrm{BS} 53$ [4], Bl. 13). Der in einer Randnotiz erwähnte Klausthal ist einer der drei Autoren, die sich in der ersten Endfassung von Das unbekannte Leben (dort allerdings Claustal geschrieben) um die Erstellung des Drehbuchs für den Film über die Unbekannte streiten (vgl. TS16/BS 71, Bl. 16-19). Auf diese Szene dürfte auch die Notiz "Die drei Autoren [als Anfang des Aktes]“ in $\mathrm{E}^{10}$ verweisen.

\section{$\mathrm{H}^{7}=$ ÖLA 3/W 63 - BS 51 [5], Bl. 1-3}

3 Blatt kariertes Papier $(297 \times 210 \mathrm{~mm})$, schwarzblaue Tinte, Paginierung 1-3 $\mathrm{E}^{11}=$ Strukturplan in 8 Szenen zum V. Akt

Materiell ähneln die vorliegenden Blätter jenem von $\mathrm{H}^{8}$ (vgl. den Kommentar dort). In $\mathrm{E}^{11}$ arbeitet Horváth einen Strukturplan in acht Szenen zum fünften Akt aus, der den Schluss der Komödie darstellen sollte. Auch wenn manche Szenen nur angedeutet wirken, hat man doch davon auszugehen, dass das Stück für Horváth zum Zeitpunkt des Entstehens von $\mathrm{E}^{11}$, ähnlich wie bereits in $\mathrm{E}^{10}$, zu Ende gedacht, wenn auch noch nicht zu Ende geführt war. Ein fünfter Akt "Filmbüro" findet sich zuletzt in $\mathrm{E}^{10}$, der eine Überarbeitung der Aktfolge von $\mathrm{E}^{9}$ darstellt. Der Ausreifungsgrad von $\mathrm{E}^{11}$ und die darin vorkommenden Figuren (Direktor bzw. Semper, Diener, Sekretär bzw. Dr. Huelsen, Marquis, Bossard, Unbekannte, Adolf, Assistent und Pianist) deuten auf eine Positionierung in der Nähe von $E^{5}-E^{9}$, wohl aber erst nach $E^{10}$, da der dort skizzierte Schlussakt genetisch hinter $\mathrm{E}^{11}$ zurückfällt.

Der fünfte Akt gliedert sich gemäß $\mathrm{E}^{11}$ in acht Szenen. Zunächst sind der Direktor und sein Diener zu sehen. Der Direktor fragt nach dem "Doktor" (Bl. 1), womit sein Sekretär Dr. Huelsen gemeint ist. Dieser taucht denn auch in der zweiten Szene auf. Er seh "schlecht aus" (ebd.), wie ihm der Direktor direkt ins Gesicht sagt. Huelsen erklärt seinen Zustand mit den Worten "[I]ch hab eine aufregende Nacht hinter mir" (ebd.), was der Direktor auf die Unbekannte bezieht. Der Sekretär antwortet darauf nur mit einem mehrdeutigen "Das auch“ (ebd.). In Szene drei taucht der Marquis auf. Dieser behauptet, einen Film finanzieren zu wollen, „vorausgesetzt, dass eine junge Schauspielerin die Hauptrolle spielt" (ebd.). Der Direktor ist gerne bereit dazu, möchte aber wissen, wer die Schauspielerin sei. Der Marquis weiß es nicht, meint aber, sie sei "ungemein begabt" (ebd.). Als der Direktor nach dem Titel des Filmes fragt, repliziert der Marquis: "Die Unbekannte der Seine“ (ebd.). Das bringt den Di- 
rektor in Rage: „Ausgeschlossen! Das Geld gibt es nicht! Den Film mach ich - mit einer Besetzung, die seinesgleichen sucht!“ (ebd.). In Szene 3a) soll der Direktor jedoch in das Angebot des Marquis einwilligen, auch wenn sich sein Sekretär querlegt (vgl. Bl. 2). Der Marquis will den Sekretär aufklären, um ihn ebenfalls für sich zu gewinnen (vgl. ebd.). In Szene vier kündigt Semper Huelsen wegen „unqualifizierte[n] Benehmen[s]" und "geschäftsschädigende[n]" (ebd.) Verhaltens. In Szene fünf taucht Bossard auf und muss den sichtlich mitgenommenen Direktor behandeln, der von sich sagt: "Ich hab grad eine solche Aufregung hinter mir - Ich hab mich in einem Menschen getäuscht!“ (ebd.). Szene sechs zeigt den Marquis und den Sekretär, der um Verzeihung bittet und den Direktor über Bossards wahren Beruf, nämlich Statist, aufklären will. In Szene sieben sollen zunächst Bossard und seine Leute (Unbekannte, Adolf, Assistent und Pianist) im "Vorzimmer" (Bl. 3) sitzen. Dann kommen sie zu Semper ins Büro. Der Marquis beteuert, dass man "das nicht verfilmen“ kann, womit die Geschichte der Unbekannten gemeint ist: "[S]ie ist erst im Tod so schön geworden! - Und das ist kein Film!“ (ebd.; vgl. E², TS ${ }^{16} / \mathrm{BS} 71, \mathrm{Bl} .105, \mathrm{TS}^{17} / \mathrm{BS} 52, \mathrm{Bl}$. 93 und $\mathrm{K}^{3} / \mathrm{TS}^{21}$ /BS 53 [4], Bl. 15). Auf die Frage des Direktors, was sie dann verfilmen sollen, erwidert die Unbekannte: „Verfilmen Sie die Geschichte von uns fünf Menschen - unsere Kämpfe, unsere Hoffnungen - wo Sie immer anfangen, das gibt einen Film!“ (ebd.; vgl. auch TS ${ }^{13}$ ). Als der Direktor nach einem möglichen Drehbuchautor fragt, meldet sich sein Sekretär. Der Direktor scheint damit nicht völlig einverstanden, weshalb die Unbekannte hinzufügt: „Ich werde assistieren!“, was er mit den Worten quittiert: „Dann ist es schon besser! Ihr Beide, diese Kombination, ist als Autoren vielleicht nicht schlecht -!“ Die Unbekannte behält das letzte Wort, indem sie darauf repliziert: „Nicht nur als Autoren!“

Mit diesem Ende ist einerseits der Schluss von Das unbekannte Leben vorweggenommen, in dem ebenfalls das Projekt eines Filmes über die Unbekannte fallen gelassen wird und stattdessen ein Film über "eine junge Studentin, eine Chemikerin" gedreht werden soll (vgl. TS ${ }^{16} / \mathrm{BS}$ 71, Bl. 106 und TS ${ }^{17} / \mathrm{BS}$ 52, Bl. 93 sowie die Kommentare dort). Andererseits ist mit dem Ende von $\mathrm{E}^{11}$ bereits jenes von Mit dem Kopf durch die Wand antizipiert, in dem das Exposé der Unbekannten, das auf die Erzählung des Marquis zurückgeht, von Huelsen bearbeitet werden soll (vgl. K³/TS²1/BS 53 [4], Bl. 16).

\section{$\mathrm{H}^{8}=$ ÖLA 3/W 63 - BS 51 [5], Bl. 4}

1 Blatt kariertes Papier (297 $\times 210 \mathrm{~mm})$, schwarzblaue Tinte, roter Buntstift und Bleistift $\mathrm{E}^{12}=$ Konfigurationsplan in 4 Szenen mit Notizen, Dialogskizzen und einer Replik

Materiell ähnelt das vorliegende Blatt jenen von $\mathrm{H}^{7}$. In beiden Fällen handelt es sich um kariertes Papier der Größe $297 \times 210 \mathrm{~mm}$, weshalb von einem genetischen Naheverhältnis von $\mathrm{E}^{11}$ und $\mathrm{E}^{12}$ ausgegangen werden kann. Die auf BS 51 [5], Bl. 3 (E $\left.\mathrm{E}^{11}\right)$ erwähnte "Panerga-Film" mutiert auf BS 51 [5], Bl. 4 (E'12) zur "Panna-Film” (vgl. auch die \{Panropa\}-Film in TS², Grundschicht) und schließlich in den Endfassungen von Das unbekannte Leben und Mit dem Kopf durch die Wand zur vieldeutigen "PandoraFilm“ (vgl. TS ${ }^{16}$, TS ${ }^{17}$ und $\mathrm{K}^{3} / \mathrm{TS}^{21}$ ). Mit ihr spielt Horváth nicht zuletzt auf Frank Wedekinds Drama Die Büchse der Pandora (1902; vgl. auch den Kommentar zu K³/TS'1) an.

Vermutlich handelt es sich bei $\mathrm{E}^{12}$ um einen Konfigurationsplan zu einem der Akte, die $\mathrm{E}^{11}$ vorangehen, wahrscheinlich zum (dritten) Akt „Auf dem Filmball“ bzw. „Beim 
Marquis" (vgl. $\mathrm{K}^{1} / \mathrm{E}^{39}, \mathrm{E}^{48}$ und $\mathrm{K}^{2} / \mathrm{E}^{10}$ ), der jedoch in $\mathrm{E}^{12}$ nicht explizit genannt wird. Die skizzierten Szenen spielen aber eindeutig auf einem solchen. Auch werden mehrfach "Logen" genannt, in denen sich die Figuren befinden. Die Szenennummerierung beginnt mit zehn und reicht bis dreizehn. Die in $\mathrm{E}^{12}$ erwähnten Figuren, etwa die Schauspielerinnen Carry (bzw. Kary) und Barbou, der Autor Hell und der Boxer, wurden in den Entwürfen und Textstufen von $\mathrm{K}^{2}$ bisher nur teilweise genannt (vgl. TS ${ }^{2}$ und $\mathrm{E}^{10}$ ), weshalb $\mathrm{E}^{12}$ vermutlich später als diese entstanden ist. Da diese Figuren in $\mathrm{K}^{3}$ wieder aus dem Werkprojekt ausscheiden, ist eine Positionierung innerhalb von $\mathrm{K}^{2}$ wahrscheinlich.

In $\mathrm{E}^{12}$ werden vier Szenen geschildert. Zu Szene zehn ist nur ein Konfigurationsplan unter dem Titel "Logen“ angedeutet, der die Unbekannte und einen Kellner, sowie die Unbekannte und Hell umfasst. Szene elf trägt den Titel "Spiegel“ und soll den Direktor und die Carry zeigen, die Horváth abwechselnd als Carry und als $\operatorname{Kar}(\mathrm{r})$ y schreibt (vgl. $\left.\mathrm{E}^{10}\right)$. Die Carry stellt dem Direktor den Boxer vor. Dieser reagiert aber äußerst ablehnend auf ihn und tritt dann ab, worauf die Carry dem Boxer erklärt, dass Semper ein "Plebejer“ sei. Die nächste Sequenz von Auftritt elf zeigt die Unbekannte, die einem Fotografen aufs Bild gekommen ist. Der ist darüber nicht sehr erfreut, weil er sie nicht kennt. Die Unbekannte soll sich daraufhin mit dem Photographen „über Star“ unterhalten. Zuletzt ist für diesen Auftritt ein Zusammentreffen der Unbekannten mit dem Sekretär - gemeint ist: Huelsen - vorgesehen. Auftritt zwölf spielt wieder in einer "Loge“. Hier kommen der Direktor, Hell, Mayberg und die Barbou zusammen. Der Direktor versichert in einer Replik, dass er "nach diesem Erlebnis" (vgl. den Kommentar zu TS $8 / \mathrm{A}^{2}$ ) allein sein müsse und an die Bar gehe. Szene dreizehn spielt folgerichtig an der "Bar", zeigt aber zunächst nur die Kary und den Boxer. Später soll der Marquis dazukommen. Der Boxer wird von seinem Trainer "nachhause gebracht". Damit bricht der Entwurf ab. Wahrscheinlich ist Material verloren gegangen, auf dem der Beginn und das Ende des Aktes skizziert waren. Die Bedeutung, die in $\mathrm{E}^{12}$ den Figuren Carry und Boxer zukommt, lässt vermuten, dass der Entwurf bereits in der unmittelbaren Konzeptionsphase der Komödie Das unbekannte Leben entstanden ist, in deren erster Endfassung (TS ${ }^{16}$ ) beide Figuren eine wichtige Rolle im Akt „Filmball“, aber auch im Schlussakt spielen.

\section{$\mathrm{H}^{9}=$ ÖLA 3/W 60 - BS 51 [2], Bl. 4V}

1 Blatt kariertes Papier $(330 \times 209 \mathrm{~mm})$, schwarzblaue Tinte und roter Buntstift, Paginierung 2 $\mathrm{E}^{13}=$ Konfigurationsplan und Dialogskizzen zum 13. Auftritt

$\mathrm{E}^{13}$ ist auf der Rückseite von BS 51 [2], Bl. 4 notiert, das zu TS² zählt (vgl. $\mathrm{H}^{4}$ ). Das Blatt trägt eine mit rotem Buntstift eingetragene Pagina 2, zu der es aber keine entsprechende Pagina 1 gibt. Möglicherweise stellt $\mathrm{E}^{13}$ eine Fortsetzung von $\mathrm{E}^{12}$ dar, denn der Entwurf enthält einen Konfigurationsplan und Dialogskizzen zum 13. Auftritt des zweiten oder dritten Aktes „Auf dem Filmball“ (vgl. $\mathrm{K}^{1} / \mathrm{E}^{39}$, $\mathrm{E}^{48}$ und $\mathrm{K}^{2} / \mathrm{E}^{12}$ ). Entgegen $\mathrm{E}^{10}$, wo der Ball noch beim Marquis spielt, ist der Ball in diesem Fall eindeutig ein Filmball. Entgegen $\mathrm{E}^{12}$ wird der Direktor hier durchgehend Semper genannt, was dafür spricht dass $\mathrm{E}^{13}$ nach $\mathrm{E}^{12}$ entstanden ist. An weiteren Figuren finden sich die Unbekannte, Huelsen, der Marquis, Carry, Barbou und Traverson, der hier erstmals so genannt wird, was auf eine relativ späte Entstehung innerhalb von $\mathrm{K}^{2}$ hindeutet. Auf dem Blatt ist der Dialog zwischen Semper und Huelsen über Bossards 
vermeintliche Arbeit in Rio und die Tatsache, dass er im Haus der Eltern der Unbekannten verkehrt sei, weitestgehend ausgearbeitet. Auch nimmt der Marquis die Unbekannte hier schon in Schutz, wie er dies auch in den Endfassungen von Das unbekannte Leben und Mit dem Kopf durch die Wand tun wird (vgl. TS16/BS 71, Bl. $62 \mathrm{f}$. und $\mathrm{TS}^{17}$ bzw. $\mathrm{K}^{3} / \mathrm{TS}^{21} / \mathrm{BS} 52$, Bl. 46f.). Auch die Fotografie-Szene trägt in $\mathrm{E}^{13}$ bereits deutliche Züge ihrer Pendants in den Endfassungen (vgl. TS ${ }^{16} / \mathrm{BS} 71, \mathrm{Bl}$. $65 \mathrm{f}$. und TS ${ }^{17}$ bzw. $\mathrm{K}^{3} / \mathrm{TS}^{21} / \mathrm{BS}$ 52, Bl. 49f.). Insgesamt stellt der Entwurf einen wesentlichen Fortschritt in der Konzeption des Bildes "Filmball“ dar.

\section{$\mathrm{H}^{10}=$ ÖLA 3/W $65-\mathrm{BS} 53$ [1], Bl. 1}

1 Blatt unliniertes Papier $(223 \times 141 \mathrm{~mm})$, schwarzblaue Tinte

$\mathrm{E}^{14}=$ Konfigurationsplan zum V. Akt mit Notizen, Dialogskizzen und Repliken

Laut $\mathrm{E}^{14}$ soll der fünfte Akt "[i]m Hotel Terminus“ spielen, wie der Akttitel verrät und wie dies noch in $\mathrm{E}^{9}$ vorgesehen war und auch in der ersten Endfassung von Das unbekannte Leben (TS ${ }^{16}$ ) der Fall ist (vgl. auch den Schlussakt von TS ${ }^{17}$, der aber der vierte Akt ist, und anders in $\mathrm{K}^{3} / \mathrm{TS}^{21}$, in der der Schlussakt im Büro der Pandora-Film spielt). Horváth skizziert mit $\mathrm{E}^{14}$ einen Verlauf für den fünften Akt, den er in sechs Szenen unterteilt, womit der Akt aber noch nicht zu Ende ausformuliert scheint. Die handschriftliche Ausarbeitung von $\mathrm{E}^{14}$ und die fragmentarischen Notizen zu den einzelnen Szenen lassen die Annahme zu, dass es sich dabei um einen relativ spät in $\mathrm{K}^{2}$ zu situierenden Entwurf handeln dürfte. Laut $\mathrm{E}^{14}$ sollen zunächst Bossard, Manuel, der Assistent und der Pianist auftreten. Dies ist bereits die Konfiguration des 1. Auftritts des fünften bzw. vierten Aktes der Endfassungen von Das unbekannte Leben (TS ${ }^{16}$ und TS ${ }^{17}$ ). In den weiteren Szenen erscheinen Huelsen, dann die Unbekannte, weiters Semper und schließlich, in der sechsten Szene, der Marquis. Zu Beginn des Aktes fragt Bossard nach der Unbekannten, worauf Huelsen auftritt, der sie sucht. In der dritten Szene bekräftigt die Unbekannte, dass sie "am Ball“ und nicht „beim Marquis" war. Für die vierte Szene ist ein "Diener" vorgesehen, der "Geld" bringt (vgl. $\mathrm{K}^{1} / \mathrm{E}^{49}$ ), sowie ein wohl daraus resultierender "Krach Huelsen - Unb.“ (vgl. $\mathrm{E}^{10}$ ). In diesem Streit werfen sich die beiden vor, ihr "Ehrenwort" gebrochen zu haben. Die Unbekannte versichert aber, nur "aus filmischen Gründen“ beim Marquis gewesen zu sein. In der fünften Szene zeigt sich Semper begeistert von den "Probeaufnahmen", die "grandios" seien. In der sechsten Szene schließlich taucht der Marquis auf, der behauptet, "gerne einen Film finanzieren" zu wollen, und zwar "[m]it der Dame [gemeint ist die Unbekannte; Anm.] in der Hauptrolle. Aber nicht die Unbekannte der Seine“ (vgl. $\left.\mathrm{E}^{10}\right)$. Damit endet $\mathrm{E}^{14}$. Wahrscheinlich hat Horváth auch zu anderen Akten vergleichbare Konfigurationspläne entworfen, diese sind aber nicht erhalten, sodass die Genese der Komödie Das unbekannte Leben nicht wirklich Schritt für Schritt nachvollzogen werden kann.

\section{$\mathrm{H}^{11}=$ ÖLA 3/W $65-$ BS 53 [1], Bl. 9}

1 Blatt unliniertes Papier $(344 \times 210 \mathrm{~mm})$, schwarzblaue Tinte $\mathrm{TS}^{3}=$ fragm. Fassung des 11 . Auftritts (Korrekturschicht)

Bei TS 3 handelt es sich um eine in weiterer Folge wieder ausgeschiedene Szene zwischen Huelsen und zwei "Filmnutten", die von ihm zum Film gebracht werden wollen. Die Szene spielt "an der Bar" auf dem Filmball des zweiten Aktes (vgl. E ${ }^{12}$, TS4 
und TS7). In TS ${ }^{3}$ ist von einem "Boxerfilm“ die Rede (vgl. den Schluss von TS ${ }^{16}$ und $\mathrm{TS}^{17}$ ), in dem die Erste der beiden "Filmnutten“ "das Mädchen mit den Blumen“ spielen möchte. Huelsen behauptet, diese Rolle nicht zu kennen. Mit der fragmentarischen Replik der zweiten "Filmnutte" "Aber das Mädel“ bricht die Ausarbeitung ab. Horváth überarbeitet diesen Auftritt in den folgenden Fassungen von TS ${ }^{4}$ und TS7.

\section{$\mathrm{H}^{12}=$ ÖLA 3/W $65-\mathrm{BS} 53$ [1], Bl. 5}

1 Blatt unliniertes Papier $(286 \times 221 \mathrm{~mm})$, dünn, schwarzblaue Tinte $\mathrm{TS}^{4}=$ fragm. Fassung eines Auftritts (Grundschicht)

In TS4 überarbeitet Horváth den 11. Auftritt von $\mathrm{TS}^{3}$ und ersetzt die beiden „Filmnutten“ (TS3) durch zwei Mädchen. Außerdem sind die beiden "Mixer“ Adolf und Robert in der Szene nicht mehr anwesend. Schauplatz ist wieder die Bar auf dem Filmball. Das erste Mädchen hält Huelsen einen Ballon an die Zigarette, damit dieser "explodiert", um eine Kontaktaufnahme mit dem Sekretär anzubahnen. Als sie ihm vorwirft, ihren Ballon zerplatzt zu haben, meint dieser, er kaufe ihr sofort einen neuen. Sie spricht ihn dann mit seinem Namen an, worauf er verwundert ist, dass sie ihn kenne. Dazu meint sie nur: „Wer kennt Sie nicht? Dr. Peter Huelsen, die rechte Hand der Pandora!“ Zum ersten Mal fällt damit der definitive Name der Filmgesellschaft des Direktors Semper (vgl. die Kommentare zu E ${ }^{12}$ und $\mathrm{K}^{3} / \mathrm{TS}^{21}$ ). Sowohl die Ballonszene, als auch ein Teil dieser Replik werden in TS7 wiederaufgenommen. In der Folge behauptet das erste Mädchen: "Wir haben uns doch mal kennen gelernt, im Pigalle!", woran sich Huelsen aber nicht erinnert. Sie erklärt daraufhin, dass sie "damals" "Schokoladenverkäuferin" "an der Bar" gewesen sei, dann jedoch die "Stellung" aufgegeben habe und zum Film gegangen sei, das heißt, sie wolle zum Film und hätte "so gern eine Rolle“. Huelsen erwehrt sich dieser Zudringlichkeiten nur durch ein rasch hingeworfenes: „[W]enn Sie wüssten, wer alles von mir protegiert werden möchte“", das sich in ähnlicher Form auch in TS7 findet. Statt die beiden Mädchen zum Film zu bringen, will er ihnen zwei Ballons kaufen, "[e]inen roten und einen grünen“. Als er weggeht, ruft ihm das eine "Mädel“ verzweifelt nach. Damit bricht die Ausarbeitung ab.

\section{$\mathrm{T}^{1}=$ ÖLA 3/W $66-\mathrm{BS} 53$ [2], Bl. 5-7}

3 Blatt unliniertes Papier $(290 \times 225 \mathrm{~mm})$, teilweise Durchschlag, hs. Eintragungen mit schwarzblauer Tinte, hs. Eintragungen mit Bleistift von fremder Hand $\mathrm{TS}^{5} / \mathrm{A}^{1}=$ fragm. Fassung eines Auftritts, konstituiert durch BS 53 [2], Bl. 5 (Grundschicht) $\mathrm{TS}^{5} / \mathrm{A}^{2}$ = fragm. Fassung eines Auftritts, konstituiert durch BS 53 [2], Bl. 6 (nicht gedruckt) $\mathrm{TS}^{5} / \mathrm{A}^{3}$ = fragm. Fassung eines Auftritts, konstituiert durch BS 53 [2], Bl. 7 (Korrekturschicht)

Bei den drei Ansätzen von TS ${ }^{5}$ handelt es sich um frühe Fassungen eines (vermutlich des 13.) Auftritts des wahrscheinlich vierten Aktes, in der Nevieux und seine Tante, die vermeintliche Unbekannte, zum Marquis kommen und ihm alles beichten, nämlich dass die Tante zwar in die Seine gegangen sei, nachdem sie das ihr anvertraute Geld verloren habe, dann aber wieder herausgeschwommen sei. Der Marquis äußert schon in TS ${ }^{5} \mathrm{~A}^{1}$ die bis in die Endfassungen in ähnlicher Form erhalten bleibende Pointe: "Sie sind eben eine gute Schwimmerin." (vgl. TS ${ }^{16} / \mathrm{BS} 71, \mathrm{Bl} .87, \mathrm{TS}^{17}$ und $\mathrm{K}^{3} / \mathrm{TS}^{21} / \mathrm{BS} 52, \mathrm{Bl} .73$ ). Die Szene endet in $\mathrm{TS}^{5} / \mathrm{A}^{2}$ und $\mathrm{A}^{3}$ mit gegenseitigen Entschuldigungen, die in späteren Fassungen nicht mehr vorkommen. Auf Bl. 5 sind am Ende 
des Blattes noch ein paar Repliken in Kurzschrift ergänzt, die wohl von einem fremden Schreiber stammen; diese entsprechen möglicherweise den auf Bl. 6 und Bl. 7 zuletzt getippten Passagen, die Horváth in $\mathrm{A}^{3}$ noch einmal handschriftlich überarbeitet. Die Grundschicht von $\mathrm{A}^{3}$ entspricht $\mathrm{A}^{2}$, dessen Durchschlag $\mathrm{A}^{3}$ ist, weshalb $\mathrm{A}^{2}$ nicht gedruckt wird. $\mathrm{A}^{1}-\mathrm{A}^{3}$ geben der Tante noch wesentlich mehr Raum, als ihr in den Endfassungen von Das unbekannte Leben (TS ${ }^{16}$ bzw. TS $^{17}$ ) und Mit dem Kopf durch die Wand $\left(\mathrm{K}^{3} / \mathrm{TS}^{21}\right)$ zukommen wird.

\section{$\mathrm{H}^{13}=$ ÖLA 3/W $65-\mathrm{BS} 53$ [1], Bl. 10, 4V}

Insgesamt 2 Blatt, davon 1 Blatt unliniertes Papier $(340 \times 210 \mathrm{~mm})$ und 1 Blatt unliniertes Papier $(286 \times 221 \mathrm{~mm})$, dünn, schwarzblaue Tinte

$\mathrm{TS}^{6} / \mathrm{A}^{1}=$ fragm. Fassung des 12. und 13. Auftritts, konstituiert durch BS 53 [1], Bl. 10 (Grundschicht)

$\mathrm{TS}^{6} / \mathrm{A}^{2}=$ fragm. Fassung eines Auftritts, konstituiert durch BS 53 [1], Bl. 4v (Korrekturschicht)

In den beiden Ansätzen von TS 6 arbeitet Horváth den 12. bzw. 13. Auftritt des vierten Aktes "Beim Marquis“ handschriftlich aus. Wieder geht es um das Verzeihen (vgl. $\mathrm{TS}^{5} / \mathrm{A}^{3}$ ), das hier jedoch ganz an den Anfang gerückt wird, wo es auch in den Fassungen dieses Auftritts in den Endfassungen von Das unbekannte Leben und Mit dem Kopf durch die Wand zu stehen kommt (vgl. TS $16 / \mathrm{BS}$ 71, Bl. $87 \mathrm{f} ., \mathrm{TS}^{17}$ und $\mathrm{K}^{3} / \mathrm{TS}^{21} / \mathrm{BS}$ 52, Bl. 72f.). Während dort jedoch die Tante "Wird er mir verzeihen?" (vgl. TS ${ }^{16} / \mathrm{BS} 71, \mathrm{Bl} .87, \mathrm{TS}^{17}$ und $\mathrm{K}^{3} / \mathrm{TS}^{21} / \mathrm{BS} 52, \mathrm{Bl}$. 73) fragt, äußert sie hier noch "Wird er uns verzeihen?" (TS6 $/ \mathrm{A}^{1}$ und $\mathrm{A}^{2}$ ) und bezieht damit Nevieux in die Schuldfrage ein. $\mathrm{A}^{1}$ endet mit der aus TS ${ }^{5} / \mathrm{A}^{1}-\mathrm{A}^{3}$ bekannten Pointe des Marquis "Sie sind eine gute Schwimmerin, wie?", die hier jedoch zu einer Frage umformuliert ist.

$\mathrm{A}^{2}$ setzt wie $\mathrm{A}^{1}$ mit Nevieux' Replik "Tante! Komm herein!“ ein. Ein nachträglich eingetragener Pfeil deutet darauf hin, dass Horváth das in $\mathrm{A}^{1}$ noch folgende "Wird er uns verzeihen?" in der Überarbeitung tilgen wollte, was aber in der Folge zurückgenommen wurde, denn diese Passage findet sich in ähnlicher Form noch in den Endfassungen von Das unbekannte Leben und Mit dem Kopf durch die Wand (vgl. oben). Stattdessen fährt $\mathrm{A}^{2}$ mit der Entschuldigung der Tante: "Seien Sie uns nicht böse, dass wir Sie so mitten in der Nacht überfallen -" fort. Daran schließt sich ihre Bemerkung über Schlaflosigkeit und schlechte Träume, worauf sie sich an die Vergangenheit erinnert, in der sie immer gut geschlafen habe. Das Gespräch kommt auf Bientôt, den Gärtner, von dem der Marquis behauptet, dass es ihm gut gehe. Schließlich äußert der Marquis wieder das aus $\mathrm{A}^{1}$ bekannte "Sie sind eine gute Schwimmerin, wie?", das die Tante in $\mathrm{A}^{2}$ mit folgenden Worten quittiert: "Das war einmal! Passé, passé! Ich hab zwei Pokale gewonnen. - - Sie sollten auch Sport treiben." Der Marquis erwidert auf diese Replik mit einem nonchalant hingeworfenen: "Man schwimmt sich so durch." Die Tante erzählt weiters, dass sie oft allein zuhause sitze und sich dann selbst prophezeie. Ihr "sehnlichster Wunsch" sei es immer schon gewesen, dem Marquis zu prophezeien, was sie schließlich auch tut: „Ich sehe in der Nähe ein Mädchen, aber die liegt auf einem jungen Mann - Caro Ass! - - und dann seh ich für Sie: ein neues Leben -“. Der Marquis quittiert dies mit einem Lachen. Den ausführlichen Dialog zwischen der Tante und dem Marquis lässt Horváth in weiterer Folge wieder fallen und kürzt die Szene in den beiden Endfassungen auf das Nötigste zusammen. Die Pointe "Sie sind eine gute Schwimmerin, wie?" bleibt indes in der Form "Sie waren eine gute Schwimmerin, wie?" bis in die Endfassungen von Das un- 
bekannte Leben und Mit dem Kopf durch die Wand erhalten (vgl. TS ${ }^{16} / \mathrm{BS}$ 71, Bl. 87, $\mathrm{TS}^{17}$ und $\mathrm{K}^{3} / \mathrm{TS}^{21} / \mathrm{BS} 52, \mathrm{Bl} .73$ ).

\section{$\mathrm{T}^{2}=$ ÖLA 3/W 66 - BS 53 [2], Bl. 1}

1 Blatt unliniertes Papier (290 × 225 mm), Durchschlag, Paginierung "seite 42"

$\mathrm{TS}^{7}=$ Fassung des XI. Auftritts des II. Aktes (Grundschicht)

In TS7 fixiert Horváth den mit TS ${ }^{3}$ und TS 4 handschriftlich erarbeiteten XI. Auftritt des zweiten Aktes „Auf dem Filmball“ maschinenschriftlich (vgl. $\mathrm{K}^{1} / \mathrm{E}^{39}$ und $\mathrm{E}^{48}$ ). Da das Blatt die Paginierung "seite 42" trägt und es sich um einen Durchschlag handelt, ist davon auszugehen, dass es Teil einer längeren ausgearbeiteten Fassung der ersten beiden Akte oder sogar der gesamten Komödie war. Vermutlich klafft zwischen TS 6 und TS7 eine große überlieferungsgeschichtliche Lücke, sodass die Genese von Das unbekannte Leben nur bruchstückhaft nachvollzogen werden kann. In TS ${ }^{7}$ treten neuerlich Huelsen und zwei Mädchen auf, die sich "an der Bar" befinden (vgl. TS ${ }^{3}$ und TS4). Die eine wirft Huelsen vor, er habe ihren Luftballon „zerdrückt", worauf jener ihr einen neuen kaufen will (vgl. TS4). Wie sich herausstellt, sind die beiden Mädchen aber nur an einer Protektion durch Huelsen interessiert, den sie als "die rechte Hand der Pandora“ (vgl. TS4) bezeichnen und als den "Mann, der über Rollen gebietet“. Der Hinweis auf die Filmgesellschaft, die hier bereits den Namen "Pandora“ (vgl. auch TS4) trägt, weist die Fassung als späte aus, denn noch in $\mathrm{E}^{12}$ war von der "Panna-Film“ die Rede gewesen (vgl. auch die Kommentare zu TS${ }^{1}$, TS ${ }^{2}, \mathrm{E}^{12}$ und $\mathrm{K}^{3} / \mathrm{TS}^{21}$ ).

\section{$\mathrm{T}^{3}=$ ÖLA 3/W 66 - BS 53 [2], Bl. 2-4}

3 Blatt unliniertes Papier $(297 \times 209 \mathrm{~mm})$, hs. Eintragungen mit schwarzblauer Tinte und rotem Buntstift, Paginierung 45-47

$\mathrm{TS}^{8} / \mathrm{A}^{1}=$ fragm. Fassung des 5. bis 7. Auftritts, konstituiert durch BS 53 [2], Bl. 2 (nicht gedruckt) $\mathrm{TS}^{8} / \mathrm{A}^{2}=$ fragm. Fassung des 5 . bis 11. Auftritts, konstituiert durch BS 53 [2], Bl. 2-4 (Korrekturschicht: schwarzblaue Tinte)

Bei den vorliegenden Blättern dürfte es sich um Teile einer Gesamtfassung von Das unbekannte Leben handeln. Dies lässt sich aus der bereits sehr ausgereift wirkenden typografischen und inhaltlichen Gestaltung der Auftritte sowie aus der durchgängigen Paginierung schließen, die mit 45 einsetzt und mit 47 endet.

Da auf Bl. 2 unten eine Replik des Marquis steht, die auch zuoberst auf Bl. 3 zu finden ist, auf $\mathrm{Bl} .2$ unten aber handschriftlich gestrichen wurde, ist davon auszugehen, dass Bl. 2 einen eigenen Ansatz $\mathrm{A}^{1}$ konstituiert. Auf Bl. 2 folgen in $\mathrm{A}^{2}$ die Bl. 3 und 4. $\mathrm{TS}^{8} / \mathrm{A}^{2}$ umfasst, wie $\mathrm{E}^{12}, \mathrm{TS}^{3}, \mathrm{TS}^{4}$ und $\mathrm{TS}^{7}$, einige Szenen des zweiten oder dritten Aktes "Auf dem Filmball“ (vgl. $\mathrm{K}^{1} / \mathrm{E}^{39}$ und $\mathrm{E}^{48}$ ). Die Fassung setzt mitten im 5. Auftritt ein, der die Unbekannte und den Marquis zeigt. Die Unbekannte ist gerade dabei, sich vom Marquis zu lösen, um vermutlich Huelsen zu suchen. Beim Weggehen stößt sie mit der Schauspielerin Carry zusammen (vgl. TS² und $\mathrm{E}^{12}$ ), die mit dem Boxer (vgl. $\mathrm{E}^{12}$ und $\mathrm{E}^{13}$ ) aus dem Saal kommt, der hier wie schon in $\mathrm{E}^{13}$ Traverson heißt. Sowohl die Schauspielerin Carry als auch der Boxer Traverson sind ein eindeutiger Hinweis auf $\mathrm{K}^{2}$, Das unbekannte Leben, denn in $\mathrm{K}^{3}$, Mit dem Kopf durch die Wand, kommen diese beiden Figuren nicht mehr vor. Den Zusammenstoß mit der Unbekannten quittiert die Carry mit den Worten: "So eine Ziege --“, eine Wortwahl, die Horváth der wirklichen Begegnung zwischen der Schauspielerin Maria Elsner, kurz- 
zeitig Horváths Ehefrau, und der Schauspielerin und Autorin Hertha Pauli angelehnt haben dürfte, mit der Horváth eine (platonische) Beziehung bzw. Freundschaft bis zu seinem Lebensende verband. Pauli war auch für Horváths Beschäftigung mit dem Stoff der Unbekannten ausschlaggebend (vgl. WA 6, S. 3f., den Kommentar zu $\mathrm{K}^{1} / \mathrm{E}^{12}-\mathrm{E}^{14}$ sowie das Vorwort zu diesem Band, S. $333 \mathrm{f}$.).

Der 7. Auftritt zeigt die Carry, den Marquis und Traverson, die über die Schmerzempfindlichkeit von Frauen und Männern sprechen. Der Kellner Robert bemerkt zum Marquis, dass die Carry "die Hauptrolle in der ,Geheiligten Liebe“" (vgl. TS"16/BS 71, Bl. 6, 45 und 63 sowie TS ${ }^{17} / \mathrm{BS} 52, \mathrm{Bl} .29$ und 48; in $\mathrm{K}^{3} / \mathrm{TS}^{21}$ wurden die entsprechenden Passagen gestrichen) sei und Traverson ein "Weltmeister". Im 8. Auftritt debattieren die Carry und Traverson, die nun allein sind, über eine mögliche Verpflichtung Traversons durch Semper zum Film. Die Carry will ihn dazu bewegen, sich für "Sport oder Kunst“ zu entscheiden, doch Traverson kontert: „Aber Film ist doch keine Kunst! Film ist ein Geschäft! Wenn mir Semper zweihundert Mill bar auf den Tisch legt -- warum nicht? Vorausgesetzt, dass ich die Titelrolle spiele!" (Bl. 3). Damit verweist Traverson, für den wohl der Profiboxer Max Schmeling Pate gestanden haben dürfte (vgl. KW 7, S. 482), auf die ökonomischen Aspekte der Filmbranche, die ein (negatives) Leitmotiv von Das unbekannte Leben und Mit dem Kopf durch die Wand darstellen. Außerdem nimmt er die Schlusspointe der Komödie Das unbekannte Leben vorweg, in der Direktor Semper die Idee äußert, einen "Boxerfilm für Traverson“ mit dem Titel „Der Unbekannte der Seine“ schreiben zu lassen (vgl. TS"16/BS 71, Bl. 106 und $\mathrm{TS}^{17} / \mathrm{BS} 52$, Bl. 93).

Der 9. Auftritt zeigt die Vorigen mit einem Bildreporter (vgl. $\mathrm{E}^{12}$ ), der eine Fotoaufnahme von den beiden haben möchte. Traverson, ganz Kapitalist, überredet die Carry dazu, denn "Pflicht ist Pflicht" (vgl. E ${ }^{16}$ ) und "Geschäft ist Geschäft" (Bl. 3). Im 10. Auftritt diskutieren die beiden Mixer Robert und Adolf (vgl. TS ${ }^{3}$ ) über Traverson, wobei Robert auf dessen Geldgier anspielt, Adolf aber darauf besteht, dass er "der geborene Sportsmann" (Bl. 4) sei. Der 11. und letzte Auftritt von TS8/A2 ist nicht vollständig erhalten. Er zeigt die beiden Mixer mit Semper, der behauptet, "das grösste Erlebnis [s] eines Lebens" hinter sich zu haben (vgl. E $\mathrm{E}^{11} / \mathrm{Bl}$. 2) und deshalb einen "doppelten Cognak“ (Bl. 4) zu brauchen. Semper beschreibt sein "Erlebnis" folgendermaßen: "Wenn Gott will, hab ich heut Nacht den leuchtendsten Stern entdeckt!“ (ebd.). Auf Adolfs Nachfrage, ob es sich um eine Frau handelt, repliziert Semper: „Einen Engel! Ein absolut einmaliges Talent -- Kasse, Kasse! Morgen lass ich mir in aller früh die Probeaufnahmen vorführen, unberufen!“ (ebd.). Die neuerliche Verbindung von Film und Geschäft verweist auf eine zentrale Thematik von Das unbekannte Leben und Mit dem Kopf durch die Wand (vgl. nicht zuletzt Horváths eigene Einschätzung in $\mathrm{K}^{3} / \mathrm{TS}^{22}$ ). Die Apostrophierung der Frau als Engel lässt Bezüge herstellen zu Horváths Stücken Geschichten aus dem Wiener Wald (1931; vgl. K5 $/$ TS $^{12} / \mathrm{SB}$ Arcadia 1931, S. 51f.) und Eine Unbekannte aus der Seine (1933; vgl. $\mathrm{K}^{1} / \mathrm{TS}^{2} /$ ÖLA 27/W 15, Bl. 72f.). 


\section{$\mathrm{T}^{4}=$ ÖLA 3/W $66-$ BS 53 [2], Bl. 9, 10}

2 Blatt unliniertes Papier $(297 \times 209 \mathrm{~mm})$, hs. Eintragungen mit schwarzblauer Tinte, Paginierung 84,85 , hs. Paginierung 86, 87

$\mathrm{TS}^{9} / \mathrm{A}^{1}=$ fragm. Fassung des 16 . bis 18. Auftritts, konstituiert durch BS 53 [2], Bl. 9,10 (nicht gedruckt)

$\mathrm{TS}^{9} / \mathrm{A}^{2}=$ fragm. Fassung des 15. bis 17. Auftritts, konstituiert durch BS 53 [2], Bl. 9, 10 (nicht gedruckt)

$\mathrm{TS}^{9} / \mathrm{A}^{3}=$ fragm. Fassung des 14. bis 16. Auftritts, konstituiert durch BS 53 [2], Bl. 9, 10 (Korrekturschicht)

Bei TS ${ }^{9} \mathrm{~A}^{1}$ und $\mathrm{A}^{2}$ handelt es sich um drei Auftritte des vierten Aktes „Beim Marquis“. Die vorliegenden Blätter sind aufgrund ihrer relativ hohen, durchgängigen Paginierung wohl Teil einer bereits vollständig vorliegenden Fassung dieses Aktes, die Horváth noch einmal überarbeitete. In der Grundschicht $\mathrm{A}^{1}$ ist es noch Bientôt, der eine Beziehung zu der Unbekannten gehabt hatte, der er das Geld, das sie scheinbar verloren hat, abgenommen hat: "Wir hatten einen furchtbaren Krach und sie ist wegen mir, weil ich ihr meine Liebe gekündigt hab! Sie ist aus gebrochenem Herzen ins Wasser! Ich bin ihr moralischer Mörder, nur ich! Da lesens ihren Abschiedsbrief an mich!“ $\left(\mathrm{TS}^{9} / \mathrm{A}^{1}\right)$. Bientôt habe außerdem den Marquis beschwindelt, dass ihm ein Mann das Geld gegeben habe (vgl. ebd.). Der Marquis verzeiht ihm jedoch. Im 17. Auftritt verbrennt der Marquis den Brief an einer Kerze. Im darauffolgenden 18. Auftritt will die Unbekannte fort, und der Marquis behauptet, dass er seinen "Lebensinhalt" (ebd.) verloren habe. Damit bricht die Fassung ab.

In der Überarbeitung $\left(\mathrm{A}^{2}\right)$ korrigiert Horváth die Paginae von 84 zu 86 bzw. von 85 zu 87 sowie die Nummern der Auftritte zuerst um eins $\left(A^{2}\right)$, dann noch einmal um eins $\left(\mathrm{A}^{3}\right)$ nach unten, die davor ausgearbeiteten Abschnitte des Aktes wurden also erweitert, sodass das Gespräch zwischen dem Marquis und Bientôt erst später folgt. Zugleich wurden im Übergang von $\mathrm{A}^{1} \mathrm{zu} \mathrm{A}^{3}$ wohl zwei Auftritte gestrichen oder mit (einem) anderen zusammengelegt. Die Passage über den Grund, warum die Unbekannte ins Wasser ging, lässt Horváth weitgehend unverändert. Demgegenüber arbeitet er die Stelle nach der Übergabe des Abschiedsbriefs komplett um. Erstmals führt er die Replik des Marquis "Die Schrift gefällt mir nicht -“ ein, die bis in die Endfassungen von Das unbekannte Leben und Mit dem Kopf durch die Wand erhalten bleibt (vgl. TS ${ }^{16} /$ BS 71, Bl. 88, TS ${ }^{17}$ und $\mathrm{K}^{3} / \mathrm{TS}^{21} / \mathrm{BS} 52, \mathrm{Bl}$. 74). Der Szene geht in allen drei Fassungen eine voran, in der der Marquis der Unbekannten den Brief zu lesen gibt und sie es ist, die den Satz über die Schrift zuerst äußert (vgl. TS ${ }^{16} / B S$ 71, Bl. 80, TS ${ }^{17}$ und $\mathrm{K}^{3} / \mathrm{TS}^{21}$ /BS 52, Bl. 65). Bientôt will nun „in die Seine“, weil sich die Unbekannte seinetwegen umgebracht hat, doch der Marquis redet ihm das aus. Auch den letzten, nun 16. Auftritt überarbeitet Horváth peripher. Die Idee mit dem verlorenen "Lebensinhalt" behält er in der Korrektur bei. Immerhin gibt der Marquis zu, jetzt seinen "Frieden“ zu haben, denn er habe durch die Unbekannte jetzt "Wahrheit und Klarheit" (Bl. 9) erfahren. Er möchte ihr danken und fragt sie, was er für sie tun könne. Sie bittet ihn daraufhin, ihre „Kollegen im Terminus" auszulösen (Bl. 10). 


\section{$\mathrm{H}^{14}=0 ̈ \mathrm{LA} 3 / \mathrm{W} 66-\mathrm{BS} 53$ [2], Bl. 16}

1 Blatt unliniertes Papier $(297 \times 209 \mathrm{~mm})$, schwarzblaue Tinte, Paginierung 86 $\mathrm{TS}^{9} / \mathrm{A}^{4}=$ fragm. Fassung eines Auftritts (Grundschicht)

Auf BS 53 [2], Bl. 16 wurde von Horváth vermutlich ein weiterer Ansatz von TS ${ }^{9}$ notiert, der aber nur eine Replik Bientôts umfasst. Demnach ging die Unbekannte zwar wegen Bientôt ins Wasser, aber nicht aus enttäuschter Liebe, sondern weil er ihr das Geld weggenommen hat, "weil sie es hat unterschlagen wollen". Damit skizziert Horváth eine weitere Begründungsvariante für den Selbstmord der Unbekannten. Davon, dass sie wegschwimmen und sich damit retten konnte, ist in diesen Textstufen keine Rede mehr. Möglicherweise hat Horváth dieses Motiv, das bereits in TS $/ \mathrm{A}^{1}-\mathrm{A}^{3}$ und $\mathrm{TS}^{6} / \mathrm{A}^{1}$ sowie $\mathrm{A}^{2}$ ausgearbeitet war, wieder verworfen, für die Endfassungen von Das unbekannte Leben (TS ${ }^{16}$ und TS $\left.{ }^{17}\right)$ und Mit dem Kopf durch die Wand $\left(\mathrm{K}^{3} / \mathrm{TS}^{21}\right)$ aber wiederaufgenommen.

\section{$\mathrm{T}^{5}=0$ ÖLA 3/W 66 - BS 53 [2], Bl. 8}

1 Blatt unliniertes Papier $(297 \times 209 \mathrm{~mm})$, hs. Eintragungen mit schwarzblauer Tinte, Paginierung 85

$\mathrm{TS}^{10}=$ fragm. Fassung des 13. bis 15. Auftritts (Korrekturschicht)

$\mathrm{TS}^{10}$ erscheint aufgrund der Paginierung wie ein Ansatz von TS ${ }^{9}$. Allerdings lassen die Nummerierung der Auftritte und inhaltliche Argumente vermuten, dass TS ${ }^{10}$ erst einige Zeit nach TS ${ }^{9}$ entstanden ist. Der vierte Akt dürfte zum Zeitpunkt des Entstehens von $\mathrm{TS}^{10}$ in puncto Länge der einzelnen Auftritte bereits wesentlich erweitert worden sein, denn der 14. Auftritt folgt hier erst auf einem Blatt mit der Pagina 85, während in $\mathrm{TS}^{9} / \mathrm{A}^{1}$ (Grundschicht) auf einem Blatt mit der Pagina 84 bereits der 17. Auftritt begann. Die Korrelation von Auftritt und Pagina von TS ${ }^{10}$ entspricht in etwa jener von $\mathrm{TS}^{9} / \mathrm{A}^{3}$, wo der 14. Auftritt wahrscheinlich ebenfalls auf einem Blatt mit der Pagina 85 begann.

In TS $^{10}$ geht der Szene zwischen dem Marquis und Bientôt jene zwischen dem Marquis, Nevieux und der Tante voraus, in der diese lebt (was sie in TS $9 / \mathrm{A}^{3}$ und $\mathrm{A}^{4}$ nicht tut). Nevieux will dem Marquis das Geld, das er von diesem bekommen hat, zurückerstatten, der Marquis lehnt dies jedoch ab. Der Wortlaut dieser Passage entspricht über weite Strecken den Endfassungen von Das unbekannte Leben und Mit dem Kopf durch die Wand (vgl. TS ${ }^{16} / \mathrm{BS} 71, \mathrm{Bl} .88, \mathrm{TS}^{17}$ und $\mathrm{K}^{3} / \mathrm{TS}^{21} / \mathrm{BS} 52, \mathrm{Bl}$. 73). Der 14. Auftritt zeigt den Marquis gleichfalls wie dort allein. In der Grundschicht folgt dem, anders als in der Endfassung, in der der Akt an dieser Stelle schließt, der Auftritt Bientôts "mit der geleerten Cognakflasche“. An dieser Stelle bricht die maschinenschriftliche Ausarbeitung ab.

Horváth notiert in der Folge auf dem unteren Blatt eine Fortsetzung des 15. Auftritts, in der Bientôt davon spricht, dass er "ein Geständnis, ein finsteres Geständnis" abzulegen habe. Der Marquis erwidert darauf, dass er bereits alles wisse, und zwar von Nevieux. Worauf Bientôt repliziert: „[W]as weiss denn schon dieser Kohlenhändler! Nichts, radikal nichts!“ In der zweiten Korrektur streicht der Autor diese Passage wieder und lässt den 14. Auftritt damit enden, dass der Marquis den Abschiedsbrief der Unbekannten liest und mit den Worten: "Die Schrift gefällt mir nicht -“ zerreißt. Dabei finden sich zwei Überarbeitungsvarianten. Erst in der zweiten finden sich die Worte, die in ganz ähnlicher Form in die Endfassungen von Das 
unbekannte Leben (vgl. TS'16/BS 71, Bl. 88 und TS${ }^{17} / \mathrm{BS} 52, \mathrm{Bl} .74$ ) und Mit dem Kopf durch die Wand (vgl. $\mathrm{K}^{3} / \mathrm{TS}^{21}$ /BS 52, Bl. 74) eingehen: "(er liest ihren Abschiedsbrief nocheinmal durch, starrt dann vor sich hin, als würde er sein ganzes Leben abrollen sehen; nickt) Stimmt. Die Schrift gefällt mir nicht - (er lächelt und zerreisst ihren Abschiedsbrief)“. Der 15. Auftritt umfasst in der Korrekturschicht nur noch die Szenenanweisung "Marquis. Bientôt."

\section{$\mathrm{H}^{15}=0$ ÖLA 3/W $66-\mathrm{BS} 53$ [2], Bl. 11}

1 Blatt unliniertes Papier $(297 \times 209 \mathrm{~mm})$, Bleistift und schwarzblaue Tinte, Paginierung 88 $\mathrm{TS}^{11}=$ fragm. Fassung des 3. und 4. Auftritts (Korrekturschicht)

Mit TS ${ }^{11}$ liegt eine fragmentarische Fassung des 3. und 4. Auftritts des Schlussaktes vor. Die Paginierung 88 ließe einen Anschluss an die vorhergehenden Textstufen, vor allem an $\mathrm{TS}^{9} / \mathrm{A}^{3}$ herstellen, allerdings fällt die dort zuletzt genannte Szene mit der Unbekannten in weiterer Folge weg. Außerdem fehlen vor TS ${ }^{11}$ die ersten beiden Auftritte des fünften Aktes. Der 3. und 4. Auftritt, wie sie in TS ${ }^{11}$ ausgearbeitet sind, weisen bereits große Ähnlichkeiten mit den entsprechenden Szenen der Endfassungen von Das unbekannte Leben auf (vgl. TS ${ }^{16} / \mathrm{BS} 71, \mathrm{Bl} .93$ und TS${ }^{17} / \mathrm{BS}$ 52, Bl. 79). In der Endfassung von Mit dem Kopf durch die Wand $\left(\mathrm{K}^{3} / \mathrm{TS}^{21}\right)$ fallen diese Szenen weg, denn der Schlussakt spielt dort im Büro der Pandora-Filmgesellschaft. Da es sich bei TS $^{11}$ um eine handschriftliche Ausarbeitung handelt, ist von einem relativ frühen Textzustand auszugehen, die Paginierung lässt aber annehmen, dass die zuvor gereihten Blätter zum Zeitpunkt der Niederschrift von $\mathrm{TS}^{11}$ bereits vorgelegen haben. Es könnte aber auch sein, dass Horváth mit TS ${ }^{11}$ eine Umarbeitung der bereits (maschinenschriftlich) gefertigten 3. und 4. Auftritte vornimmt.

\section{$\mathrm{T}^{6}=$ ÖLA 3/W 66 - BS 53 [2], Bl. 12-14}

3 Blatt unliniertes Papier $(297 \times 209$ mm), hs. Eintragungen mit schwarzblauer Tinte, Paginierung 93-95

$\mathrm{TS}^{12} / \mathrm{A}^{1}=$ fragm. Fassung eines Auftritts, konstituiert durch BS 53 [2], Bl. 12 (Grundschicht)

$\mathrm{TS}^{12} / \mathrm{A}^{2}=$ fragm. Fassung des 5. und 6. Auftritts, konstituiert durch BS 53 [2], Bl. 13, 14 (Korrekturschicht)

Die Paginierung lässt vermuten, dass $\mathrm{TS}^{12} / \mathrm{A}^{1}$ und $\mathrm{A}^{2}$ Teile einer längeren ausgearbeiteten Fassung des Werkprojekts Das unbekannte Leben waren. Allerdings legt der Ausreifungsgrad des Textes und der Abbruch von $\mathrm{A}^{1}$ mitten im Satz nahe, dass es sich um einen verworfenen Teil der Werkgenese handelt. Wahrscheinlich bilden $\mathrm{A}^{1}$ und $\mathrm{A}^{2}$ Vorstufen zum 5. Auftritt des fünften Aktes, des Schlussaktes von Das unbekannte Leben (TS ${ }^{16}$ bzw. TS ${ }^{17}$ ), in dem Huelsen und die Unbekannte unter vier Augen miteinander reden können. In Mit dem Kopf durch die Wand (K $/ \mathrm{TS}^{21}$ ) bildet diese Passage den 3. Auftritt des vierten Aktes.

In $\mathrm{A}^{1}$ behauptet die Unbekannte, dass sie die ganze Nacht auf dem Ball gewesen sei, was ihr Huelsen aber nicht glaubt. Sie verschweigt ihren wahren Aufenthaltsort, weshalb es zu einer Auseinandersetzung zwischen den beiden kommt (vgl. den Eintrag "Krach Huelsen - Unb.“ in $\mathrm{E}^{14}$ ). Sowohl die Lüge bezüglich des Balles als auch die Tatsache, dass die Unbekannte nicht "mehr sagen" darf, finden sich noch in den Endfassungen von Das unbekannte Leben und Mit dem Kopf durch die Wand (vgl. $\mathrm{TS}^{16} / \mathrm{BS}$ 71, Bl. 96, TS${ }^{17} / \mathrm{BS}$ 52, Bl. 82 und $\mathrm{K}^{3} / \mathrm{TS}^{21} / \mathrm{BS} 53$ [4], Bl. 5). Die bekenntnis- 
hafte Replik der Unbekannten, die den Schluss von $\mathrm{A}^{1}$ bildet: "Peter, ich hab es zu weit getrieben, und um ein Haar wär es eine Tragödie geworden" mit der Variante "und fast wär es tragisch geworden" fehlt jedoch in den späteren Fassungen dieser Szene. Möglicherweise war sie der Grund, warum Horváth die Ausarbeitung dieser Fassung abbrach. In den Endfassungen von Das unbekannte Leben (TS ${ }^{16}$ und TS ${ }^{17}$ ) und Mit dem Kopf durch die Wand ( $\mathrm{K}^{3} / \mathrm{TS}^{21}$ ) schließt die Szene mit dem Bekenntnis der Unbekannten, dass sie Huelsen noch nie belogen habe, er also kein Recht habe, ihr nicht zu glauben. In den beiden Fassungen von Das unbekannte Leben (TS ${ }^{16}$ und TS ${ }^{17}$ ) folgt dem der 6 . Auftritt, der mit dem versöhnenden Kuss zwischen der Unbekannten und Huelsen endet, während dieser Auftritt in der Endfassung von Mit dem Kopf durch die Wand $\left(\mathrm{K}^{3} / \mathrm{TS}^{21}\right)$ mit dem vorhergehenden verschmolzen wird.

Die Bl. 13 und 14 setzen mit der Paginierung (94 und 95) A ${ }^{1}$ fort. Allerdings ist davon auszugehen, dass Bl. 12 durch ein anderes, nicht überliefertes ersetzt wurde, das die vorherige Szene zwischen Huelsen und der Unbekannten in veränderter Form enthielt. Mit Bl. 13 wird aber in gewisser Weise Bl. 12 dennoch fortgesetzt. Die beiden Liebenden umarmen und vergeben sich. Darauf folgt auf Bl. 13 der Auftritt Manuels, des Assistenten und des Pianisten. Diese treffen auf das Liebespaar und gratulieren ihm zur Versöhnung. Danach berichten sie, dass sich Semper im Nebenzimmer befinde und von den Probeaufnahmen der Unbekannten begeistert sei. Diese ist sichtlich erleichtert, wirkt aber verstört, als sie erfährt, dass Semper noch nicht die Wahrheit erfahren habe und von Bossard gerade untersucht werde. Semper habe nämlich „Angst vor einem Tobsuchtsanfall“ (Bl. 13). Die Fassung TS'2/ ${ }^{2}$, die über weite Strecken bereits den 7. Auftritt der Endfassungen von Das unbekannte Leben vorwegnimmt (vgl. TS $16 / \mathrm{BS} 71, \mathrm{Bl} .97 \mathrm{f}$. und TS${ }^{17} / \mathrm{BS}$ 52, Bl. 84f.), endet mit der Debatte über das Exposé, das die Unbekannte verfasst hat. Sie selbst behauptet jetzt mit Blick auf Huelsen, dass es miserabel sei und nicht verfilmt werden könne. Der Text bricht mit der Replik des Pianisten ab, der froh ist, dass er noch keine Musik dazu geschrieben hat. In der Endfassung von Mit dem Kopf durch die Wand (K $/ \mathrm{TS}^{21}$ ) fällt die Szene weg bzw. wird gänzlich umgearbeitet.

\section{$\mathrm{T}^{7}=$ ÖLA 3/W 66 - BS 53 [2], Bl. 15}

1 Blatt unliniertes Papier $(297 \times 209$ mm), hs. Eintragungen mit schwarzblauer Tinte und Bleistift, Paginierung 101

TS $^{13}=$ fragm. Fassung eines Auftritts (Korrekturschicht)

Bei TS ${ }^{13}$ handelt es sich um eine Fassung des letzten Auftritts des Schlussaktes von Das unbekannte Leben. Die Paginierung lässt vermuten, dass TS ${ }^{13}$ Teil einer vollständigen Fassung des Stückes war. Allerdings dürfte es sich dabei nicht um die erste Endfassung von Das unbekannte Leben (TS ${ }^{16}$ ) gehandelt haben, denn diese umfasst 106 Blatt, wobei sie mit der Pagina 103 endet, da die Bl. 1-3 mit I-III paginiert sind (vgl. den Kommentar zu TS ${ }^{16}$ ). Der Ausreifungsgrad der Fassung TS ${ }^{13}$ ist sehr hoch. Sie weist einige Ähnlichkeiten mit den entsprechenden Passagen der beiden Endfassungen von Das unbekannte Leben (TS ${ }^{16}$ und $\mathrm{TS}^{17}$ ) auf, vor allem der Beginn und die Schlusspointe sind weitgehend identisch. Dazwischen finden sich jedoch bemerkenswerte Varianten. Die Idee des Marquis, statt den "unbekannten Tod“ doch „lieber das Leben einer armen Jugend“ zu verfilmen (vgl. E11/Bl. 3), findet allgemeine Zustimmung. Huelsen meint dazu: „Das ist mein Roman!“ Worauf die Unbekannte einwirft: "Ich habs ihm erzählt! Schreib ihn als Film! Wer liest heut schon ein Buch?" (vgl. 
TS $16 / B S$ 71, Bl. 106 und TS ${ }^{17} / \mathrm{BS}$ 52, Bl. 93). Huelsen erklärt sich dazu bereit, und der Marquis will den Film unter der Voraussetzung finanzieren, dass die Unbekannte und ihre Kollegen mitspielen können. In der Korrekturschicht stellt der Marquis darüber hinaus die Bedingung, dass Semper den Film "Die Unbekannte der Seine“ nicht herausbringen solle: "Lassen Sie die Toten ruhen!“ Semper ist damit einverstanden, doch der ebenfalls anwesende Autor Hell fühlt sich übergangen. Auf dessen Frage, was er und seine Drehbuchautorenkolleginnen dann machen sollen, fällt Semper schnell eine Lösung ein. Hell solle den neuen „Boxerfilm für Traverson“ schreiben. Er habe auch schon den Titel dafür: "Der Unbekannte der Seine“. Dies ist der Schluss, der sich auch in den beiden Endfassungen von Das unbekannte Leben findet (vgl. $\mathrm{TS}^{16} / \mathrm{BS}$ 71, Bl. 106 und TS${ }^{17} / \mathrm{BS}$ 52, Bl. 93). Damit endet TS ${ }^{13}$ und zugleich das Stück, wie die abschließende Szenenanweisung „(Vorhang)“ erkennen lässt. Die zuletzt eingetragenen handschriftlichen Korrekturen, mit denen Horváth das Ende seines Stücks noch einmal revidiert, lassen vermuten, dass die Ausarbeitung von Das unbekannte Leben für den Autor mit TS ${ }^{13}$ noch nicht abgeschlossen war (vgl. auch TS ${ }^{12}$ ).

$\mathrm{H}^{16}=$ ÖLA 3/W $59-$ BS 51 [1], Bl. 1

1 Blatt unliniertes Papier $(297 \times 209 \mathrm{~mm})$, Bleistift und schwarzblaue Tinte

$\mathrm{E}^{15}=\mathrm{tw}$. gestrichene Werktitel (oben)

$\mathrm{E}^{16}=\mathrm{tw}$. gestrichene Werktitel (unten)

Auf dem vorliegenden Blatt skizziert Horváth in zwei Anläufen Titelentwürfe zu seinem Werkprojekt. Diese schwanken zwischen "L'inconnue dans la Seine“ - der noch mit Bleistift eingetragen ist, also die früheste Entwurfsschicht von $\mathrm{E}^{15}$ darstellt -, ",Das unbekannte Leben“, "Ein unbekanntes Leben“ und "Unbekanntes Leben“ in E ${ }^{15}$ und "Ein Lebensinhalt" , "Unbekanntes Leben“, ,"Totes Leben“" ,Bekannt und unbekannt", "Komödie der Pflicht" und „Das unbekannte Leben“ bzw. „La vie inconnue“ in $\mathrm{E}^{16}$. Die meisten Titel streicht Horváth jedoch wieder. Nur die beiden Titel "Das unbekannte Leben" und "Unbekanntes Leben“ lässt er stehen. Neben seiner französischen Form notiert er diesen in $\mathrm{E}^{16}$ auch auf Ungarisch, was ein weiterer Hinweis darauf ist, dass es derjenige ist, für den er sich schließlich entscheidet. $\mathrm{E}^{15}$ und $\mathrm{E}^{16}$ dokumentieren den auch titelmäßigen Übergang von $\mathrm{K}^{1} \mathrm{zu} \mathrm{K}^{2}$, sind aber wahrscheinlich erst gegen Ende von $\mathrm{K}^{2}$ entstanden, als Horváth daran ging, den Titel seines Werkprojekts an das fertige Stück anzupassen. Einen Hinweis auf die späte Entstehung des Werktitels von $\mathrm{K}^{2}$ bietet auch der folgende Entwurf $\mathrm{E}^{17}$ auf BS 53 [1], Bl. 2, auf dessen Rückseite eine Replik $\left(E^{18}\right)$ eingetragen ist, die Horváth mit Sicherheit erst nach Fertigstellung der Typoskripte $\mathrm{T}^{8}-\mathrm{T}^{10}$ der ersten Endfassung von Das unbekannte Leben $\left(\mathrm{TS}^{16}\right)$ notiert hat.

\section{$\mathrm{H}^{17}=$ ÖLA 3/W $65-\mathrm{BS} 53$ [1], Bl. 2}

1 Blatt unliniertes Papier $(186 \times 114 \mathrm{~mm})$, Notizbuchblatt, perforiert, eingerissen, schwarzblaue Tinte

$\mathrm{E}^{17}=$ Werktitel

Auf dem vorliegenden Blatt, das Horváth einem Notizbuch entnommen hat, notiert er dreimal den Werktitel "Unbekanntes Leben", der auch in $\mathrm{E}^{15}$ und $\mathrm{E}^{16}$ genannt, dort aber durch "Das unbekannte Leben" ersetzt wird. Auf der Rückseite des vorliegenden Blattes hat Horváth eine Variante zur Endfassung von Das unbekannte Leben (TS ${ }^{16}$ ) vermerkt (vgl. $\mathrm{E}^{18}$ ), was ein Hinweis darauf sein könnte, dass auch die Werktitelno- 
tizen relativ spät in der Genese entstanden sind. Der Titel "Das unbekannte Leben“ ist neben $\mathrm{E}^{15}-\mathrm{E}^{17}$ nur auf dem Titelblatt des Regie- und Soufflierbuchs des Max Pfeffer Verlags überliefert (vgl. TS ${ }^{17}$ und $\mathrm{K}^{3} / \mathrm{TS}^{21} / \mathrm{BS} 52, \mathrm{Bl}$. 1). Dort wird er jedoch wieder gestrichen und zunächst durch "Falsche Komplexe“ und dann, allerdings nur auf dem Kartonumschlag des Typoskripts, durch „Mit dem Kopf durch die Wand“ ersetzt (vgl. auch die Kommentare zu TS ${ }^{17}$ und $\mathrm{K}^{3} / \mathrm{TS}^{21}$ ).

\section{$\mathrm{T}^{8}$ = ÖLA 3/W $69-$ BS 54 [1], Bl. 1-94}

94 Blatt unliniertes Papier (297 × 210 mm), Durchschlag, Paginierung 1, 3-65, 69, 71-99

$\mathrm{TS}^{14}=$ fragm. Fassung (nicht gedruckt)

Bei TS ${ }^{14}$ handelt es sich um eine fragmentarisch überlieferte Fassung der Komödie in fünf Akten Das unbekannte Leben. T8 ist ein Durchschlag eines nicht erhaltenen Originals. Die Grundschicht ist textident mit jener von $\mathrm{T}^{9}$ und $\mathrm{T}^{10}$, wobei einzig Letzterer eine vollständig überlieferte Fassung der ersten Fassung von Das unbekannte Leben, jener in fünf Akten, darstellt. T8 umfasst kein Titelblatt, weshalb der Titel nur erschlossen werden kann (vgl. die Kommentare $\mathrm{zu} \mathrm{E}^{15}$ und $\mathrm{E}^{16}$ sowie $\mathrm{zu} \mathrm{E}^{17}$ ). Es fehlen die Blätter mit den Paginae 2, 66-68 und 70. Außerdem ist der Schluss des Stückes nicht überliefert. Die Fassung bricht im 11. Auftritt des Schlussaktes ab. Dem folgen laut TS ${ }^{16}$ noch drei Auftritte, die mit Sicherheit auch schon Teil von T ${ }^{8}$ waren, der auch bis Pagina 103 gereicht haben dürfte. Was mit diesen Blättern geschehen ist, darüber kann nur spekuliert werden. Möglicherweise hat Horváth sie für Umarbeitungen oder aber für die Erstellung eines anderen Typoskripts verwendet. Vielleicht sind sie aber auch auf anderem Wege verloren gegangen. Da TS ${ }^{14}$ mit der Grundschicht von TS ${ }^{16}$ textident ist, wird TS ${ }^{14}$ nicht gedruckt.

\section{$\mathrm{T}^{9}=$ ÖLA 3/W 70 - BS 54 [2], Bl. 1-61}

61 Blatt unliniertes Papier (297 × 210 mm), Durchschlag, Paginierung 3-14, 16-64 $\mathrm{TS}^{15}=$ fragm. Fassung (nicht gedruckt)

$\mathrm{TS}^{15}$ ist wie TS ${ }^{14}$ nur fragmentarisch überliefert und ein Durchschlag eines nicht mehr erhaltenen Originals einer Fassung von Das unbekannte Leben in fünf Akten. In T ${ }^{9}$ fehlt etwa ein Drittel des Textes der Endfassung, die einzig mit $\mathrm{T}^{10}\left(\mathrm{TS}^{16}\right)$ vollständig gegeben ist. Warum die fehlenden Blätter von $\mathrm{T}^{9}$ nicht überliefert sind, kann nicht mehr eruiert werden. Möglicherweise wurden sie von Horváth selbst für die Zusammenstellung eines anderen Typoskripts verwendet, eventuell sind sie auch im Zuge der Nachlassbearbeitung bzw. dessen Neuordnung verloren gegangen. Da TS ${ }^{15}$ mit $\mathrm{TS}^{14}$ und der Grundschicht von TS ${ }^{16}$ textident ist, wird TS ${ }^{15}$ nicht gedruckt.

$\mathrm{T}^{10}=$ ÖLA 3/W 58 - BS 71, Bl. 1-106

106 Blatt unliniertes Papier $(295 \times 210 \mathrm{~mm})$, dünn, Durchschlag, hs. Eintragungen mit roter und schwarzer Tinte, Paginierung I-III, 1-103

$\mathrm{TS}^{16}=$ Endfassung in 5 Akten mit Werktitel "Das unbekannte Leben / Komödie in fünf Akten von

Ödön von Horváth“ (Korrekturschicht)

Druck in: KW 7, S. 215-324.

Bei dem vorliegenden Typoskript $\mathrm{T}^{10}$ handelt es sich um die einzige vollständig überlieferte Endfassung in fünf Akten von Das unbekannte Leben (vgl. auch TS ${ }^{17}$ ). $\mathrm{T}^{10}$ ist 
wie $\mathrm{T}^{8}$ und $\mathrm{T}^{9}$ ein Durchschlag eines nicht erhaltenen 0riginals. $\mathrm{TS}^{14}$ und $\mathrm{TS}^{15}$ sind textident mit der Grundschicht von TS ${ }^{16}$, allerdings sind diese beiden Fassungen nur fragmentarisch überliefert. TS ${ }^{16}$ weist darüber hinaus handschriftliche Eintragungen Horváths mit roter und schwarzer Tinte auf, ist also gegenüber den anderen Typoskripten genetisch später zu verorten. Traugott Krischke hatte bei der Erstveröffentlichung von Das unbekannte Leben im Rahmen der Kommentierten Werkausgabe wahrscheinlich dieses Typoskript vorgelegen, denn er vermerkt, dass er die Druckfassung von Das unbekannte Leben auf der Grundlage eines "103seitigen Typoskript[s] (ohne Titelblatt und Personenregister)“ (KW 7, S. 450) erstellt habe. Ein genauer Textvergleich zeigt, dass Krischke $\mathrm{T}^{10}$ inklusive der handschriftlichen Korrekturen Horváths, also die Korrekturschicht, ediert hat. In Mappe BS 71 befindet sich neben $\mathrm{T}^{10}$ auch ein Blatt eines Briefpapiers Horváths mit dem (inkorrekten) Briefkopf "Oeden von Horváth“. Horváth hat dieses Briefpapier, wahrscheinlich aufgrund seiner mangelhaften Ausführung, für keinen seiner überlieferten Briefe verwendet.

Das vorliegende Typoskript $\mathrm{T}^{10}$ enthält zusätzlich zu den von Krischke erwähnten 103 Blättern mit den Paginae 1-103 drei mit römisch I-III paginierte Blätter, die dem Typoskript möglicherweise später in der archivalischen Ablage beigegeben wurden. Da die römisch paginierten Blätter materiell den arabisch paginierten Blättern entsprechen, ist davon auszugehen, dass sie auch ursprünglich zu diesem Typoskript gehört haben, Krischke aber offensichtlich nicht vorgelegen haben. $\mathrm{T}^{10}$ umfasst also 106 Blatt. Auf den Blättern mit römischer Paginierung befinden sich Titel, Figurenund Schauplatzverzeichnis. Den Titel Das unbekannte Leben hat Horváth in $\mathrm{E}^{15}-\mathrm{E}^{17}$ entwickelt, wobei er sich offensichtlich für eine zuletzt in $\mathrm{E}^{16}$ notierte Variante entschieden hat. Als Ort der Handlung wird auf Bl. 3 "Paris“ angegeben, die Dauer der Handlung reicht "[v]om Nachmittag bis zum nächsten Morgen“ (ebd.), entspricht also der klassischen Vorgabe von einem Tag (24 Stunden).

Bei TS ${ }^{16}$ handelt es sich um die erste Endfassung von Das unbekannte Leben. Aus Autorensicht war die Komödie nach Abschluss der handschriftlichen Redaktion von $\mathrm{TS}^{16}$ für Horváth beendet, weshalb die vorliegende Fassung in fünf Akten als gültige Endfassung anzusehen ist. Warum der Autor $\mathrm{TS}^{16}$ dann doch noch einmal umgearbeitet hat, kann nicht mehr eruiert werden. Auch fehlt genetisches Material, das diesen Bearbeitungsprozess nachvollziehen ließe. Durch die Umarbeitung kommt die zweite Endfassung von Das unbekannte Leben TS ${ }^{17}$ zustande (vgl. den Kommentar dort).

TS ${ }^{16}$ umfasst folgende fünf Akte: „Bureaux des Generaldirektors der Pandora-Filmgesellschaft", „Appartement des Professor Bossard im Hotel Terminus", "Auf dem Filmball“, "Beim Marquis" und "Appartement des Professor Bossard im Hotel Terminus“. In TS ${ }^{17}$, der Stammbuch-Fassung von Das unbekannte Leben, sowie in $\mathrm{K}^{3} / \mathrm{TS}^{21}$, der Endfassung von Mit dem Kopf durch die Wand, finden sich nur noch vier Akte: "Appartement des Professor Bossard im Hotel Terminus", "Auf dem Filmball“, "Beim Marquis" und "Appartement des Professor Bossard im Hotel Terminus" (TS ${ }^{17}$ ) bzw. "Im Büro des Generaldirektors der Pandora-Filmgesellschaft" (K $\left.\mathrm{K}^{3} / \mathrm{TS}^{21}\right)$. Sowohl in $\mathrm{TS}^{17}$ als auch in $\mathrm{K}^{3} / \mathrm{TS}^{21}$ fehlt also der erste Akt „Bureau des Generaldirektors der Pandora-Filmgesellschaft". Der zweite Akt wurde deshalb adaptiert, indem etwa die Figuren Huelsen oder Semper bei ihrem ersten Auftreten durch Szenen- bzw. Regieanweisungen exponiert werden. Horváth verlegt also gewissermaßen den ersten Akt von $\mathrm{TS}^{16}$ schließlich an den Schluss von $\mathrm{K}^{3} / \mathrm{TS}^{21}$ und ersetzt damit das Schlussbild von TS $^{16}$ bzw. TS ${ }^{17}$ im Appartement des Professors Bossard durch ein Bild im Büro 
Sempers (vgl. dazu auch den Kommentar zu TS ${ }^{17}$ ). Abgesehen von diesen makrostrukturellen Permutationen finden sich jedoch auch zahlreiche mikrostrukturelle Veränderungen und Überarbeitungen im Übergang von Das unbekannte Leben zu Mit dem Kopf durch die Wand (vgl. dazu detailliert die Übersichtsgrafik Tab ${ }^{1}$ im Kommentarteil dieses Bandes).

Horváth dürfte zumindest Teile des Typoskripts $\mathrm{T}^{10}$ mit einer ungarischen Schreibmaschine getippt haben, denn teilweise finden sich darin statt der deutschsprachi-

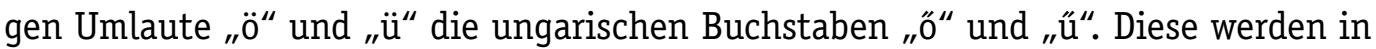
der Transkription von TS ${ }^{16}$ stillschweigend korrigiert. Schrägstriche in den Regieund Szenenanweisungen werden kommentarlos durch Klammern ersetzt. Außerdem werden fehlende oder überzählige Leerzeichen emendiert, ohne dies einzeln zu vermerken. Die Markierungen mit " $\mathrm{x}^{\prime \prime}$ in roter Tinte, die Horváth überall dort als Marginalien an den Blattrand setzt, wo er Korrekturen vornimmt, werden in der Transkription nicht abgebildet. Außerdem ist der Text an manchen Stellen unvollständig, da es sich um einen Durchschlag handelt, in dem manche Textstellen nicht vollständig durchgedruckt wurden. Die entsprechenden Stellen werden unter Ausweis im kritischen Apparat ergänzt.

\section{$\mathrm{H}^{18}=0$ ÖLA 3/W $65-\mathrm{BS} 53$ [1], Bl. 2v}

1 Blatt unliniertes Papier $(186 \times 114 \mathrm{~mm})$, Notizbuchblatt, perforiert, eingerissen, Bleistift und schwarzblaue Tinte, Paginierung 34

$\mathrm{E}^{18}=$ Replik

$\mathrm{E}^{18}$ ist auf der Rückseite eines Notizbuchblatts notiert, auf dem Horváth Werktitelentwürfe eingetragen hat (vgl. $\mathrm{E}^{17}$ ), die früher notiert worden sein dürften. Auf Bl. 2v vermerkt Horváth eine Replik Sempers aus dem 12. Auftritt des ersten Aktes, die er mit der Pagina 34 versieht. Die entsprechende Passage befindet sich auf TS ${ }^{16} /$ BS 71, Bl. 37 mit der Pagina 34; E ${ }^{18}$ bezieht sich also auf die erste Endfassung von Das unbekannte Leben. Horváth entwirft darin eine Variante zu einer dort befindlichen Replik Sempers, in der es um die Probeaufnahmen geht, die er sich sofort ansehen würde, noch bevor er zum Filmball gehe, wenn sein "Privatapparat" nicht "defekt" wäre. Aufgrund der späten Entstehung von $\mathrm{E}^{18}$ ist anzunehmen, dass auch die Werktitelentwürfe von $\mathrm{E}^{17}$ (sowie $\mathrm{E}^{15}$ und $\mathrm{E}^{16}$ ) relativ spät in $\mathrm{K}^{2}$ entstanden sind.

\section{$\mathrm{T}^{11}=$ ÖLA 3/W 64 - BS 52, Bl. 1-93 (vgl. $\left.\mathrm{K}^{3} / \mathrm{T}^{1}\right)$}

Regie- und Soufflierbuch des Max Pfeffer Verlags, Wien 1935, als Manuskript vervielfältigt, 93 Blatt unliniertes Papier (285 × $225 \mathrm{~mm})$, dünn, Durchschlag, gelocht, grüne Mappe mit Aufschrift "Mit dem Kopf durch die Wand / von / Oedön von Horvath“ (Grundschicht: "Das unbekannte Leben“, erste Korrektur: „Falsche Komplexe“), hs. Eintragungen mit schwarzer Tinte und Bleistift, hs. Eintragungen mit Bleistift von fremder Hand, Paginierung 3-93 auf BS 52, Bl. 3-93

$\mathrm{TS}^{17}$ = Endfassung in 4 Akten mit Werktitel "Das unbekannte Leben. / Komödie in vier Akten von 0edön von Horváth“ (Grundschicht)

Das vorliegende maschinenschriftlich angefertigte Regie- und Soufflierbuch des Max Pfeffer Verlags trägt das Copyright 1935 und dürfte noch im Spätsommer oder Frühherbst 1935 angefertigt worden sein. $\mathrm{T}^{11}$ ist mit einer grünen Mappe umschlagen, die einzelnen Blätter sind gelocht, die Klammerung wurde aber gelöst. Mit TS ${ }^{17}$ liegt eine Fassung der Komödie Das unbekannte Leben vor, die in dieser Form bisher nie veröffentlicht wurde. Man hat in ihr aber die Letztfassung des Stückes unter diesem Titel 
zu sehen, da sie von Horváth autorisiert und vom Max Pfeffer Verlag vervielfältigt wurde.

Zwischen der Erstellung von TS ${ }^{16}$, der Fassung in fünf Akten, und der Vervielfältigung des Regie- und Soufflierbuchs dürfte nicht allzu viel Zeit vergangen sein. Was Horváth bewogen hat, seine Komödie um einen Akt zu kürzen, kann nicht mehr eruiert werden. Auch findet sich kein genetisches Material, das die Umarbeitung der Fassung in fünf Akten zur Fassung in vier Akten nachvollziehen ließe. TS ${ }^{17}$ wird deshalb auch nicht als eigene Konzeption geführt, sondern mit TS ${ }^{16}$ im Rahmen von $\mathrm{K}^{2}$, Das unbekannte Leben, behandelt. Diese weist deshalb zwei Endfassungen auf, jene in fünf Akten von TS ${ }^{16}$ und jene in vier Akten von TS ${ }^{17}$ (vgl. dazu den ähnlich gelagerten Fall in WA 6/Eine Unbekannte aus der Seine/K/TS ${ }^{1}$ und TS2).

Das Figurenverzeichnis, das in $\mathrm{T}^{11}$ enthalten ist, führt in der Grundschicht, die TS ${ }^{17}$ konstituiert, noch Figuren wie Mayberg, Hell und Traverson, die Horváth im Laufe von $\mathrm{K}^{3}$ streicht. Außerdem wird darin eine sonst nirgends erwähnte Figur namens Simone genannt, die weder in der Typoskript-Fassung von Das unbekannte Leben (TS ${ }^{16}$ ) noch in der Endfassung von Mit dem Kopf durch die Wand $\left(\mathrm{K}^{3} / \mathrm{TS}^{21}\right)$ zu finden ist. Bei der Figur der Simone handelt es sich um eine Umbenennung der Figur der Drehbuchautorin und Schauspielerin Barbou, die Horváth möglicherweise doch zu nahe an ihrem realen Vorbild, der Romanschriftstellerin und Drehbuchautorin Thea von Harbou (1888-1954), war (vgl. KW 7, S. 477).

Wahrscheinlich lag Direktor Rudolf Beer vom Wiener Theater Scala, bei dem Horváth sein Stück zur Uraufführung eingereicht hatte, dieses Regie- und Soufflierbuch vor, denn in dem auf Bl. 2 enthaltenen Figurenverzeichnis befinden sich Eintragungen von Schauspielernamen mit Bleistift von fremder Hand, die vermutlich von Rudolf Beer oder einem Dramaturgen der Scala stammen. Sie wurden zum Teil von Horváth korrigiert, so hat er etwa im Namen seiner damaligen Lebensgefährtin Wera Liessem ein "e" eingefügt. Die Namenseinträge in Bleistift von fremder Hand dürften die früheste Korrekturschicht von $\mathrm{T}^{11}$ bilden und deuten darauf hin, dass das vorliegende Typoskript in der Grundschicht von Beer oder einem Dramaturgen gelesen wurde, bevor Horváth weitere Korrekturen an seiner Komödie vornahm. Diese führten zunächst zu der Zwischenfassung Falsche Komplexe $\left(\mathrm{K}^{3} / \mathrm{TS}^{4}\right)$ und schließlich zur Endfassung von Mit dem Kopf durch die Wand $\left(\mathrm{K}^{3} / \mathrm{TS}^{21}\right)$. In einem Brief an Horváth bestätigt Beer, dass ihm das Stück "ausserordentlich gefallen" habe und dass man sich "über die Besetzung und die übrigen Details" "wie über den Titel des Stückes" noch "unterhalten“ werde (Brief Rudolf Beers an Ödön von Horváth vom 22. Oktober 1935, zitiert nach dem masch. Original in ÖLA 27/B 7; vgl. auch das Vorwort zu diesem Band, S. 335, 342 und 345f.). Dies lässt vermuten, dass Horváth in der Folge sowohl am Titel als auch an den „übrigen Details“ des Stückes feilte.

Horváth entwickelt also vermutlich erst nach Beers Schreiben vom 22. Oktober 1935 in $\mathrm{K}^{3}$ den Titel "Falsche Komplexe“, den er auf dem Kartonumschlag und auf dem Titelblatt mit Bleistift einträgt. Auch die handschriftlichen Korrekturen, die er im Dramentext vermerkt, dürften aus dieser Bearbeitungsphase stammen. Erst in weiterer Folge tauscht er den vierten Akt aus und fügt den neuen Titel "Mit dem Kopf durch die Wand“ (auf dem Kartonumschlag) ein. Der Untertitel „Komödie in vier Akten" findet sich bereits in der Grundschicht von TS ${ }^{17}$. Bemerkenswerterweise liegt also mit $\mathrm{TS}^{17}$ bereits eine Fassung in vier Akten von Das unbekannte Leben vor, während $\mathrm{TS}^{16}$ noch fünf Akte aufwies, $\mathrm{K}^{3} / \mathrm{TS}^{4}$ und $\mathrm{TS}^{21}$ aber ebenfalls vier Akte umfassen werden. Die Titelkorrekturen auf dem Kartonumschlag von $\mathrm{T}^{11}$ entsprechen also zwei 
unterschiedlichen Konzeptionsphasen innerhalb von $\mathrm{K}^{3}$, wobei zu wenig Material überliefert ist, um diese wirklich nachvollziehen zu können. Die erste endet mit $\mathrm{K}^{3} / \mathrm{TS}^{4}$, die zweite mit $\mathrm{K}^{3} / \mathrm{TS}^{21}$ (vgl. die Kommentare dort).

TS $^{17}$ umfasst vier Akte, wobei folgende Akttitel aus dem Typoskript eruierbar sind: "Im Appartement des Professor Bossard im Hotel Terminus", "Auf dem Filmball", "Beim Marquis" und "Im Appartement des Professor Bossard im Hotel Terminus". Diese Aktfolge entspricht weder TS ${ }^{16}$, die ja noch fünf Akte enthielt und von der der erste Akt, "Bureaux des Generaldirektors der Pandora-Film-Gesellschaft", in TS ${ }^{17}$ fehlt, noch $\mathrm{K}^{3} / \mathrm{TS}^{21}$, in der der letzte Akt durch einen im Büro Sempers ersetzt ist. Der Schluss von $\mathrm{TS}^{17}$ ist ähnlich wie jener von $\mathrm{TS}^{16}$. In beiden Fassungen einigt man sich zuletzt darauf, doch nicht das Leben einer Toten (der Unbekannten) zu verfilmen, sondern die Toten ruhen zu lassen und stattdessen lieber die Geschichte eines Mädchens zu verfilmen, "das sich durchsetzt im Leben", vielleicht das einer "junge[n] Studentin, eine[r] Chemikerin" (TS16/BS 71, Bl. 106 und TS17/BS 52, Bl. 93; vgl. auch den Kommentar zu E $\left.{ }^{11}\right)$. Damit scheint Horváth auf den Erfolgsroman Stud. chem. Helene Willfüer (1929) von Vicki Baum anzuspielen, der ein Ullstein-Bestseller war und schließlich auch verfilmt wurde (D 1929/30, Regie: Fred Sauer, mit Olga Tschechowa und Ernst Stahl-Nachbaur). Außerdem sollen am Ende beider Fassungen von Das unbekannte Leben die drei Autoren Hell, Barbou/Simone und Mayberg statt eines Drehbuchs über die Unbekannte eines für einen Boxerfilm für Traverson mit dem Titel "Der Unbekannte der Seine" schreiben (vgl. TS"16/BS 71, Bl. 106 und $\mathrm{TS}^{17} / \mathrm{BS}$ 52, Bl. 93). Dieser Schluss findet sich in Mit dem Kopf durch die Wand $\left(\mathrm{K}^{3} / \mathrm{TS}^{21}\right)$ nicht mehr, da dort die Figur des Boxers Traverson gänzlich entfällt. Außerdem kehrt Horváth in $\mathrm{K}^{3} / \mathrm{TS}^{21} \mathrm{zu}$ der Idee zurück, dass das Leben der Unbekannten verfilmt werden sollte und der Marquis den Film finanziert (vgl. K³/TS²1/BS 53 [4], Bl. 15f. und Tab ${ }^{1}$ im Kommentarteil dieses Bandes).

Im vorliegenden Stammbuch finden sich unregelmäßige Zeichenabstände. Diese werden in der Transkription von TS ${ }^{17}$ stillschweigend korrigiert. Die Zahl der Bindestriche wird vereinheitlicht, ein und zwei Bindestriche werden zu einem Doppelbindestrich korrigiert, drei und vier Bindestriche zu zwei Doppelbindestrichen mit einem Leerzeichen dazwischen.

Im Splitternachlass Horváth ÖLA 27 befinden sich vier Stammbücher (ÖLA 27/ W 30-W 33), die offensichtlich auf der Grundlage von $\mathrm{T}^{11}$ erstellt wurden. Sie sind undatiert, wurden aber alle vom Georg Marton Verlag, Wien I, Bösendorferstraße 4, hergestellt, bei dem als erstes Stück Horváths Eine Unbekannte aus der Seine (1933) vervielfältigt worden war (vgl. WA 6). Der Name Marton ist ein Hinweis darauf, dass die Stammbücher noch zwischen 1935 und 1952 erstellt wurden, denn der Marton Verlag ging 1952 im Thomas Sessler Verlag auf. ÖLA 27/W 30 und W 33 weisen die gleiche Zahl der Paginae auf, sie reichen bis 69, allerdings findet sich in W 33 noch "Ss"-Schreibung, in W 30 aber " $\beta^{\prime \prime}$, was vermuten lässt, dass W 30 erst später hergestellt wurde, deutet doch die "ss"-Schreibung auf eine größere Nähe zu Horváths Orthografie. Bei ÖLA 27/W 31 und W 32 handelt es sich um identische Durchschläge mit "ss"-Schreibung, hier läuft die Paginierung bis 84 (die Blätter mit der Pagina 24 fehlen in beiden zuletzt genannten Stammbüchern). Ob diese beiden Stammbücher vor ÖLA 27/W 33 oder nach diesem entstanden sind, lässt sich schwer beurteilen. In einem Teil der Stammbücher wurde der Name Marton mit einem Etikett des Thomas Sessler Verlags überklebt. In ÖLA 27/W 31 wurde der in der Grundschicht notierte Titel "Das unbekannte Leben“ von fremder Hand durch "Mit dem Kopf durch die Wand" 
korrigiert. ÖLA 27/W 32 trägt auf dem Kartonumschlag den Schriftzug "Unikat!", was aufgrund der großen Zahl der überlieferten Stammbücher nicht zutrifft. Textlich handelt es sich bei allen vier Durchschlägen um Abschriften von $\mathrm{T}^{11}$, das heißt, sie reproduzieren alle die Fassung TS ${ }^{17}$, die Komödie in vier Akten, die offensichtlich von Horváth und seinen Verlegern in weiterer Folge als die verbindliche Fassung angesehen wurde, wahrscheinlich auch nach der Uraufführung von Mit dem Kopf durch die Wand in der Fassung K ${ }^{3} / \mathrm{TS}^{21}$ im Dezember 1935. Aufgrund dieser Tatsache wird TS ${ }^{17}$ auch in emendierter Form dargeboten, denn man hat in ihr die letztlich autorisierte Fassung des Stückes Das unbekannte Leben zu sehen.

\section{Konzeption 3: Mit dem Kopf durch die Wand - Komödie in vier Akten}

\section{$\mathrm{H}^{1}=$ ÖLA 3/W $65-\mathrm{BS} 53$ [1], Bl. 15}

1 Blatt unliniertes Papier $(340 \times 210 \mathrm{~mm})$, schwarze Tinte und Kopierstift

$\mathrm{E}^{1}=$ Dialogskizze zum I. Akt (ganz oben)

$\mathrm{E}^{2}=$ Notiz (oben links)

$\mathrm{E}^{3}=$ Dialogskizze (oben links)

$\mathrm{E}^{4}=$ Konfigurationsplan (mittig links)

$\mathrm{E}^{5}=$ Replik und Notiz (mittig links)

$\mathrm{TS}^{1}$ = fragm. Fassung eines Auftritts mit Werktitel "Komplexe“ (mittig rechts; Korrekturschicht)

$\mathrm{TS}^{2}$ = fragm. Fassung eines Auftritts (unten; Grundschicht)

$\mathrm{TS}^{3}=$ fragm. Fassung eines Auftritts (ganz unten; Grundschicht)

BS 53 [1], Bl. 15 enthält eine Fülle von Notizen und längeren Ausarbeitungen. Der obere Teil des Blattes wurde mit schwarzer Tinte beschrieben und ist wahrscheinlich um einiges früher als der rechte mittlere und untere Teil desselben entstanden. Die Entwürfe, die Horváth oben einträgt, beziehen sich vermutlich bereits auf die geplante Neufassung des Stückes, das später den Werktitel Mit dem Kopf durch die Wand (erstmals in $\mathrm{E}^{6}$ bzw. $\mathrm{E}^{9}$ ) bekommen wird. Denn der Autor notiert darin eine knappe Dialogskizze $\mathrm{E}^{1}$ zwischen Bossard und Semper zum ersten Akt, wobei Ersterer in der Neufassung des Stückes in vier Akten $\left(\mathrm{K}^{2} / \mathrm{TS}^{17}\right)$ bereits im ersten Akt auftaucht. In $\mathrm{K}^{2} / \mathrm{TS}^{16}$, der ersten Endfassung von Das unbekannte Leben, tritt Bossard erst im zweiten Akt in Erscheinung. Die vorliegenden Entwürfe können also frühestens im Umfeld von $\mathrm{K}^{2} / \mathrm{TS}^{17}$ entstanden sein. Mit großer Sicherheit sind sie jedoch im Übergang von $\mathrm{K}^{2} \mathrm{zu} \mathrm{K}^{3}$ notiert worden.

In dem Dialog zwischen Semper und Bossard geht es vermutlich um die Rollen, die Bossard als "Statist von der Filmbörse“ gespielt hat (vgl. K²/TS $16 / B S 71, \mathrm{Bl}$. 42, TS ${ }^{17}$ und $\mathrm{K}^{3} / \mathrm{TS}{ }^{21} / \mathrm{BS} 52$, Bl. 26). Erwähnt wird dazu "[e]in Leutnant bei Königgrätz", "ein Sachse“, kein "Preuss". Konkrete Rollen, die Bossard gespielt hat, finden sich auch in den Endfassungen von Das unbekannte Leben und Mit dem Kopf durch die Wand, allerdings ist dort vom "Oberkellner in ,Flammende Begierde" und vom "Oberstleutnant in "Des Königs Husaren"“ die Rede (vgl. K²/TS'16/BS 71, Bl. 101, TS ${ }^{17} / \mathrm{BS}$ 52, Bl. 88 und $\mathrm{K}^{3} / \mathrm{TS}^{21} / \mathrm{BS} 53$ [4], Bl. 6). $\mathrm{E}^{2}$ dürfte damit in Zusammenhang stehen, denn Horváth notiert hier, dass der Pianist den Deckel des Klaviers zuschlagen soll. Den darunter eingetragenen knappen Dialog zwischen dem Marquis und der Unbekannten $\mathrm{E}^{3}$ hat man dem dritten Akt der Fassungen in vier Akten zuzuweisen. Darin geht es um die Frage, ob die Unbekannte das Schlafzimmer des Marquis zur "allerpersön- 
lichsten Verfügung" haben solle (vgl. $\mathrm{K}^{2} / \mathrm{TS}^{17}$ und $\mathrm{K}^{3} / \mathrm{TS}^{21} / \mathrm{BS} 52, \mathrm{Bl}$. 70). Bei $\mathrm{E}^{3}$ könnte es sich um eine leichte Revision der entsprechenden Passage handeln.

Die darunter notierten Konfigurationspläne $E^{4}$ streicht Horváth größtenteils wieder. Eine Szene zwischen Huelsen und dem Marquis findet sich ebenfalls im dritten Akt der Fassungen in vier Akten $\left(\mathrm{K}^{2} / \mathrm{TS}^{17}\right.$ und $\left.\mathrm{K}^{3} / \mathrm{TS}^{21}\right)$, und zwar im unmittelbaren Anschluss an die erste Szene mit der Unbekannten. Möglicherweise wollte Horváth aber mit dem Eintrag $E^{4}$ auch eine bereits bestehende Szene zwischen Semper und dem Marquis aus dem Schlussakt auf Huelsen und den Marquis übertragen. Zuletzt vermerkt Horváth eine Replik $E^{5}$ des Mixers Robert, wonach sich in der Zeitung ein interessanter Artikel über den Marquis finde. Eine Notiz dazu deutet an, dass es in der Folge zu einem "Gespräch über geheime Schuld“ kommen solle. Ein solches Gespräch zwischen Robert und dem Marquis gibt es in keiner der drei Endfassungen, wohl aber spricht der Marquis mit Nevieux und Bientôt sowie mit der Unbekannten über seine vermeintliche Schuld (vgl. K²/TS ${ }^{16} / \mathrm{BS} 71, \mathrm{Bl} .74$ und 80, TS ${ }^{17}$ sowie $\mathrm{K}^{3} / \mathrm{TS}^{21}$ BS 52, Bl. 58f. und 65).

Die Fassungen von TS ${ }^{1}-\mathrm{TS}^{3}$, die Horváth daneben und darunter auf dem Blatt einträgt, scheinen durch den in TS ${ }^{1}$ notierten Titel "Komplexe“ mit einiger Sicherheit auf die Frühphase der Konzeption Mit dem Kopf durch die Wand $\left(\mathrm{K}^{3}\right)$ bezogen, die mit der Zwischenfassung TS4 endet, die den Titel "Falsche Komplexe“ trägt (vgl. auch E6). TS $^{1}-$ TS $^{3}$ dürften aufgrund des veränderten Schreibmaterials in einigem Abstand zu $\mathrm{E}^{1}-\mathrm{E}^{5}$ entstanden sein (vgl. oben). In den drei Textstufen skizziert Horváth Monologe der Unbekannten, die er möglicherweise für die Séance-Szene des ersten Aktes oder aber für das später mehrfach erwähnte "Vorspiel“ verwenden wollte (vgl. TS4, E ${ }^{6}$ und den Kommentar zu TS ${ }^{21}$ ), zu dem es vermutlich weitere Ausarbeitungen in Form von $\mathrm{TS}^{15}-\mathrm{TS}^{18}$ gibt.

In TS ${ }^{1}$ geht es um "Mord“. Der dazu ausgearbeitete Monolog ist in Versen gehalten: „Ein Mensch bringt einen um - / Gewiss, dass ist dumm - / Gewiss, das ist peinlich - / Denn man ist doch reinlich. / Das Leben - oh herjeeh! / Vergeht wie der Schnee / Wenn die Sonne drauf scheint. / Wenn Wärme erscheint." Horváth ergänzt diesen rechts mittig notierten Abschnitt um einen weiteren, den er links unten hinzufügt und über einen Pfeil mit Ersterem verbindet. Dort befürchtet das Ich, dass es der "einzige Zeuge" eines "Meuchelmord[es]" sei. Aber, wenn der "Mörder" das Ich liebte, würde es alles "vergess[en]”. Damit spielt Horváth deutlich auf den Inhalt seiner schwarzen „Komödie“ Eine Unbekannte aus der Seine (1933) an, der vor allem für die frühe Konzeptionsphase des Werkprojekts Mit dem Kopf durch die Wand, Die Unbekannte der Seine (VA) und L'inconnue de la Seine $\left(\mathrm{K}^{1}\right)$, relevant war, die er aber in $\mathrm{K}^{3}$ offensichtlich neuerlich in irgendeiner Form einbauen wollte. Diese Anspielungen sind Teil eines intertextuellen Verweissystems, das die Komödien Eine Unbekannte aus der Seine, Das unbekannte Leben und Mit dem Kopf durch die Wand bis hinein in die Endfassungen miteinander verbindet. Sie sind zugleich Teil eines modifizierten poetologischen Konzepts Horváths ab Mitte der dreißiger Jahre. So zeichnen sich auch die späten Dramen Figaro läßt sich scheiden, Don Juan kommt aus dem Krieg (beide 1936), Ein Sklavenball / Pompeji und Ein Dorf ohne Männer (alle 1937) durch vielfältige intertextuelle Bezüge aus.

In TS2 notiert Horváth eine Replik der Unbekannten, in der es um die "Sehnsucht nach dem Leben" und "nach dem Tod" geht. Sie endet mit den Versen: "Der Tag ist mir unbekannt / Ich liebe nur die Nacht." Darunter trägt Horváth eine weitere Fassung ein, jene von $\mathrm{TS}^{3}$, in der es heißt: „In der grossen Stadt / Kam ich allein - / Man 
schickte mich aufs Postchekamt / Zu kassieren ein." Damit verarbeitet Horváth das Motiv des verlorenen Geldes, womit der Text als Monolog der Unbekannten zu erkennen ist, und nimmt stärker Bezug auf die bereits bestehenden Ausarbeitungen der Vorarbeit, bzw. von $\mathrm{K}^{1}$ und $\mathrm{K}^{2}$. Eine nachträglich zu TS${ }^{1}$ eingetragene Notiz mit Bezug auf die Unbekannte lautet: „Verlier auch den Verstand.“

\section{$\mathrm{T}^{1}=$ ÖLA 3/W $64-$ BS 52, Bl. 1-93 (vgl. $\mathrm{K}^{2} / \mathrm{T}^{11}$ )}

Regie- und Soufflierbuch des Max Pfeffer Verlags, Wien 1935, als Manuskript vervielfältigt, 93 Blatt unliniertes Papier $(285 \times 225 \mathrm{~mm})$, dünn, Durchschlag, gelocht, grüne Mappe mit Aufschrift "Mit dem Kopf durch die Wand / von / Oedön von Horvath“ (Grundschicht: "Das unbekannte Leben“, erste Korrektur: „Falsche Komplexe“), hs. Eintragungen mit schwarzer Tinte und Bleistift, hs. Eintragungen mit Bleistift von fremder Hand, Paginierung 3-93 auf BS 52, Bl. 3-93

$\mathrm{TS}^{4}$ = fragm. Fassung in 4 Akten mit Werktitel „Falsche Komplexe / Komödie in einem Vorspiel und vier Akten von 0edön von Horvath“ (nicht gedruckt)

Mit TS4 endet gewissermaßen die erste Konzeptionsphase von $\mathrm{K}^{3}$. TS4 kann man deshalb als Zwischenfassung im Übergang von Das unbekannte Leben zu Mit dem Kopf durch die Wand ansehen. Wohl auf Anregung Direktor Rudolf Beers vom Theater Scala in Wien hat Horváth seine Komödie Das unbekannte Leben, wie sie Beer mit K²/TS17 vorgelegen hatte, noch einmal überarbeitet und dazu das Regie- und Soufflierbuch des Max Pfeffer Verlags noch einmal zur Hand genommen, das in der Grundschicht die Fassung $\mathrm{K}^{2} / \mathrm{TS}^{17}$ konstituierte (vgl. den Kommentar dort). Zunächst hat er vermutlich $\mathrm{E}^{1}-\mathrm{E}^{5}$ und TS${ }^{1}-\mathrm{TS}^{3}$ ausgearbeitet und wollte das Stück unter den Titel "Falsche Komplexe" stellen, wie der neu eingetragene Titel auf BS 52, Bl. 1 lautet. Schließlich hat er jedoch das ganze Stück noch einmal überarbeitet und zahlreiche Korrekturen eingetragen, die die Korrekturschicht in schwarzer Tinte von $\mathrm{T}^{1}$ darstellen.

Das im Titel nachträglich vermerkte "Vorspiel“ (TS4/BS 52, Bl. 1, vgl. TS²1/ebd.) ist nicht überliefert, wahrscheinlich sind in ihm der Marquis de Bresançon, Bientôt und Jean aufgetreten, wie die Nummerierung der Figuren in der Figurenliste (TS4/BS 52, Bl. 2, vgl. TS²1/ebd. und den Kommentar dort) annehmen lässt. Ein weiterer Hinweis darauf, dass etwa der Diener Jean im Vorspiel aufgetreten ist, besteht darin, dass Horváth in der Szenenanweisung des dritten Aktes (TS4/BS 52, Bl. 53) die Apposition zu Jean "sein dicker Diener" streicht. Der Diener wurde nämlich vermutlich bereits im nicht überlieferten Vorspiel von TS4 exponiert. Außerdem hat Horváth in der Überarbeitung zunächst neue Figuren hinzugefügt, wie den Notar und den Elektrotechniker, diese kommen jedoch in der Fassung des Regie- und Soufflierbuchs nicht vor. Offensichtlich enthält das Stammbuch mehrere Korrekturschichten, in denen etwa die Figur Hell bereits gestrichen wird, jene des Regisseurs Mayberg und der Drehbuchautorin Simone jedoch noch nicht (vgl. auch die Figurennummerierung, in der Hell ausgelassen, Mayberg und die Simone jedoch nummeriert werden). Erst in der zweiten Korrektur werden auch Mayberg und Simone gestrichen. Alle drei Drehbuchautoren kommen aber noch in dem kaum mehr korrigierten vierten Akt des Stammbuchs vor, was ein Hinweis darauf sein könnte, dass dieser vierte Akt nie fertig überarbeitet wurde und daher eigentlich nicht zu TS4 $\mathrm{zu}$ rechnen ist. Den vierten Akt von TS ${ }^{4}$ ersetzt Horváth später durch jenen von $\mathrm{TS}^{20} / \mathrm{A}^{2}$. Die ebenfalls in der Korrektur eingetragene Zeitangabe: „Vorspiel - Dritter Akt: Vom Nachmittag bis zum nächsten Morgen“ sowie „Vierter Akt: Ein Jahr später" (TS4/BS 52, Bl. 2, vgl. TS21/ebd.) lässt allerdings vermuten, dass es nicht nur ein Vorspiel gab, das nicht 
mehr erhalten ist, sondern auch einen weiteren vierten Akt. Dieser hat wahrscheinlich ein Jahr später gespielt und wurde mit einiger Sicherheit bereits im Rahmen von $\mathrm{TS}^{4}$ erstellt, ist aber nicht überliefert. Der vierte Akt von $\mathrm{TS}^{20} / \mathrm{A}^{2}$ spielt, wie jener von $\mathrm{K}^{2} / \mathrm{TS}^{17}$, am nächsten Morgen, wie einige Hinweise im Text erkennen lassen.

Besonders stark fallen die Korrekturen im zweiten Akt aus. Hier lassen sich zwei Korrekturschichten unterscheiden. Wahrscheinlich hat Horváth zunächst in der Mitte des zweiten Aktes den 14. Auftritt, der Traverson exponiert, und den 15. Auftritt, in dem Hell vorkommt, gestrichen und deshalb die Auftrittsnummern in der Folge um zwei nach unten korrigiert. Im Rahmen derselben Korrekturschicht werden auch der 17. Auftritt, der neben anderen Figuren, wieder Hell, Mayberg und Simone enthält, sowie der 18. Auftritt gestrichen. Die Auftrittsnummerierungen in unmittelbarer Folge werden deshalb zunächst um vier nach unten korrigiert. Im 13. (nun 11.) Auftritt korrigiert Horváth in der ersten Korrekturschicht überall Hell zu Mayberg und lässt den Auftritt offensichtlich in der ersten Korrektur noch stehen. In der zweiten Korrekturschicht streicht der Autor jedoch auch einen Großteil des 1. Auftritts und den gesamten 2. und 3. Auftritt, weshalb er die Auftrittsnummern der folgenden Auftritte um zwei nach unten korrigieren muss. Deshalb ersetzt er etwa auf BS 52, Bl. 45 die Auftrittsnummer 16 zunächst - nach der Streichung des 14. und 15. Auftritts - durch 14, und erst in der zweiten Korrektur, nachdem er auch den 13. sowie den 2. und 3. Auftritt gestrichen hat, durch 11. Dementsprechend wird der 19. in der ersten Korrektur - nach Streichung des 14., 15., 17. und 18. - zum 15. und in der zweiten - nach der Streichung des 13. sowie des 2. und 3. Auftritts - zum 12. Auftritt korrigiert. Dem entspricht die Korrektur des 20. Auftritts zum 16., dann zum 13., und des 21. zum 17., dann zum 14., sowie des 22. zum 18., dann zum 15. (vgl. den kritischen Apparat von TS'1).

Im dritten und vierten Akt finden sich nur wenige Korrekturen, meist einzelne Wortkorrekturen, in selteneren Fällen Ersetzungen mehrerer Repliken durch neu ausgearbeitete Dialogteile. Der vierte Akt wurde aber wahrscheinlich nicht mehr zu Ende redigiert, sondern möglicherweise bereits im Rahmen von TS4 durch einen anderen vierten Akt („Ein Jahr später") ersetzt (vgl. oben). Aufgrund der nicht gegebenen Deckungsgleichheit von Titelblatt, Figurenverzeichnis und Dramentext wird auf einen Abdruck von TS ${ }^{4}$ verzichtet. Die ersten drei Akte von TS ${ }^{4}$ entsprechen in der Korrekturschicht bereits der Endfassung von Mit dem Kopf durch die Wand (TS ${ }^{21}$ ), den letzten Akt arbeitet Horváth schließlich mit TS20/A² neu aus. Traugott Krischke hat in seiner Ausgabe von Mit dem Kopf durch die Wand in der Kommentierten Werkausgabe wohl zu Recht die ersten drei Akte von TS ${ }^{4}$ mit dem durch TS20/A² gegebenen vierten Akt zusammengefügt und damit eine Gesamtfassung von Mit dem Kopf durch die Wand erstellt (vgl. KW 7, S. 450 sowie die Kommentare zu TS $20 / \mathrm{A}^{2}$ und TS ${ }^{21}$ ). Eine solche, aus $\mathrm{TS}^{4}$ und $\mathrm{TS}^{20} / \mathrm{A}^{2}$ kompilierte Gesamtfassung wird auch im vorliegenden Band mit TS ${ }^{21}$ konstituiert (zu den Unterschieden zwischen $\mathrm{K}^{2} / \mathrm{TS}^{16}, \mathrm{TS}^{17}, \mathrm{~K}^{3} / \mathrm{TS}^{4}$ und TS $^{21}$ vgl. die Übersichtsgrafik Tab ${ }^{1}$ im Kommentarteil dieses Bandes, S. 892-903). 


\section{$\mathrm{H}^{2}=$ ÖLA 3/W 65 - BS 53 [1], Bl. 3}

1 Blatt unliniertes Papier $(290 \times 230 \mathrm{~mm})$, gefaltet, schwarzblaue Tinte $\mathrm{TS}^{5}=$ fragm. Fassung eines Auftritts (Korrekturschicht)

In TS ${ }^{5}$ skizziert Horváth einen Schluss für sein Werkprojekt. Wahrscheinlich handelt es sich um eine Schlussvariante zu der Fassung Falsche Komplexe (TS4), denn die Bedeutung, die in den Repliken der vorliegenden Fassung dem Begriff der "falschen Komplexe" zukommt, lässt eine unmittelbare Beziehung zu dieser Fassung vermuten. Wahrscheinlich wurde Horváth von der Dramaturgie des Theaters Scala gebeten, den Bezug zu den Falschen Komplexen im Titel am Schluss des Stückes deutlicher herauszustellen. Die Motivketten "Lebensinhalt", "die unbekannten Toten ruhen" lassen und sein "Ehrenwort" brechen verweisen indes zurück auf $\mathrm{K}^{2}$ (vgl. etwa $\mathrm{K}^{2} / \mathrm{E}^{13}$ sowie $\left.\mathrm{TS}^{9} / \mathrm{A}^{3}\right)$. Allerdings spielen diese Begriffe auch in den Stammbuch-Fassungen von $\mathrm{K}^{2} / \mathrm{TS}^{17}$ bzw. $\mathrm{K}^{3} / \mathrm{TS}^{4}$ weiterhin eine gewichtige Rolle. Wahrscheinlich hat Horváth jedoch diesen Schluss in weiterer Folge wieder fallen gelassen und den Schluss noch mehrfach bearbeitet (vgl. auch TS${ }^{6}$ ), sodass schließlich, beginnend mit TS ${ }^{9}$, der Schlussakt überhaupt in das Büro der Pandora-Film verlegt wird.

\section{$\mathrm{H}^{3}=$ ÖLA 3/W $65-\mathrm{BS} 53$ [1], Bl. 10V}

1 Blatt unliniertes Papier $(340 \times 210 \mathrm{~mm})$, schwarzblaue Tinte

$\mathrm{E}^{6}=$ gestrichener Werktitel (ganz oben)

$\mathrm{E}^{7}=$ gestrichene Schauspielerliste (oben)

$\mathrm{E}^{8}=$ gestrichener Akttitel (mittig)

$\mathrm{TS}^{6}=$ fragm. Fassung eines Auftritts (mittig; Grundschicht)

Mit dem vorliegenden Blatt setzt eine neuerliche Überarbeitung der Komödie Falsche Komplexe (TS ${ }^{4}$ ) ein, die schließlich in die Komödie in vier Akten Mit dem Kopf durch die Wand (TS ${ }^{21}$ ) mündet (vgl. auch die Kommentare $\mathrm{zu} \mathrm{K}^{2} / \mathrm{TS}^{17}, \mathrm{~K}^{3} / \mathrm{TS}^{4}$ und TS ${ }^{21}$ ). In $\mathrm{E}^{6}$ notiert Horváth erstmals den Werktitel "Mit dem Kopf durch die Wand“, der den zuerst eingetragenen Titel "Komplexe“ (vgl. TS ${ }^{1}$ und den Kommentar zu TS4) ersetzt. Der Autor versieht den Titel mit dem Zusatz "Komödie in einem Vorspiel und fünf Akten von Ödön von Horváth“. Die Aktzahl entspricht nicht der in $\mathrm{TS}^{4}$ - es sei denn, man zählt das Vorspiel als eigenen Akt -, es ist aber möglich, dass Horváth mit E6 neuerlich zu einer Struktur in fünf Akten zurückkehren wollte. Der Hinweis „Pause nach dem dritten Akt" stellt eine Referenz zu einer wirklichen dramatischen Umsetzung des Stückes dar, genauso wie die darunter notierte Schauspielerliste $\mathrm{E}^{7}$ (vgl. dazu auch die Besetzungs- und Schauspielerlisten in der Werkgenese von Geschichten aus dem Wiener Wald, WA $3 / \mathrm{K}^{4} / \mathrm{E}^{23}, \mathrm{~K}^{5} / \mathrm{E}^{13}, \mathrm{E}^{18}$ und $\left.\mathrm{E}^{19}\right)$. Beide Entwürfe sind ein deutlicher Hinweis darauf, dass die Überarbeitung von Das unbekannte Leben zunächst zu der Zwischenfassung Falsche Komplexe (TS $\left.{ }^{4}\right)$ und dann zu Mit dem Kopf durch die Wand (TS ${ }^{21}$ ) inklusive der Titeländerung erst nach der Annahme des Stückes durch Direktor Rudolf Beer vom Wiener Theater Scala erfolgt ist (vgl. den Kommentar zu K²/TS ${ }^{17}$ und weiter unten).

Bemerkenswert sind die Schauspielernamen, die Horváth in $\mathrm{E}^{7}$ einträgt. Mit Wera Liessem (1909-1991) als möglicher Darstellerin der Unbekannten ist Horváths damalige Lebensgefährtin genannt, die auch einen wesentlichen Anteil an der ,Geburt' der Komödie hatte (vgl. auch den Kommentar $\mathrm{zu} \mathrm{K}^{2} / \mathrm{TS}^{17}$ sowie das Vorwort in diesem Band, S. 334f.). Weiters erwähnt die Schauspielerliste $E^{7}$ Luise (eigtl. Louise) Kar- 
tousch, Egon Friedell, Kurt von Zedlitz und Friedrich Kühne. Die Namen Kartousch, Friedell, Zedlitz und Kühne tauchen auch in der von Horváths Hand stammenden Korrekturschicht mit schwarzer Tinte des Personenverzeichnisses von TS $4 / \mathrm{BS} 52, \mathrm{Bl}$. 2 (vgl. TS21/BS 52, Bl. 2) auf, was ein Hinweis darauf ist, dass die in $\mathrm{E}^{7}$ notierte Schauspielerliste etwa zeitgleich mit jener entstanden ist. Aufgrund des in $\mathrm{E}^{6}$ notierten Titels "Mit dem Kopf durch die Wand“ ist anzunehmen, dass $E^{7}$ jedoch erst nach $\mathrm{TS}^{4}$ entstanden ist.

Louise Kartousch (1896-1964) war eine österreichische Tänzerin sowie Opern- und Operettensängerin, die als Soubrette unter anderem am Raimundtheater und am Theater in der Josefstadt wirkte. Egon Friedell (1878-1938) war ein bekannter österreichischer Schriftsteller (Kulturgeschichte der Neuzeit, 1925-1931), Journalist (unter anderem beim Neuen Wiener Journal), Dramatiker (Goethe im Examen, Intimes Theater), Schauspieler (mit Engagements am Deutschen Theater Berlin und am Theater in der Josefstadt in Wien) und Kabarettist (Cabaret Fledermaus). Einen Schauspieler namens Kurt von Zedlitz sucht man vergeblich; Horváth meinte Hans von Zedlitz (1890-1948), einen deutschen Schauspieler, der unter anderem im 0peretten-Film Der letzte Walzer (D 1934, Regie: Georg Jacoby) nach Oscar Straus mit Ernst Dumcke und Max Gülstorff mitwirkte. Weiters spielte er in der Komödie Einmal eine große Dame sein (D 1934, Regie: Gerhard Lamprecht) mit Käthe von Nagy und Wolf Albach-Retty. Friedrich Kühne (1870-1958) war ein österreichisch-deutscher Schauspieler, der ab 1907 zum Ensemble des Deutschen Theaters Berlin zählte und seit 1913 auch in kleineren Filmrollen auftrat (vgl. zu den erwähnten Schauspielernamen auch die fragmentarische Besetzungsliste in $\mathrm{K}^{3} / \mathrm{TS}^{21}$ ).

Die Komödie Mit dem Kopf durch die Wand wurde schließlich am 12. Dezember 1935 am Wiener Theater Scala uraufgeführt. Unter der Regie von Rudolf Beer spielten unter anderem Hans von Zedlitz, Karl Forest, Friedrich Kühne, Wera Liessem, Egon Friedell, Hans Holt und Louise Kartousch (vgl. auch das Vorwort in diesem Band, S. 346-348). Bereits am 22. Oktober 1935 hatte der Direktor des Theaters, Rudolf Beer, Horváths Stück Das unbekannte Leben gelesen (vgl. KW 7, S. 448 und den Kommentar zu K ${ }^{2} / \mathrm{TS}^{17}$ ). Wahrscheinlich handelte es sich dabei um die Fassung $\mathrm{K}^{2} / \mathrm{TS}^{17}$. Der Brief Beers stellt einen Terminus post quem für die Erstellung des vorliegenden Blattes dar bzw. generell von $\mathrm{K}^{3}$, in der Horváth offensichtlich auf Wunsch Rudolf Beers seine Komödie noch einmal überarbeitete.

In $E^{8}$ notiert Horváth den Akttitel "V. Akt", hält also weiterhin an einer Struktur in fünf Akten fest. In TS ${ }^{6}$ skizziert der Autor einen Dialog zwischen dem Marquis und der Unbekannten, der darauf hindeutet, dass der Schluss der Komödie zu diesem Zeitpunkt noch immer nicht wirklich feststand. In der Fassung sprechen der Marquis und die Unbekannte über die Einrichtung eines Zimmers, wohl für eine Filmaufnahme. Gemeint ist damit wahrscheinlich das Zimmer des Marquis, der sich an der Position eines Sessels stört. Außerdem wirft er der Unbekannten ihr Engagement vor und dass sie ihm ihr "Ehrenwort" gegeben habe, "nicht zu spielen". Horváth streicht abschließend alle Entwürfe und die Textstufe von Bl. 10v. Dies könnte als Hinweis darauf gewertet werden, dass er die Textstufe der Rectoseite $\left(\mathrm{K}^{2} / \mathrm{TS}^{6} / \mathrm{A}^{1}\right)$ erst danach eingetragen hat. Allerdings lässt sich diese aufgrund des geringen Ausreifungsgrads mit einiger Sicherheit $\mathrm{K}^{2}$ zuordnen, weshalb davon auszugehen ist, dass Horváth $\mathrm{K}^{3} / \mathrm{E}^{6}-\mathrm{E}^{8}$ und $\mathrm{TS}^{6}$ erst später notiert, aber wieder gestrichen hat. 


\section{$\mathrm{H}^{4}=$ ÖLA 3/W 65 - BS 53 [1], Bl. 6}

1 Blatt unliniertes Papier $(286 \times 221 \mathrm{~mm})$, dünn, schwarzblaue Tinte $\mathrm{TS}^{7} / \mathrm{A}^{1}=$ fragm. Fassung eines Auftritts (oben; Grundschicht)

$\mathrm{TS}^{7} / \mathrm{A}^{2}=$ fragm. Fassung eines Auftritts (mittig und unten; Korrekturschicht)

Die Stellung des vorliegenden Blattes in der Chronologie ist ungewiss. Möglicherweise handelt es sich dabei bereits um eine Ausarbeitung zum Werkprojekt Das unbekannte Leben $\left(\mathrm{K}^{2}\right)$. Aufgrund materieller Indizien kann jedoch eine genetische Nähe zu TS ${ }^{10}$ vermutet werden. Auf dem Blatt entwirft Horváth in zwei Ansätzen eine Szene zwischen Direktor Semper und der Unbekannten, die wahrscheinlich im vierten und letzten Akt von Mit dem Kopf durch die Wand platziert werden hätte sollen, dann aber in dieser Form nicht vorkommt. Die Unbekannte spricht in $\mathrm{A}^{1}$ und $\mathrm{A}^{2}$ davon, dass sie sich vor sich selbst retten müsse. Ein weiteres Verbindungsglied zwischen den beiden Ansätzen ist die Frage der Unbekannten: "Herr Direktor, was ist denn mit unserem Film?" bzw. „Was ist denn mit unserem Film?!“ Eine Passage in A², in der die Unbekannte Semper daran erinnert, wer sie ist, streicht Horváth in der Korrektur. In den Endfassungen von Das unbekannte Leben $\left(\mathrm{K}^{2} / \mathrm{TS}^{16}\right.$ und $\left.\mathrm{TS}^{17}\right)$ und Mit dem Kopf durch die Wand erinnert sich Semper sehr wohl an die Unbekannte, die er auf dem Filmball kennen gelernt hatte (vgl. K²/TS ${ }^{16} / \mathrm{BS} 71, \mathrm{Bl} .99, \mathrm{TS}^{17} / \mathrm{BS} 52$, Bl. 85 und $\mathrm{K}^{3} / \mathrm{TS}^{21} / \mathrm{BS} 53$ [4], Bl. 6).

\section{$\mathrm{H}^{5}=$ ÖLA 3/W $65-$ BS 53 [1], Bl. 11}

1 Blatt unliniertes Papier $(340 \times 210 \mathrm{~mm})$, schwarzblaue Tinte $\mathrm{TS}^{8}=$ fragm. Fassung zweier Auftritte (Korrekturschicht)

In TS ${ }^{8}$ arbeitet Horváth zwei (oder mehr) Auftritte zum Schlussakt seines Werkprojekts aus. Wahrscheinlich geht er dabei schon davon aus, dass seine Komödie vier Akte umfassen sollte (vgl. aber $\mathrm{E}^{6}$ und $\mathrm{E}^{8}$ ). Die Ausarbeitung erfolgt also zum vierten Akt, mit dessen Umarbeitung Horváth in TS ${ }^{8}$ beginnt (vgl. die gestrichene Aktnummer IV am Kopf des Blattes). Die Zugehörigkeit zu K kann durch zwei Repliken eindeutig belegt werden. Zunächst ist es der Marquis, der sagt: "Ich bin mit dem Kopf durch die Wand - durch eine unsichtbare; ich habe sie durchbohrt und habe Schrecken gesehn und Angst. Es sind die Mächte, die gnädig das Unbekannte verhüllen." Zuletzt notiert Horváth eine Replik der Unbekannten, in der diese gegenüber Huelsen bemerkt: "Geh nie mit dem Kopf durch die Wand!“ Diese Passage sollte wohl laut TS ${ }^{8}$ den Schluss des Stückes bilden (vgl. die Ähnlichkeit des Schlusses in TS ${ }^{21}$ ). Die Konfiguration der ersten beiden Auftritte entspricht noch nicht der Endfassung von Mit dem Kopf durch die Wand (TS21), weshalb davon ausgegangen werden kann, dass $\mathrm{TS}^{8}$ vor $\mathrm{TS}^{20} / \mathrm{A}^{2}$ bzw. TS ${ }^{21}$ entstanden ist.

\section{$\mathrm{T}^{2}=0 ̈ \mathrm{LA} \mathrm{3/W} 67-\mathrm{BS} 53$ [3], Bl. 1, 1v, 2, 2v}

2 Blatt unliniertes Papier $(340 \times 210 \mathrm{~mm})$, hs. Eintragungen mit schwarzblauer Tinte $\mathrm{TS}^{9}=$ Prosaexposé zum 4. Akt (Korrekturschicht)

Bei TS9 ${ }^{9}$ handelt es sich um ein Prosaexposé zum vierten Akt. Dieser ist die wesentlichste Neuerung im Übergang von der Fassung in vier Akten mit dem Werktitel Das unbekannte Leben $\left(\mathrm{K}^{2} / \mathrm{TS}^{17}\right)$ und der Zwischenfassung mit dem Titel Falsche Komplexe $\left(\mathrm{K}^{3} / \mathrm{TS}^{4}\right) \mathrm{zu}$ der Endfassung mit dem Werktitel Mit dem Kopf durch die Wand (K $/ \mathrm{TS}^{21}$; 
vgl. auch die Übersichtsgrafik Tab ${ }^{1}$ im Kommentarteil dieses Bandes, S. 892-903). Mit TS $^{8}$ beginnt Horváth den Umbau des vierten Aktes, der laut TS ${ }^{9}$ erstmals im Büro Sempers spielt (vgl. den ersten Akt der ersten Endfassung von Das unbekannte Leben, $\left.\mathrm{K}^{2} / \mathrm{TS}^{16}\right)$.

Warum Horváth das Prosaexposé erstellte, darüber kann nur spekuliert werden. Möglicherweise wollte er sich selbst über den Verlauf des Aktes Gewissheit verschaffen, bevor er an dessen dramatische Ausarbeitung ging. Die darin erwähnten Handlungselemente, die sich noch nicht vollständig mit der Handlungsfolge des vierten Aktes von TS ${ }^{10} \mathrm{bzw}$. TS $20 / \mathrm{A}^{2}$ und TS ${ }^{21}$ decken, sprechen für eine relativ frühe Platzierung von $\mathrm{TS}^{9}$. So bittet Semper in $\mathrm{TS}^{9}$ die Mitarbeiter Bossards in sein Büro (vgl. TS ${ }^{8}$ ). Semper geht indes zuerst noch zur Bank, was sich in späteren Fassungen dieses Aktes nicht mehr findet. Dann taucht in TS $^{9}$ die Unbekannte auf, und es kommt zu einem Zwiegespräch mit Huelsen, der sich bei ihr für seine Verdächtigungen entschuldigt. Schließlich erscheinen Bossard und seine Mitarbeiter, und Semper kehrt zurück, der ihnen vorwirft, einen "Schwindel“ (Bl. 1v) mit ihm getrieben zu haben, und ihnen polizeiliche Schritte androht (vgl. TS21/BS 53 [4], Bl. 6).

Eine Szene, in der Robert den Brief des Marquis an Semper übergibt, findet sich in der Endfassung von Mit dem Kopf durch die Wand (TS ${ }^{21}$ ) nicht mehr. Dort ist es eine Sekretärin, die ein "Telegramm“ des Marquis überbringt (vgl. ebd./BS 53 [4], Bl. 7). Semper erfährt aus dem Brief, dass der Marquis zu jedem "geldlichen 0pfer" (Bl. 1v) bereit sei, um die „ins Lebenrufung dieses Filmes“ (Bl. 1v, 2) zu verhindern. Er reagiert darauf paradox, indem er die Statisten wieder zu sich ruft und "die Vorbereitungen für diesen Film" (Bl. 2) sofort in Angriff nehmen will. Da niemandem "etwas brauchbares" einfällt, gibt die Unbekannte "die Erzählung des Marquis" als "eigene Idee“ (ebd.) zum Besten, worauf Huelsen von Semper aufgefordert wird, "ein szenisches Exposee mit Hilfe der Statisten zu improvisieren" (ebd.). Kurze Zeit später taucht der Marquis auf, von dem sich Semper große finanzielle Zuwendungen erhofft. Der Marquis behauptet jedoch, dass der durch Robert überbrachte Brief inzwischen „in den Voraussetzungen überholt“ (ebd.) sei. Semper bittet den Marquis, sich das Geprobte anzusehen. Der Marquis ist begeistert davon und der "erwartete Widerstand [...] unterbleibt" (ebd.). Semper kann sich nur mit einer weiteren Finte behelfen. Er erklärt plötzlich sein "Desinteressement" (ebd.) an dem Film, worauf der Marquis sich dazu verpflichtet, ihn zu finanzieren. Der Marquis will sich mit dem Film "ein Spiegelbild schaffen“, um von "diesen falschen Komplexen geheilt zu werden" (vgl. TS1, TS4 und TS5), von jener "Wahnidee", die ihm "30 Jahre [s]eines Lebens gestohlen hat" (Bl. 2). Semper wird daraufhin ungehalten, denn das sei seines Erachtens nicht die Aufgabe des Filmes. Der Marquis hält aber daran fest, dass der Film dazu da sei, "dem Menschen ein Spiegel zu sein in dem er all seine schlechten, verborgenen, geheimen Regungen sieht" (Bl. 2v). Die Nähe dieser Vorstellung zu dem, was Horváth in der Gebrauchsanweisung vom Theater verlangt, zeigt, dass er dem Film und dem Theater ähnliche Aufgaben zuweist (vgl. Horváth 2009, S. 161-163). 


\section{$\mathrm{H}^{6}=$ ÖLA 3/W 65 - BS 53 [1], Bl. 4, 5v, 7, 8, 13, 14}

Insgesamt 6 Blatt, davon 3 Blatt unliniertes Papier $(286 \times 221 \mathrm{~mm})$, dünn, und 3 Blatt unliniertes Papier $(340 \times 210 \mathrm{~mm})$, schwarzblaue Tinte

$\mathrm{TS}^{10}=$ fragm. Fassung des IV. Aktes, konstituiert durch BS 53 [1], Bl. 4, 5v, 7, 8, 13, 14 (Korrekturschicht)

$\mathrm{E}^{9}=$ Werktitel (Bl. 8 oben)

Die Zusammengehörigkeit der vorliegenden Blätter erschließt sich nicht materiell, sondern inhaltlich. Mit TS ${ }^{10}$ arbeitet Horváth den vierten Akt fast vollständig aus und verändert ihn maßgeblich gegenüber TS ${ }^{9}$. Der vierte Akt in der Fassung in fünf Akten von Das unbekannte Leben $\left(\mathrm{K}^{2} / \mathrm{TS}^{16}\right)$ spielt "[b]eim Marquis", der vierte der Fassung in vier Akten von Das unbekannte Leben $\left(\mathrm{K}^{2} / \mathrm{TS}^{17}\right)$ im "Hotel Terminus"; der mit TS ${ }^{10}$ vorliegende vierte Akt ist aber "[b]ei Semper" (vgl. auch TS ${ }^{9}$ ) lokalisiert, wodurch klar wird, dass es sich dabei um eine Ausarbeitung zu K³ , Mit dem Kopf durch die Wand, handelt. Ein weiteres Indiz dafür sind die auf Bl. 4 eingetragenen Seitenzahlen. Mit ihnen verweist Horváth auf das Regie- und Soufflierbuch des Max Pfeffer Verlags, das in der Grundschicht $\mathrm{K}^{2} / \mathrm{TS}^{17}$ bildet. Aus diesem übernimmt Horváth mit Hilfe der eingetragenen Seitenzahlen einiges unverändert in $\mathrm{TS}^{10}$ und später in $\mathrm{TS}^{20} / \mathrm{A}^{2}$.

Der Autor plant laut TS ${ }^{10}$ zunächst eine Szene, in der Huelsen alleine ist. Diese wird in der Endfassung von Mit dem Kopf durch die Wand (TS ${ }^{21}$ ) gleich in den 1. Auftritt (mit Bossard) verlegt. Dieser zeigt zunächst nur den am Schreibtisch sitzenden Huelsen und dann, wie in TS ${ }^{10}$, den dazukommenden Bossard. Der Dialog zwischen Huelsen und Bossard, wie er in TS 10 ausgearbeitet wird, ähnelt bereits stark dem 1. Auftritt von TS20/A2 bzw. TS 21 . Der 3. Auftritt zeigt, wie der zweite von TS20/A² bzw. TS'21, Huelsen, Bossard und Semper. Horváth folgt darin, wie eine Notiz erkennen lässt, dem Dialog von "S. 80" von $\mathrm{K}^{2} / \mathrm{TS}^{17}$, der Stammbuch-Fassung. Im 4. Auftritt von TS ${ }^{10}$ figurieren, wie im 3. von TS ${ }^{21}$, Huelsen und die Unbekannte, die durch die Tapetentüre erschienen ist. Horváth folgt darin "S. 82/83/84" von $\mathrm{K}^{2} / \mathrm{TS}^{17}$. Im 5. Auftritt sind Huelsen, die Unbekannte, Semper und Bossard anwesend. Er entspricht dem 4. von TS ${ }^{21}$ mit dem in $\mathrm{TS}^{10}$ notierten Hinweis auf die Statistenrollen Bossards, dem "Oberkellner in ,Flammende Begierde" und dem "stummen Oberstleutnant in des ,Königs Husaren "' (Bl. 4; vgl. auch $\mathrm{K}^{2} / \mathrm{TS}^{16} / \mathrm{BS} 71, \mathrm{Bl} .101$, TS${ }^{17} / \mathrm{BS}$ 52, Bl. 88 und $\mathrm{K}^{3} / \mathrm{TS}^{21} / \mathrm{BS} 53$ [4], Bl. 6). Die Pointe "Stumm in einem Tonfilm!", die sich auch in TS21/BS 53 [4], Bl. 6 findet, entwickelt Horváth in TS ${ }^{10}$. Der 5. Auftritt wird mit Bl. 5v fortgesetzt. Der hier folgende Dialog zwischen den vier genannten Figuren entspricht über weite Strecken jenem von TS ${ }^{21}$. Der 6. Auftritt zeigt den Diener Jean, der einen Brief des Marquis überbringt (vgl. TS ${ }^{9}$ ). Er wird in $\mathrm{TS}^{21}$ durch eine Sekretärin ersetzt, die ein Telegramm abgibt. Darin bittet der Marquis Semper, den Film über die Unbekannte nicht zu machen. Es folgt die Diskussion über das Exposé der Unbekannten und die Frage, ob dieses "miserabel“ sei oder nicht. Die Unbekannte spricht sich für Ersteres aus, behauptet aber, jetzt die wahre Geschichte der Unbekannten zu kennen (vgl. TS ${ }^{9}$ ). Horváth arbeitet diesen Teil des Auftritts in der zweiten Variante aus, die er auf Bl. 8 am rechten Rand notiert.

Ebenfalls auf Bl. 8 befinden sich zwei Werktitelentwürfe. Zunächst notiert Horváth in $\mathrm{E}^{9}$ den Titel "Mit dem Kopf durch die Wand / Komödie in einem Vorspiel und vier Akten“. Im Gegensatz zu E ${ }^{6}$ streicht er diesen nun nicht mehr. Er dürfte also ab TS $^{10}$ bzw. E ${ }^{9}$ Gültigkeit für den Autor haben (vgl. auch die Titeländerung auf dem 
Kartonumschlag von $\mathrm{T}^{1}=\mathrm{TS}^{4}$ bzw. $\mathrm{TS}^{21}$ ). Die Strukturierung in ein Vorspiel und vier Akte entspricht wahrscheinlich TS ${ }^{10}$, in der Horváth den neuen vierten Akt ausgearbeitet hat (vgl. auch $\mathrm{E}^{6}$ und $\mathrm{E}^{8}$, in denen noch von fünf Akten die Rede ist). In der Endfassung von Mit dem Kopf durch die Wand (TS ${ }^{21}$ ) findet sich indes kein Vorspiel mehr - möglicherweise ist dieses verloren gegangen -, sondern nur noch eine Strukturierung in vier Akte (vgl. die Kommentare zu TS ${ }^{4}$ und zu TS ${ }^{21}$ ). Der zweite Titeleintrag von Bl. 8 betrifft das Werkprojekt Figaro läßt sich scheiden (1936; vgl. WA 8). Horváth notiert hier den Titel von WA $8 / \mathrm{VA}^{2}$ "Die Hochzeit des Figaro in unserer Zeit". Möglicherweise handelt es sich dabei um die früheste Niederschrift dieses Titels.

\section{$\mathrm{H}^{7}=$ ÖLA 3/W 65 - BS 53 [1], Bl. 12}

1 Blatt unliniertes Papier $(340 \times 210 \mathrm{~mm})$, schwarzblaue Tinte $\mathrm{TS}^{11}$ = Fassung des 4. Auftritts des IV. Aktes (links; Grundschicht) $\mathrm{TS}^{12}$ = fragm. Fassung eines Auftritts (rechts oben und mittig; Korrekturschicht) $\mathrm{TS}^{13}$ = fragm. Fassung eines Auftritts (rechts unten; Korrekturschicht)

Mit den vorliegenden Textstufen arbeitet Horváth mehrere Auftritte des Schlussaktes neu aus. In TS ${ }^{11}$ skizziert er einen neuen 4. Auftritt des vierten Aktes zwischen der Unbekannten und Huelsen (vgl. TS ${ }^{10}$ ). Wahrscheinlich wollte Horváth mit dem in TS ${ }^{11}$ ausgearbeiteten Dialog den bereits bestehenden zwischen der Unbekannten und Huelsen ergänzen. Dieser bildet in Das unbekannte Leben (K2/TS ${ }^{16}$ und $\mathrm{TS}^{17}$ ) den 5. und 6. Auftritt des fünften Aktes und in der Endfassung von Mit dem Kopf durch die Wand $\left(\mathrm{K}^{3} / \mathrm{TS}^{21}\right)$ den dritten Auftritt des vierten Aktes. Damit modifiziert Horváth zugleich $\mathrm{TS}^{10}$, in der im Wesentlichen eine simple Wiederaufnahme des Auftritts aus $\mathrm{K}^{2} / \mathrm{TS}^{17}$ vorgesehen war. Allerdings hatte Horváth bereits in TS ${ }^{10}$ eine kurze Dialogskizze notiert, wieder gestrichen und noch einmal für gültig erklärt, in der der Begriff "Vergebung" fällt. In TS ${ }^{11}$ arbeitet er diese Notiz weiter aus. Hier ist es nun die "Verzeihung", um die Huelsen bittet. Die letzte Replik der Unbekannten: „Beruhige Dich, es muss oft nichts passieren, damit etwas passiert. - -“ geht in ähnlicher Form, aber in eine andere Szene der Endfassung von Mit dem Kopf durch die Wand ein (vgl. TS21/BS 53 [4], Bl. 12).

Mit TS ${ }^{12}$ ist eine Szene zwischen Semper, der Unbekannten und dem Marquis gegeben, die ebenfalls für den Schlussakt vorgesehen ist und von der Teile in der Endfassung von Mit dem Kopf durch die Wand enthalten sind (vgl. TS21/BS 53 [4], Bl. 11f.), so etwa das Motiv der vertraglichen Bindung und die Replik der Unbekannten: „Marquis her, Marquis hin! Er ist doch ganz filmfremd!“ Mit TS ${ }^{13}$ arbeitet Horváth noch einmal eine Variante für den Schlussdialog aus (vgl. TS ${ }^{8}$ ). Auch hier steht das Motiv des Mit-dem-Kopf-durch-die-Wand-Gehens im Mittelpunkt (vgl. TS ${ }^{15}{ }^{-T S}{ }^{18}$ und TS21/BS 53 [4], Bl. 16).

\section{$\mathrm{H}^{8}=$ ÖLA 3/W $65-\mathrm{BS} 53$ [1], Bl. 11v}

1 Blatt unliniertes Papier $(340 \times 210 \mathrm{~mm})$, schwarzblaue Tinte $\mathrm{TS}^{14}=$ fragm. Fassung eines Auftritts (Korrekturschicht)

Ähnlich wie in TS ${ }^{11}$ feilt Horváth in TS ${ }^{14}$ noch einmal an der (Schlüssel-)Szene zwischen Huelsen und der Unbekannten. Möglicherweise wollte er die Szene, die er laut $\mathrm{TS}^{10}$ einfach aus $\mathrm{K}^{2} / \mathrm{TS}^{17}$ übernehmen wollte, nun doch noch einmal stärker modifi- 
zieren, als dies bereits in TS ${ }^{11}$ der Fall war. Dabei arbeitet Horváth einen Dialog zwischen den beiden aus, in dem es um die Frage des gegenseitigen Vertrauens geht, der sich in dieser Form aber nicht in der Endfassung von Mit dem Kopf durch die Wand (TS ${ }^{21}$ ) findet. Dort entscheidet sich Horváth, doch wieder auf die Fassungen der Szene in Das unbekannte Leben $\left(\mathrm{K}^{2} / \mathrm{TS}^{16}\right.$ und $\mathrm{TS}^{17}$ ) zurückzugreifen und die dort enthaltenen zwei Auftritte zu einem einzigen zusammenzulegen. Die Unbekannte erhält in TS ${ }^{14}$ erstmals den Vornamen "Susanne" (vgl. Figaro läßt sich scheiden, WA 8/ $\left.\mathrm{K}^{1}-\mathrm{K}^{4}\right)$, der im genetischen Konvolut zu dem Werkprojekt Mit dem Kopf durch die Wand nur noch einmal vorkommt (vgl. TS ${ }^{16}$ und das Vorwort in diesem Band, S. 344). Die Szene, die wahrscheinlich alternativ bzw. ergänzend zum 4. Auftritt des vierten Aktes von $\mathrm{TS}^{10}$ gedacht war, endet mit dem bereits in $\mathrm{K}^{2} / \mathrm{TS}^{16}$ und $\mathrm{TS}^{17}$ den Auftritt beschließenden Kuss zwischen den beiden, der auch in $\mathrm{K}^{3} / \mathrm{TS}^{21}$ am Ende der Szene zu finden ist.

\section{$\mathrm{T}^{3}=$ ÖLA 3/W $65-\mathrm{BS} 53$ [1], Bl. 17}

1 Blatt unliniertes Papier $(340 \times 210 \mathrm{~mm})$, hs. Eintragungen mit Bleistift

$\mathrm{TS}^{15}$ = fragm. Fassung eines Vorworts mit Werktitel "Ödön von Horváth: / Mit dem Kopf durch die Wand" (Korrekturschicht)

Mit TS ${ }^{15}$ arbeitet Horváth die wahrscheinlich erste Fassung einer Art Vorwort oder Vorspiel (vgl. den Kommentar zu TS4, vgl. auch $\mathrm{E}^{6}$ ) zu seinem Werkprojekt Mit dem Kopf durch die Wand aus (vgl. auch TS ${ }^{16}-\mathrm{TS}^{18}$ ). Dieses dürfte er jedoch in der Folge wieder fallen gelassen haben, oder aber man hat davon auszugehen, dass TS ${ }^{21}$ nur fragmentarisch überliefert ist. Den Kopf des Blattes tippt Horváth mit Schreibmaschine, dann setzt er jedoch handschriftlich fort. Der Text geht von der Prämisse aus, dass "jeder von uns" wohl bereits einmal "durch eine Wand“ gewollt habe, und schließt mit der Feststellung: "Doch wo es Wände gibt, gibt es auch Türen“, die ohne abschließendes Satzzeichen notiert ist, was auf die Fragmentarität der Ausarbeitung schließen lässt.

\section{$\mathrm{H}^{9}=$ ÖLA 3/W $65-\mathrm{BS} 53$ [1], Bl. 18}

1 Blatt unliniertes Papier $(340 \times 210 \mathrm{~mm})$, Bleistift $\mathrm{TS}^{16}=$ fragm. Fassung eines Vorworts (Korrekturschicht)

TS ${ }^{16}$ dürfte nach TS ${ }^{15}$ entstanden sein. Möglicherweise war TS ${ }^{16}$ auch als Fortsetzung von TS ${ }^{15}$ gedacht. Der Erzähler spricht hier von der "Beschaffenheit" der Wände (vgl. $\mathrm{TS}^{18}$ ), davon, dass es "verschiedene Wände“ gebe, solche, die man "selbst erbaut" habe und andere. Während man für Erstere jemand "zweiten“ braucht, um durch zu kommen, ist dies bei Letzteren offensichtlich nicht der Fall. Vom Marquis de Bresançon sagt der Erzähler, dass er "nicht gegen Wände rennen“ könne, "denn er sieht nicht nur die Türen nicht, hat überhaupt vergessen, dass er einen Schlüssel hatte, selbst absperrte - er sieht auch die Wände nicht". Von "Susanne“, der Unbekannten, die hier zum zweiten und letzten Mal mit diesem Namen versehen wird (vgl. TS ${ }^{14}$ und das Vorwort in diesem Band, S. 344), heißt es, dass sie gegen die Wand renne, durch die sie zwar nicht durch komme, die ihr jedoch ausweiche. Dies kommentiert der Erzähler mit folgenden Worten: "War ihre Wand eine Wand oder nur eine Fata morgana? Ich weiss es nicht.“ Zuletzt notiert Horváth: „Es steht aber fest, dass wenn überhaupt, dass man dann nur mit dem Kopf durch eine Wand kommt - -“. Damit bricht 
die Ausarbeitung ab. Ein Teil der Wendungen von $\mathrm{TS}^{16}$ wandert weiter in $\mathrm{TS}^{17}$ und $\mathrm{TS}^{18}$.

\section{$\mathrm{H}^{10}=$ ÖLA 3/W $65-\mathrm{BS} 53$ [1], Bl. 19}

1 Blatt unliniertes Papier $(340 \times 210 \mathrm{~mm})$, schwarzblaue Tinte und Bleistift

$\mathrm{TS}^{17}$ = fragm. Fassung eines Vorworts mit Werktitel "Mit dem Kopf durch die Wand” (Korrekturschicht)

Auf dem vorliegenden Blatt arbeitet Horváth neuerlich eine Fassung des Vorworts oder Vorspiels zu seinem Werkprojekt Mit dem Kopf durch die Wand aus (vgl. E ${ }^{6}, \mathrm{TS}^{15}$, $\mathrm{TS}^{16}$ und TS ${ }^{18}$ sowie den Kommentar zu TS${ }^{4}$ ). Diese nimmt Teile von TS ${ }^{15}$ und TS ${ }^{16}$ wieder auf. So etwa den Eröffnungssatz, der wie in TS ${ }^{15}$ direkt an den Titel anschließt: "Mit dem Kopf durch die Wand zu wollen, ist weder ungefährlich noch angenehm." Die Passage über die Türen von TS 15 ändert Horváth dahingehend, dass, wer durch die Wand wolle, die Türen offensichtlich nicht sehe. Manchmal sei es ja nur eine "Tapetentüre“ (vgl. TS21/BS 52, Bl. 53 et passim), manchmal habe das "Schloss" "einen geheimen Mechanismus, manchmal hat man den Schlüssel verlegt [...] und krachbumm! Schon rennt man mit dem Kopf gegen die Wand“. Mit diesen Zeilen bricht TS ${ }^{17}$ ab. Die darunter notierte Fortsetzung: „Dass man mit dem Kopf durch die Wand wirklich durchkommt, dazu muss die Wand morsch sein, d.h. man muss Glück haben“, streicht Horváth wieder. Sie könnte in Zusammenhang stehen mit Huelsens auf die Unbekannte gemünzter Replik: „Dein hemmungsloses Vertrauen zum eigenen Glück wird dich nochmal ins Unglück stürzen!“ (TS21/BS 52, Bl. 35).

\section{$\mathrm{H}^{11}=$ ÖLA 3/W $369-0 . \mathrm{BS}, \mathrm{Bl} .43,42,41 \mathrm{v}$}

3 Blatt des Notizbuchs Nr. 2 mit orangefarbenem Kartoneinband, kariertes Papier $(165 \times 99 \mathrm{~mm})$, schwarzblaue Tinte

$\mathrm{TS}^{18}$ = fragm. Fassung eines Vorworts mit Werktitel „Mit dem Kopf durch die Wand“ (Grundschicht)

Im Notizbuch Nr. 2, das Horváth im Jahr 1935 verwendet hat, finden sich Eintragungen zu Figaro läßt sich scheiden, aber auch zu wenig ausgearbeiteten Werkprojekten wie Ein Wunschtraum und Walzertraum. Bei TS ${ }^{18}$ handelt es sich vermutlich um die am stärksten ausgereifte Fassung eines Vorworts (oder Vorspiels) zu Mit dem Kopf durch die Wand (TS'1). Die Wiederaufnahme des Motivs der "Beschaffenheit" der Wand deutet auf eine genetische Reihung nach TS ${ }^{16}$, in der dieses Motiv erstmals erwähnt wird. Ob dieses oder irgendein Vorwort bei der Uraufführung des Stückes im Theater Scala in Wien verwendet wurde, kann nicht mit Sicherheit gesagt werden.

\section{$\mathrm{H}^{12}=$ ÖLA 3/W $369-0 . \mathrm{BS}, \mathrm{Bl} .43 \mathrm{~V}$}

1 Blatt des Notizbuchs Nr. 2 mit orangefarbenem Kartoneinband, kariertes Papier $(165 \times 99 \mathrm{~mm})$, schwarzblaue Tinte

$\mathrm{TS}^{19}=$ fragm. Fassung eines Auftritts (Grundschicht)

Der ebenfalls im Notizbuch Nr. 2 (vgl. den Kommentar zu TS ${ }^{18}$ ) eingetragene kurze Dialog zwischen der Unbekannten und dem Marquis findet sich so in keiner der überlieferten Endfassungen von Das unbekannte Leben $\left(\mathrm{K}^{2} / \mathrm{TS}^{16}\right.$ und $\left.\mathrm{TS}^{17}\right)$ und Mit dem Kopf durch die Wand $\left(\mathrm{K}^{3} / \mathrm{TS}^{21}\right)$. Allerdings taucht die hier dem Marquis zugewiesene 
Replik in der ähnlichen Form "Es muss nichts passieren, damit etwas passiert" in TS11 und TS'21/BS 53 [4], Bl. 12 auf, in denen sie von der Unbekannten geäußert wird. Möglicherweise ist TS ${ }^{19}$ auch nach TS $20 / \mathrm{A}^{2}$ bzw. TS ${ }^{21}$ entstanden und wurde ergänzend zu der fertigen Endfassung von Mit dem Kopf durch die Wand verfasst.

\section{$\mathrm{T}^{4}=$ ÖLA 3/W 68 - BS 53 [4], Bl. 1-16}

16 Blatt unliniertes Papier $(290 \times 226 \mathrm{~mm})$, hs. Eintragungen mit Bleistift, schwarzer und schwarzblauer Tinte, hs. Eintragungen mit Bleistift von fremder Hand (Dramaturgie Theater Scala), Paginierung 1-16

$\mathrm{TS}^{20} / \mathrm{A}^{1}=$ fragm. Fassung des IV. Aktes, konstituiert durch BS 53 [4], Bl. 1-14 (nicht gedruckt) $\mathrm{TS}^{20} / \mathrm{A}^{2}$ = Fassung des IV. Aktes, konstituiert durch BS 53 [4], Bl. 1-16 (gedruckt als Teil von TS ${ }^{21}$ )

TS20/A ${ }^{1}$ reicht nur bis Bl. 14. Auf der unteren Hälfte des Blattes nimmt Horváth großflächige Streichungen vor, und ersetzt den dort bereits ausgearbeiteten Schluss in $\mathrm{A}^{2}$ durch $\mathrm{Bl} .15$ und 16. Mit TS ${ }^{20} / \mathrm{A}^{2}$ erstellt Horváth die letztgültige Fassung des vierten Aktes, des Schlussaktes seines Werkprojekts Mit dem Kopf durch die Wand. Wahrscheinlich enthielt die Zwischenfassung Falsche Komplexe (TS4) bereits einen anderen vierten Akt als die beiden Fassungen von Das unbekannte Leben ( $\mathrm{K}^{2} / \mathrm{TS}^{16}$ und $\mathrm{TS}^{17}$ ), in denen der Schlussakt (der fünfte bzw. vierte Akt) jeweils im "Hotel Terminus" angesiedelt ist. Mit TS ${ }^{8}$ begann die Überarbeitung des Schlussaktes, der seit TS ${ }^{9}$ und TS ${ }^{10}$ definitiv im Büro Sempers spielen soll. Dass TS ${ }^{20} / \mathrm{A}^{1}$ und $\mathrm{A}^{2}$ nach TS ${ }^{4}$ zu verorten sind, lässt sich anhand mehrerer Textstellen belegen, in denen Horváth handschriftliche Korrekturen, die er im Regie- und Soufflierbuch vermutlich im Rahmen von TS ${ }^{4}$ einträgt, in TS'0/ $\mathrm{A}^{1}$ und $\mathrm{A}^{2}$ bereits in der maschinenschriftlichen Grundschicht realisiert. Die mit einiger Sicherheit im Rahmen von TS4/BS 52, Bl. 79 (vgl. TS21/BS 53 [4], Bl. 2) eingefügte Replik Huelsens: „Unsere Unbekannte sagte mal, man könnte von Ihnen lernen - es stimmt!“ ist in TS20/A² bzw. TS $21 / B S 53$ [4], Bl. 2 in ganz ähnlicher Form schon in der maschinenschriftlichen Grundschicht vorhanden. Auch der handschriftlich hinzugefügte "kühn[e] Vorstoss in das Reich der 4. Dimension" von TS4/BS 52, Bl. 80 kehrt in TS $20 / A^{2}$ bzw. TS²1/BS 53 [4], Bl. 3 als "kühner Vorstoss ins Jenseits, so ungefähr die vierte Dimension als Rahmenhandlung zu einem handfesten Reisser --“ bereits in der maschinenschriftlichen Grundschicht wieder.

Horváth hat die Fassungen von $\mathrm{TS}^{20} / \mathrm{A}^{1}$ bzw. $\mathrm{A}^{2}$ zunächst maschinenschriftlich ausgearbeitet und dann handschriftlich überarbeitet. Außerdem weist das Typoskript Korrekturen und Streichungen mit Bleistift von fremder Hand auf. Es handelt sich dabei um Eingriffe des Regisseurs oder Dramaturgen des Theaters Scala, an dem die Uraufführung des Stückes stattfand (vgl. die Kommentare $\mathrm{zu} \mathrm{K}^{2} / \mathrm{TS}^{17}, \mathrm{~K}^{3} / \mathrm{E}^{7}$ und das Vorwort in diesem Band, S. 346-348). Die Eintragungen von fremder Hand werden in der Transkription von TS ${ }^{20} / \mathrm{A}^{2}$ im Rahmen von TS ${ }^{21}$ im kritischen Apparat ausgewiesen. Gemeinsam mit den ersten drei Akten von $\mathrm{TS}^{4}$ wird aus $\mathrm{TS}^{20} / \mathrm{A}^{2}$ die Gesamtfassung TS ${ }^{21}$ als Endfassung von Mit dem Kopf durch die Wand konstituiert. Die Komödie Mit dem Kopf durch die Wand ist einzig in dieser kompilierten Form überliefert. 


\section{$\mathrm{T}^{5}=$ ÖLA 3/W 64 - BS 52, Bl. 1-74, 0̈LA 3/W 68 - BS 53 [4], Bl. 1-16 (vgl. K³/T und $\mathrm{T}^{4}$ )}

Insgesamt 90 Blatt, davon 74 Blatt unliniertes Papier $(285 \times 225 \mathrm{~mm})$, Durchschlag, gelocht (= Regie- und Soufflierbuch des Max Pfeffer Verlags, Wien 1935, grüne Mappe mit Aufschrift „Mit dem Kopf durch die Wand / von / Oedön von Horvath“, Grundschicht: „Das unbekannte Leben“, erste Korrektur: „Falsche Komplexe“), und 16 Blatt unliniertes Papier $(290 \times 226 \mathrm{~mm})$, hs. Eintragungen mit Bleistift, schwarzer und schwarzblauer Tinte, hs. Eintragungen mit Bleistift von fremder Hand (Dramaturgie Theater Scala), Paginierung 3-74 auf BS 52, Bl. 3-74, Paginierung 1-16 auf BS 53 [4], Bl. 1-16

$\mathrm{TS}^{21}$ = fragm. Endfassung in 4 Akten mit Werktitel "Mit dem Kopf durch die Wand / Komödie in einem Vorspiel und vier Akten von Oedön von Horvath“, konstituiert durch BS 52, Bl. 1-74 und BS 53 [4], Bl. 1-16 (Korrekturschicht: Bleistift, schwarze und schwarzblaue Tinte)

Druck in: GW II, S. 325-400.

TS $^{21}$ wird aus den ersten drei Akten der Zwischenfassung Falsche Komplexe (TS4), die im Regie- und Soufflierbuch des Max Pfeffer Verlags vorliegt (vgl. auch die Kommentare $\mathrm{zu} \mathrm{K}^{2} / \mathrm{TS}^{17}$ und $\mathrm{K}^{3} / \mathrm{TS}^{4}$ ), und dem vierten Akt, der mit TS ${ }^{20} / \mathrm{A}^{2}$ gegeben ist, konstituiert. Wahrscheinlich hat Horváth seine Komödie nach der Annahme durch den Direktor des Wiener Theaters Scala, Rudolf Beer noch einmal überarbeitet (vgl. den Brief vom 22. Oktober 1935; vgl. die Kommentare $\mathrm{zu} \mathrm{K}^{2} / \mathrm{TS}^{17}$ und $\mathrm{K}^{3} / \mathrm{TS}^{4}$ sowie das Vorwort zu diesem Band, S. 335 und 342). Aus diesem Überarbeitungsprozess ist nicht nur die Zwischenfassung TS${ }^{4}$, sondern letztlich auch die Endfassung Mit dem Kopf durch die Wand TS ${ }^{21}$ zustande gekommen. Beer war noch ein Stück mit dem Titel Das unbekannte Leben vorgelegen (wahrscheinlich die Grundschicht des Regie- und Soufflierbuchs des Max Pfeffer Verlags, $\mathrm{K}^{2} / \mathrm{T}^{11}=\mathrm{K}^{2} / \mathrm{TS}^{17}$ ), auf dessen Grundlage Horváth die Zwischenfassung TS ${ }^{4}$ und dann die Endfassung TS ${ }^{21}$ herstellte. Auf dem Kartonumschlag von $\mathrm{K}^{3} / \mathrm{T}^{1}=\mathrm{TS}^{4}$ lässt sich dieser genetische Prozess deutlich nachvollziehen, denn der Titel wurde dort durch den Autor zunächst von "Das unbekannte Leben“ zu "Falsche Komplexe“ und dann zu "Mit dem Kopf durch die Wand” geändert.

Auch die Eintragungen im Figurenverzeichnis (Bl. 2) weisen auf diesen Rezeptions- und Überarbeitungszusammenhang hin, denn dort sind sowohl Schauspielernamen von fremder Hand (wahrscheinlich von Rudolf Beer oder einem Dramaturgen) als auch von Horváths Hand (später) nachweisbar. Außerdem hat Horváth die Zahl der Figuren im Vergleich zu Das unbekannte Leben ( $\mathrm{K}^{2} / \mathrm{TS}^{16}$ und $\mathrm{TS}^{17}$ ) wesentlich verringert: Die prominentesten Streichungen betreffen die Schauspielerin und Drehbuchautorin Barbou bzw. Simone, den Drehbuchautor Hell, den Regisseur Mayberg, die Schauspielerin Claire Carry und den Boxer Jack Traverson (vgl. die Kommentare zu $\mathrm{TS}^{4}$ sowie zu TS ${ }^{20} / \mathrm{A}^{1}$ und $\mathrm{A}^{2}$ ). Dementsprechend musste Horváth auch den Schluss seines Stückes ändern, in dem kein Drehbuch mit dem Titel "Der Unbekannte der Seine“ für den Boxer Traverson mehr geschrieben werden kann (vgl. K²/TS ${ }^{16} / B S$ 71, Bl. 106 und TS 17 /BS 52, Bl. 93). Stattdessen wird dort auf den Titel des Stückes "Mit dem Kopf durch die Wand" angespielt (vgl. die Genese dieses Schlusses in TS ${ }^{8}$ und $\mathrm{TS}^{13}$ ). Die nachträglich im Stammbuch handschriftlich hinzugefügten Figuren des Notars und des Elektrotechnikers, von denen nur Letzterer von Horváth wieder gestrichen wird, kommen in der Endfassung von TS ${ }^{21}$ nicht mehr vor. Dementsprechend wird der Notar im Figurenverzeichnis der vorliegenden Fassung getilgt.

Der Titel der vorliegenden Endfassung TS ${ }^{21}$ wird gemäß dem Kartonumschlag von $\mathrm{K}^{3} / \mathrm{T}^{1}$ im Text (Bl. 1) emendiert. Er entspricht auch einigen Entwürfen und Textstu- 
fen von $\mathrm{K}^{3}\left(\mathrm{E}^{6}, \mathrm{E}^{9}, \mathrm{TS}^{15}\right.$ und $\left.\mathrm{TS}^{17}\right)$. Traugott Krischke nimmt an, dass es sich bei dem zum Gattungstitel handschriftlich notierten "Vorspiel“ um den ersten Akt von TS21 handelt (vgl. KW 7, S. 450), dann würden dem aber nur noch drei Akte folgen und der von Horváth in der Grundschicht vermerkte Untertitel wäre falsch, was aufgrund der sonst relativ genauen Korrekturen unwahrscheinlich ist. Vielmehr ist anzunehmen, dass in der Uraufführung ein Vorspiel gegeben wurde, das wahrscheinlich nicht mehr vorliegt, zu dem aber TS ${ }^{15}$-TS $^{18}$ Vorstufen bilden könnten. Eventuell bezieht sich der Eintrag "Vorspiel" auch nur auf die Zwischenfassung und hat für die Endfassung TS'21, zu der der vierte Akt von TS20/A² gehört, keine Gültigkeit mehr. Die handschriftlich eingetragenen Nummerierungen der Figuren, die eine Umstellung des Personals bewirken würden, lassen vermuten, dass in diesem nicht überlieferten "Vorspiel“ der Marquis, der Gärtner Bientôt und der Diener Jean hätten auftreten sollen, da diese mit den Nummern 1 bis 3 versehen werden. Die Umstellung der Figuren im Figurenverzeichnis wird in TS ${ }^{21}$ nicht realisiert und die Nummern vor den Figurennamen werden gestrichen, weil diese offensichtlich auf das nicht vorhandene Vorspiel (vgl. auch den Kommentar zu TS4) bezogen sind.

Da nicht eindeutig ist, welches Vorspiel TS $^{21}$ zuzurechnen ist, wird die mit TS21 konstituierte Fassung ohne Vorspiel ediert. Aus demselben Grund werden der Untertitel und das im Untertitel nachträglich eingefügte "Vorspiel“ in der Transkription gestrichen. Auch die Zeitangabe muss emendiert werden, da die handschriftlich eingefügte Angabe: „Vorspiel - Dritter Akt: Vom Nachmittag bis zum nächsten Morgen. Vierter Akt: Ein Jahr später", die die in der Grundschicht notierte Zeitspanne: „Vom Nachmittag bis zum nächsten Morgen" ersetzen sollte, für den in TS ${ }^{21}$ aus den ersten drei Akten von TS ${ }^{4}$ und dem vierten Akt von TS20/A ${ }^{2}$ konstituierten Text keinen Sinn ergibt. Der mit TS ${ }^{20} / \mathrm{A}^{2}$ gegebene vierte Akt spielt nämlich am nächsten Morgen und nicht "[e]in Jahr später", wie etwa Bossards Nachfrage nach dem am Vorabend stattgefundenen "Ball“ (vgl. TS²1/BS 53 [4], Bl. 1) belegt. Die handschriftlich eingefügte Zeitangabe lässt vermuten, dass es neben $\mathrm{TS}^{20} / \mathrm{A}^{2}$ einen anderen vierten Akt gab, der tatsächlich ein Jahr später angesiedelt war und zu TS4 gehört haben dürfte (vgl. auch den Kommentar dort). Ein solcher ist aber in dem vorliegenden Nachlassmaterial nicht erhalten. In jener rekonstruierten Fassung, die sowohl das Vorspiel als auch den geänderten vierten Akt enthalten haben muss, dürften auch der Elektrotechniker und der Notar vorgekommen sein, weshalb diese im Figureninventar von TS ${ }^{21}$ aufscheinen. (Für weitere Unterschiede zwischen den Endfassungen von Das unbekannte Leben $\left(\mathrm{K}^{2} / \mathrm{TS}^{16}\right.$ und $\left.\mathrm{TS}^{17}\right)$, der Zwischenfassung Falsche Komplexe $\left(\mathrm{K}^{3} / \mathrm{TS}^{4}\right)$ und der Endfassung von Mit dem Kopf durch die Wand ( $\left.\mathrm{K}^{3} / \mathrm{TS}^{21}\right)$ vgl. die Übersichtsgrafik Tab ${ }^{1}$ im Kommentarteil dieses Bandes, S. 892-903.) Unregelmäßige Zeichenabstände werden in TS $^{21}$ stillschweigend emendiert. Die Zahl der Bindestriche wird vereinheitlicht, ein und zwei Bindestriche werden zu einem Doppelbindestrich emendiert, drei und vier Bindestriche zu zwei Doppelbindestrichen mit einem Leerzeichen dazwischen. Die Eintragungen von fremder Hand mit Bleistift im Typoskript des vierten Aktes $\left(\mathrm{TS}^{20} / \mathrm{A}^{2}\right.$ ) werden in der Transkription von TS ${ }^{21}$ abgebildet, aber als separate Korrekturschicht gewertet, die nicht in die Textkonstitution von TS ${ }^{21}$ eingeht.

Die Nähe von Das unbekannte Leben (K²/TS ${ }^{16}$ bzw. TS ${ }^{17}$ ) und Mit dem Kopf durch die Wand $\left(\mathrm{K}^{3} / \mathrm{TS}^{21}\right)$ zu Frank Wedekinds Tragödie Die Büchse der Pandora (1902), später Lulu, wurde bereits angedeutet (vgl. die Kommentare zu VA/TS 1 und $\mathrm{K}^{2} / \mathrm{E}^{12}$ ). Schon der Name der Filmgesellschaft, deren Direktor Semper ist, Pandora, legt diese Fährte (vgl. zur Genese des Namens den Kommentar $\mathrm{zu} \mathrm{K}^{2} / \mathrm{E}^{12}$ ). Aus der Büchse der Pandora 
der griechischen Mythologie kommt alles Mögliche, aber nichts Richtiges, genauso wenig wie - so die Assoziation - aus Sempers Filmgesellschaft, denn "der Film ist das dümmste was es überhaupt nur gibt" ${ }^{\prime \prime}$ wie Direktor Semper in der ersten Endfassung von Das unbekannte Leben verkündet (vgl. $\left.\mathrm{K}^{2} / \mathrm{TS}^{16} / \mathrm{BS} 71, \mathrm{Bl} .7\right)$. Aber auch die Namen der Figuren in Horváths Komödien weisen große Ähnlichkeiten zu Wedekinds Tragödie auf: Bei Wedekind gibt es einen Alwa Schön, der Schriftsteller ist, und einen

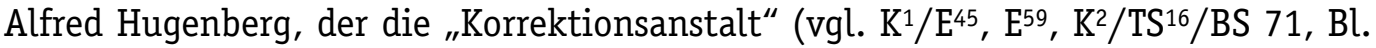
79, TS $^{17}$ und $\mathrm{K}^{3} / \mathrm{TS}^{21} / \mathrm{BS} 52, \mathrm{Bl}$. 64) leitet. Weiters findet sich bei Wedekind ein Dr. Hilt, der an Dr. Huelsen erinnert, und nicht zuletzt eine Ludmilla Steinherz, die als Ludmilla Steinmeyer in VA/E ${ }^{6}$ auftaucht. Auch eine Verwandtschaft der Unbekannten, des "Gespenst[es]“ (K³/TS²1/BS 52, Bl. 22), mit Wedekinds Erdgeist Lulu ist anzunehmen. Nicht zuletzt ist der Handlungsort teilweise derselbe, nämlich Paris.

\section{$\mathrm{H}^{13}=$ ÖLA 3/W $65-$ BS 53 [1], Bl. 16}

1 Blatt unliniertes Papier $(340 \times 210 \mathrm{~mm})$, schwarzblaue Tinte

$\mathrm{E}^{10}=$ Dialogskizze (ganz oben)

$\mathrm{E}^{11}=$ Notizen (oben)

$E^{12}=$ Notiz (mittig)

Die Entwürfe auf dem vorliegenden Blatt dürfte Horváth relativ spät in der Genese von Mit dem Kopf durch die Wand notiert haben. Darauf weist vor allem der Eintrag „Das Lied - ,Mit dem Kopf durch die Wand' -“ in $\mathrm{E}^{11}$ hin. In E ${ }^{10}$ notiert Horváth zunächst eine kurze Dialogskizze zwischen der Unbekannten und Direktor Semper. Die Unbekannte soll darin unter anderem sagen: „Ehrenwort ist eine Seifenblase!“ Die Bedeutung des Begriffs "Ehrenwort" für die Werkprojekte Das unbekannte Leben und Mit dem Kopf durch die Wand ist durch zahlreiche Stellen belegt (vgl. etwa $\mathrm{K}^{2} / \mathrm{TS}^{16} / \mathrm{BS} 71$, Bl. 21, $36 \mathrm{f}$., und 92, TS ${ }^{17} / \mathrm{BS} 52$, Bl. 19f., $67 \mathrm{f}$., 72 und 78 sowie $\mathrm{K}^{3} /$ TS21/BS 52, Bl. 19f. und BS 53 [4], Bl. 2). Durch den Ausdruck "Seifenblase“ wird das adelige Ehrenwort jedoch von der Unbekannten neusachlich gebrochen und als Illusion ausgegeben. Die Stelle ist in keine der überlieferten Fassungen des Werkprojekts eingegangen. Es dürfte sich dabei um eine spontane Idee oder eine Ergänzung möglicherweise in Hinblick auf die Inszenierung des Stückes am Wiener Theater Scala handeln. Der Hinweis auf "Argentinien“ ist in allen Endfassungen nachweisbar, in denen Semper behauptet, eine Dame aus Argentinien habe ihm von Bossards großen Heilerfolgen erzählt, womit er aber Rio de Janeiro fälschlicherweise in Argentinien verortet (vgl. $\mathrm{K}^{2} / \mathrm{TS}^{16} / \mathrm{BS} 71, \mathrm{Bl} .95$ und 99, TS ${ }^{17} / \mathrm{BS}$ 52, Bl. 81 und 85f. sowie $\mathrm{K}^{3} / \mathrm{TS}^{21} / \mathrm{BS} 52$, Bl. 47, BS 53 [4], Bl. 4 und 6). In $\mathrm{E}^{10}$ bekräftigt die Unbekannte zuletzt, dass sie in Sempers nächstem Film spielen wolle.

$\mathrm{E}^{11}$ ist nicht nur aus genetischen Gründen interessant. Horváth notiert sich dazu Begriffe wie "Strophen", "Refrain“ und "Lied“, die ein Hinweis auf musikalische Einlagen in dem Stück sein dürften. Wahrscheinlich handelt es sich dabei um Notizen, die während der Probenarbeiten entstanden sind und die Anweisungen für die Regie oder die Schauspieler sein sollten. Weiters vermerkt Horváth in $\mathrm{E}^{11}$ eine Dialogskizze zwischen Semper und der Unbekannten, die mit den zuerst erwähnten Notizen in $\mathrm{Zu}$ sammenhang stehen dürfte, in der Semper fragt: "Was summen Sie da?" Und die Unbekannte antwortet, wie oben erwähnt: „Das Lied - ,Mit dem Kopf durch die Wand” -“. Krischke vermerkt im Nachwort zur Kommentierten Werkausgabe, dass der Uraufführung ein Chanson von Fritz Eckhardt - wohl das Lied Mit dem Kopf durch die 
Wand - mit Musik von Werner Michel beigegeben wurde (vgl. KW 7, S. 449 f.), das jedoch nicht überliefert ist (vgl. auch das Vorwort zu diesem Band, S. 346). Wahrscheinlich handelt es sich bei der Notiz in $\mathrm{E}^{11}$ um einen Verweis auf dieses Chanson.

Zuletzt trägt Horváth die fragmentarische und sehr kryptische Notiz $\mathrm{E}^{12}$ ein. Hier heißt es: „Nett, sehr nett - so inoffizielle Stimmung trotz offizieller“. Möglicherweise ist dies eine Notiz, die sich auf die generelle "Stimmung" in der Komödie Mit dem Kopf durch die Wand bzw. im realen Filmbusiness bezieht. Vielleicht hält Horváth dies auch als Devise für die ,Stimmung' der Inszenierung fest.

\section{$\mathrm{H}^{14}=$ ÖLA 3/W $241-$ BS 64 a, Bl. 1v}

1 Blatt unliniertes Papier $(341 \times 208 \mathrm{~mm})$, schwarzblaue Tinte $\mathrm{E}^{13}=$ gestrichene Replik

Auf dem vorliegenden Blatt befindet sich auf der Rectoseite ein Briefentwurf Horváths an das Kleine Theater in der Praterstraße in Wien, das am 4. Februar 1935 Horváths Volksstück Kasimir und Karoline zur österreichischen Erstaufführung brachte. Im November 1935 wurde das Stück am selben Theater wieder aufgenommen (vgl. WA 4, S. 12f.). Deshalb liegt die Vermutung nahe, dass das Blatt im November 1935 beschrieben wurde. Die auf der Versoseite eingetragene Replik des Marquis erwähnt das erst mit TS ${ }^{20} / \mathrm{A}^{1}$ und $\mathrm{A}^{2}$ bzw. TS ${ }^{21} / \mathrm{BS} 53$ [4], Bl. 7 nachgewiesene Telegramm, eine Idee, die Horváth wohl erst bei der Revision seines Stückes im Zuge der Probenarbeiten im Theater Scala hatte. Der Entwurf ist deshalb genetisch relativ spät zu verorten. In E ${ }^{13}$ sagt der Marquis: "Geben Sie das Telegramm. Können Sies lesen?" Die fragmentarisch ausgearbeitete Replik wurde von Horváth nachträglich wieder gestrichen, sollte also keine weitere Gültigkeit behalten.

\section{$\mathrm{H}^{15}=$ ÖLA 3/W $370-0$. BS, Bl. 91, 90v}

2 Blatt des Notizbuchs Nr. 4 mit schwarzem, glattem Kunstledereinband, kariertes Papier (149 × 88 $\mathrm{mm})$, roter Blattschnitt, schwarzblaue Tinte

$\mathrm{E}^{14}=$ Titelliste "Fünf Filme" (Bl. 91; nicht gedruckt)

$\mathrm{E}^{15}$ = Titelliste "Fünf Filme" (Bl. 90v; nicht gedruckt)

Druck in: WA 6, S. 466f., Druck in diesem Band, S. $228 \mathrm{f}$.

Die beiden Listen unter dem Titel „Fünf Filme“ im Notizbuch Nr. 4 wurden im Kontext von Entwürfen zu den Werkprojekten Kaiser Probus in Wien, Don Juan kommt aus dem Krieg und Die Komödie des Menschen eingetragen und sind deshalb wahrscheinlich auf $1936 \mathrm{zu}$ datieren (vgl. WA 6, S. 180 und den Kommentar zu Himmelwärts $/ \mathrm{K}^{2} / \mathrm{E}^{1}$ und $\mathrm{E}^{2}$ in diesem Band, S. 325f.). In ihnen äußert sich Horváths Absicht, seine Theaterstücke Kasimir und Karoline, Glaube Liebe Hoffnung (unter dem Titel "Die kleinen Paragraphen“), Hin und her (unter dem Titel "Zwischen den Grenzen“), Himmelwärts (unter dem Titel "Ein Pakt mit dem Teufel") und Eine Unbekannte aus der Seine (unter dem Titel „Ein Kuss im Senat“ bzw. „Ein Kuss im Parlament”) zu Drehbüchern umzuarbeiten. Auf welches Stück der Titel „Denkschrift eines Dramatikers" anspielt, ist ungewiss. Ein Brief Horváths an Hans Geiringer vom 16. September 1934 legt nahe, dass er über eine Verwertung von Eine Unbekannte aus der Seine zu einem Filmdrehbuch mit dem Titel "Ein Kuss im Parlament" bereits 1934 nachgedacht oder dieses bereits realisiert hatte. Denn der Titel wird in dem Brief erwähnt, und zwar mit dem Hinweis, dass der "Kuss im Parlament" "verboten“ worden sei (Brief 
Ödön von Horváths an Hans Geiringer, Original verschollen, zitiert nach einer Kopie im Archiv der Akademie der Künste Berlin, Sammlung Horváth, $\mathrm{H}$ br (p) 16, Bl. 1, 2, hier: Bl. 2). Möglicherweise beziehen sich also die in den Listen $\mathrm{E}^{14}$ und $\mathrm{E}^{15}$ erwähnten Titel (zumindest zum Teil) auf bereits verfasste Drehbücher. Ebenso wahrscheinlich ist es aber, dass Horváth die Redaktion solcher Drehbücher durch die Listen erst plante. Vermutlich hatte der Autor im Wiener Kulturbetrieb, zu dem er seit $1935 \mathrm{zu}$ zählen ist, neuerlich Kontakte zur Filmbranche geknüpft und suchte nun nach Möglichkeiten, eigene Texte für den Film zu adaptieren (vgl. Polt-Heinzl/Schmidjell 2001, S. 253f.). Insgesamt war seine Stellung im deutschen und österreichischen Filmbetrieb dieser Zeit jedoch eher "peripher" (ebd., S. 253). Seine Mitarbeit als Drehbuchautor an großen Produktionen wie Das Einmaleins der Liebe (D 1935, Regie: Carl Hoffmann), Fiakerlied / Fahr'n ma, Euer Gnaden (D 1936, Regie: E. W. Emo) und Der Pfarrer von Kirchfeld (A 1937, Regie: Jakob und Luise Fleck) ist jedoch inzwischen nachgewiesen (vgl. ebd., S. 251-250).

Das in unmittelbarer Folge an die beiden Listen "Fünf Filme“ im Notizbuch eingetragene Exposé mit dem Titel "Kasimir und Karoline“ (ÖLA 3/W 370 - o. BS, Bl. 92-94) hat mit dem ursprünglichen Volksstück wenig zu tun. An dieses schließt im Notizbuch Nr. 4 ein Exposé mit dem Titel "Die kleinen Paragraphen“ an (vgl. ÖLA 3/W 370 - 0. BS, Bl. 95-98), das laut den Listen $\mathrm{E}^{14}$ und $\mathrm{E}^{15}$ auf dem Volksstück Glaube Liebe Hoffnung basiert. Das dazu ausgearbeitete Exposé hat jedoch ebenfalls wenige Gemeinsamkeiten mit dem ihm zugrunde liegenden Drama. Möglicherweise ist mit dem in den beiden Listen genannten Titel "L'inconnue de la Seine“ bzw. "L'inconnue dans la Seine" die Komödie Das unbekannte Leben bzw. Mit dem Kopf durch die Wand gemeint. Dies würde die Annahme der späten Entstehung der beiden Listen - Ende 1935 oder Anfang 1936 - stützen. Allerdings dürfte sich in der Zeit ihrer Niederschrift das ,Durchfallen' (vgl. TS 22 und WA 10, S. 482f.) von Mit dem Kopf durch die Wand im Wiener Theater Scala ereignet haben, weshalb nicht wirklich anzunehmen ist, dass Horváth über eine Weiterverwertung des Stoffes der Komödie von 1935 spekulierte.

\section{$\mathrm{H}^{16}=$ ÖLA 3/W 309 - BS 14 b, Bl. 6}

1 Blatt unliniertes Papier $(340 \times 208 \mathrm{~mm})$, Wasserzeichen fünfzackiger Stern, schwarze Tinte $\mathrm{TS}^{22}$ = Fassung eines Vorworts zur "Komödie des Menschen“ (Korrekturschicht)

Druck (als Faksimile) in: WA 10, S. 482 f. und WA 11, S. $634 \mathrm{f}$.

Das vorliegende Blatt dürfte Mitte bis Ende 1937 entstanden sein (vgl. WA 10, S. 565). Es ist Teil der Werkgenesen von Horváths späten Komödien Ein Dorf ohne Männer und Pompeji (beide 1937) bzw. der Planungen für eine Komödie des Menschen, die auf das Jahr 1936 zurückreichen (vgl. etwa die Eintragungen dazu im Notizbuch Nr. 4, ÖLA 3/W 370 - o. BS; vgl. auch WA 9/K5/ $\mathrm{E}^{39}$ ). Auf der oberen Seite des Blattes trägt Horváth ein Werkverzeichnis zur "Komödie des Menschen“ ein, das folgende Werke umfasst: I. „Pompeji“ und "Das Dorf ohne Männer“ sowie II. "Die Pythagoreer“ und "Die Diadochen“. Die zuerst genannten Komödien waren zu diesem Zeitpunkt schon fertig (vgl. WA 11 und WA 10), zu den zuletzt genannten gibt es nur marginale Entwürfe im Notizbuch Nr. 4.

In TS22 skizziert Horváth eine Art Vorwort zu der von ihm geplanten "Komödie des Menschen". Eine rechts oben eingetragene Notiz sieht einen "Gorilla" vor, der den "Prolog" spricht, in dem er "Protest" dagegen einlegen soll, dass die "Menschen von 
den Affen abstammen“. TS22 ist Ausdruck einer tiefen existenziellen Krise des Autors. Zunächst spricht er davon, dass er sich "ein Programm im Stückeschreiben" stellen wolle, "obwohl ich nicht weiss, was ich morgen essen werde". Er wolle sich jedenfalls "ein grosses Ziel stecken“. In der Folge verwirft Horváth einen Großteil seines bisherigen Schaffens: „Ich habe in den Jahren 1932-1936 verschiedene Stücke geschrieben, sie sind, ausser zweien, gespielt worden, und zwar, wie man so zu sagen pflegt, mit Erfolg, ausser einem. Diese Stücke ziehe ich hiermit zurück, sie existieren nicht, es waren nur Versuche. Es sind dies: Kasimir und Karoline / Liebe, Pflicht und Hoffnung / Die Unbekannte der Seine / Hin und Her. / Himmelwärts. / Figaro lässt sich scheiden / Don Juan kommt aus dem Krieg. / Das jüngste Gericht.“ Bemerkenswerterweise nennt Horváth das Stück Glaube Liebe Hoffnung mit dem Titel der Uraufführung "Liebe, Pflicht und Hoffnung", Eine Unbekannte aus der Seine wird zu "Die Unbekannte der Seine" (vgl. den Titel der Vorarbeit in diesem Band), und statt Der jüngste Tag schreibt er "Das jüngste Gericht“. Das stärkste Verdikt stellt der Autor jedoch seiner Komödie Mit dem Kopf durch die Wand aus, die er zunächst mit dem ansonsten nicht belegten Titel "Das ewige Leben“ benennt. Von ihr heißt es: „Einmal beging ich einen Sündenfall. Ich schrieb ein Stück, Mit dem Kopf durch die Wand, ich machte Kompromisse verdorben durch den neupreussischen Einfluss, und wollte ein Geschäft machen, sonst nichts. Es wurde gespielt und fiel durch. Eine gerechte Strafe." (vgl. auch den Kommentar zu Himmelwärts/K²/ $\mathrm{E}^{3}$ in diesem Band, S. 324f.)

Das Programm, das einer Art Katharsis und Neuerfindung des Autors Horváth gleichkommt, endet mit der letztlich an sich selbst gerichteten Devise: "So habe ich mir nun die Aufgabe gestellt, frei von Verwirrung die Komödie des Menschen zu schreiben, ohne Kompromisse, ohne Gedanken ans Geschäft. Es gibt nichts Entsetzlicheres als eine schreibende Hur. Ich geh nichtmehr auf den Strich und will unter dem Titel ,Komödie des Menschen' fortan meine Stücke schreiben, eingedenk der Tatsache, dass im ganzen genommen das menschliche Leben immer ein Trauerspiel, nur im einzelnen eine Komödie ist." Die "Komödie des Menschen“ bleibt ein auf wenige Notizen und Entwürfe beschränktes Projekt Horváths. Wahrscheinlich sind zu ihm jedoch die Stücke Pompeji, Ein Dorf ohne Männer und Der jüngste Tag (alle 1937) zu rechnen (vgl. WA 10/Ein Dorf ohne Männer $/ \mathrm{K}^{3} / \mathrm{E}^{1}$, WA $11 / \mathrm{K}^{7} / \mathrm{E}^{4}$ und WA $9 / \mathrm{K}^{5} / \mathrm{E}^{39}$ ).

\section{Das unbekannte Leben. Komödie in fünf Akten (Endfassung, emendiert)}

Die emendierte Endfassung der Fassung in fünf Akten von Das unbekannte Leben wurde auf der Grundlage des Typoskripts $\mathrm{K}^{2} / \mathrm{T}^{10}\left(=\mathrm{K}^{2} / \mathrm{TS}^{16}\right)$ erstellt. Unregelmäßigkeiten der Zeichenabstände, vor allem zwischen Figurennamen und Regieanweisung bzw. Figurennamen und Replik, aber auch zwischen einzelnen Wörtern, wurden korrigiert. Im Figurenverzeichnis der emendierten Fassung wurde der "Gehilfe" des "Bildreporters" ergänzt, der in jenem von $\mathrm{K}^{2} / \mathrm{TS}^{16}$ fehlt. Die emendierte Fassung folgt den Rechtschreibregeln der Entstehungszeit des Stückes (Duden 1929). Sämtliche im Kommentar sowie im kritisch-genetischen Apparat ausgewiesenen Herausgebereingriffe wurden umgesetzt. Alle weiteren Normalisierungen finden sich in den Editionsprinzipien im Anhang dieses Bandes aufgelistet (vgl. S. 913f.). 


\section{Das unbekannte Leben. Komödie in vier Akten (Endfassung, emendiert)}

Die emendierte Endfassung der Fassung in vier Akten von Das unbekannte Leben wurde auf der Grundlage der Grundschicht des Regie- und Soufflierbuchs des Max Pfeffer Verlags $\mathrm{K}^{2} / \mathrm{T}^{11}\left(=\mathrm{K}^{2} / \mathrm{TS}^{17}\right)$ erstellt. Unregelmäßigkeiten der Zeichenabstände, vor allem zwischen Figurennamen und Regieanweisung bzw. Figurennamen und Replik, aber auch zwischen einzelnen Wörtern, wurden korrigiert. Im Figurenverzeichnis der emendierten Fassung wurde der "Gehilfe" des "Bildreporters" ergänzt, der in jenem von $\mathrm{K}^{2} / \mathrm{TS}^{17}$ fehlt. Die emendierte Fassung folgt den Rechtschreibregeln der Entstehungszeit des Stückes (Duden 1929). Sämtliche im Kommentar sowie im kritisch-genetischen Apparat ausgewiesenen Herausgebereingriffe wurden umgesetzt. Alle weiteren Normalisierungen finden sich in den Editionsprinzipien im Anhang dieses Bandes aufgelistet (vgl. S. 913f.).

\section{Mit dem Kopf durch die Wand. Komödie in vier Akten (Endfassung, emendiert)}

Die emendierte Endfassung der Fassung in vier Akten von Mit dem Kopf durch die Wand wurde auf der Grundlage der Korrekturschicht des Regie- und Soufflierbuchs des Max Pfeffer Verlags $\mathrm{K}^{3} / \mathrm{T}^{1}\left(=\mathrm{K}^{3} / \mathrm{TS}^{4}\right)$ sowie des Typoskripts $\mathrm{K}^{3} / \mathrm{T}^{4}\left(=\mathrm{K}^{3} / \mathrm{TS}^{20} / \mathrm{A}^{2}\right)$ erstellt, also auf der Grundlage der kompilierten Endfassung $\mathrm{K}^{3} / \mathrm{TS}^{21}$ (vgl. den Kommentar dort). Unregelmäßigkeiten der Zeichenabstände, vor allem zwischen Figurennamen und Regieanweisung bzw. Figurennamen und Replik, aber auch zwischen einzelnen Wörtern, wurden korrigiert. Fehlende Klammern in den Regie- und Szenenanweisungen wurden ergänzt. Die uneinheitliche Realisierung der Akt- und Auftrittstitel und der Zeichensetzung in den Konfigurationen im Stammbuch bzw. im Typoskript wurde vereinheitlicht. Im Figurenverzeichnis der emendierten Fassung wurden die "Sekretärin“ und der "Gehilfe" des "Bildreporters" ergänzt, die in jenem von $\mathrm{K}^{3} / \mathrm{TS}^{21}$ fehlen. Die emendierte Fassung folgt den Rechtschreibregeln der Entstehungszeit des Stückes (Duden 1929). Sämtliche im Kommentar sowie im kritisch-genetischen Apparat ausgewiesenen Herausgebereingriffe wurden umgesetzt. Alle weiteren Normalisierungen finden sich in den Editionsprinzipien im Anhang dieses Bandes aufgelistet (vgl. S. 913f.). 